NUREG-1463

\title{
Regulatory Analysis for the Resolution of Generic Safety Issue 105: Interfacing System Loss-of-Coolant Accident in Light-Water Reactors
}

Manuscript Completed: July 1993

Date Published: July 1993

Division of Sarety Issue Resolution Office of Nuclear Regulatory Research U.S. Nuclear Regulatory Commission Washington, DC 20555-0001

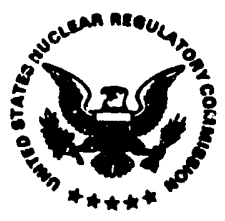




\begin{abstract}
An interfacing systems loss of coolant accident (ISLOCA) involves failure or improper operation of pressure isolation valves (PIVs) that compose the boundary between the reactor coolant system and low-pressure rated systems. PIVs can be any combination of two or more check valves or motor operated valves. Following a pressure boundary breach, overpressure in the low pressure system could cause lifting of relief valves, rupture of the low pressure systems, or loss of reactor coolant system inventory through open pathways. Some ISLOCAs can bypass containment and result in direct release of fission products to the environment. ISLOCA scenarios included in probabilistic risk assessments indicate little risk contribution from ISLOCA in boiling water reactors (BWRs) but significant to dominant risk contribution in pressurized water reactors (PWRs).
\end{abstract}

The ISLOCA program examined ISLOCA risks for Babcock and Wilcox (B\&W), Combustion Engineering (CE), and Westinghouse PWRs and BWRs. In each PWR case, the core damage frequency (CDF) attributed to ISLOCA sequences was approximately 2E-6/year. The BWR analysis consisted of a screening process and bounding calculations that resulted in a negligible ISLOCA CDF. For the B\&W plant, human error during plant startup and hardware failure of the low pressure injection PIVS were the dominant contributors to $\mathrm{CDF}$ and risk. For $\mathrm{CE}$ and Westinghouse, however, human error was less of a contributor. For all the plants, the hardware for isolating the rupture was in place, but specific procedures that would have facilitated rupture isolation were not available. Two hours, typically, would be available after a rupture before core uncovery would begin; however, in some auxiliary building designs, local flooding of the emergency core cooling system (ECCS) equipment would occur faster and could significantly shorten this time.

A cost/benefit evaluation, using the three PWR analyses, calculated the benefit of two potential modifications to the plants. Alternative I is unspecificd improvements to plant operations to optimize the operator's performance and reduce humian error probabilities to a lower bound estimate of 1E-4. Alternative II adds pressure sensing devices, cabling, and instrumentation between two PIVs to provide the control operators with continuous monitoring of the first PIV. These two alternatives were evaluated for the base case plants (Case 1) and for each plant, assuming the plants had a particular auxiliary building design in which severe flooding would be a problem if an ISLOCA occurred. The auxiliary building design (Case 2) was selected from a survey that revealed a number of designs with features that provided less than optimal resistance to ECCS equipment loss caused by a ISLOCAinduced environment. From the evaluation, cost beneficial results were obtained for the B\&W Case 2 for both Alternatives I and II, and Westinghouse Case 2 for Alternative I with or without onsite averted costs. Due to conservatisms in the analyses, these results were judged not to provide sufficient basis for generic requirements.

It was concluded that the most viable course of action to resolve Generic Issue 105 is licensee participation in individual plant examinations (IPEs). This ac'ion would be supported by issuing a supplement to the Nuclear Regulatory Commission Information Notice 92-36 to all plants with PWRs and BWRs. The information promulgated by the supplement would be useful to licensees whether or not their IPEs were completed. 


\section{CONTENTS}

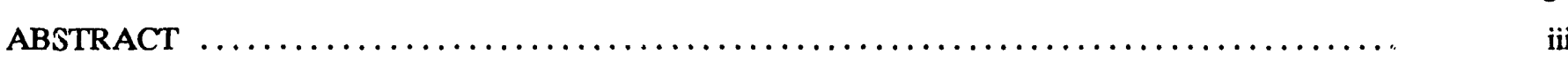

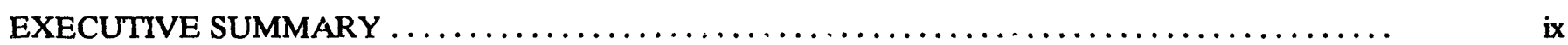

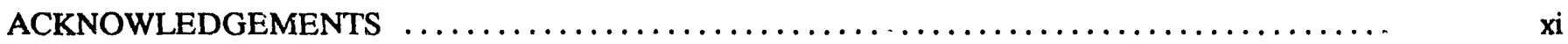

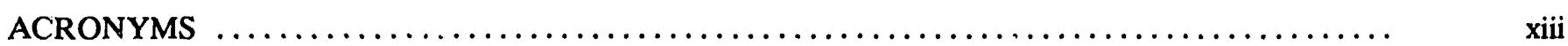

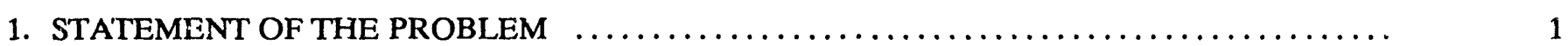

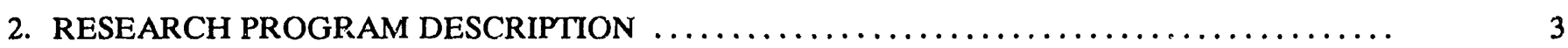

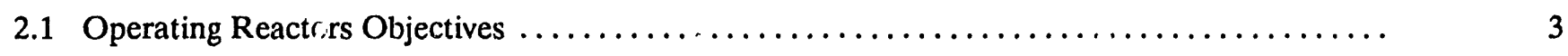

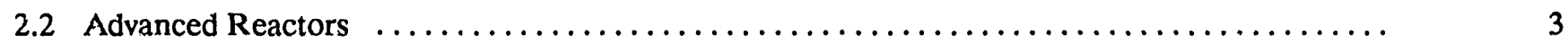

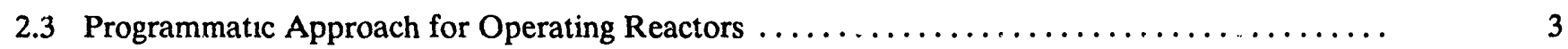

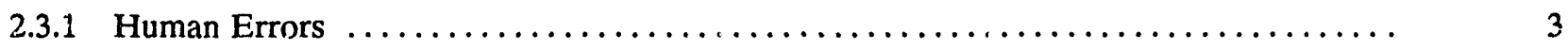

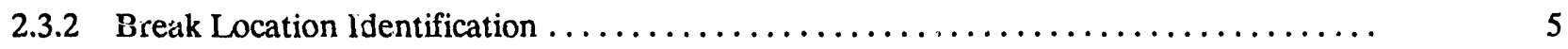

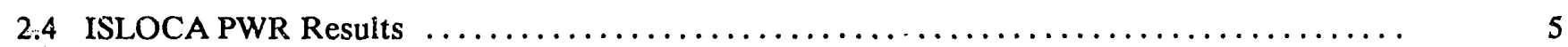

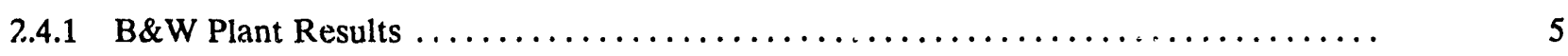

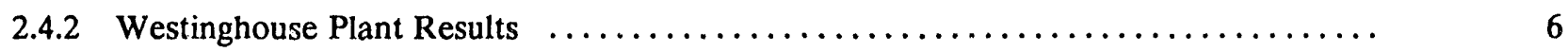

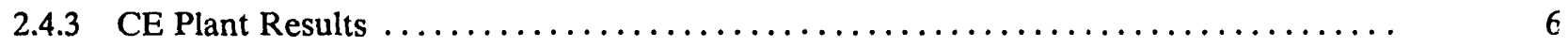

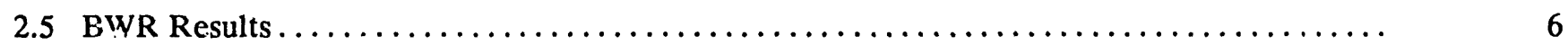

3. ISLOCA COST/BENEFIT ANALYSIS $\ldots \ldots \ldots \ldots \ldots \ldots \ldots \ldots \ldots \ldots \ldots \ldots \ldots \ldots \ldots \ldots \ldots \ldots \ldots \ldots \ldots \ldots$

3.1 Alternatives for the Current Analysis $\ldots \ldots \ldots \ldots \ldots \ldots \ldots \ldots \ldots \ldots \ldots \ldots \ldots \ldots \ldots \ldots \ldots \ldots \ldots \ldots \ldots \ldots \ldots \ldots \ldots$

3.2 Core Damage Frequency Results for the Current Analysis ...................... 9

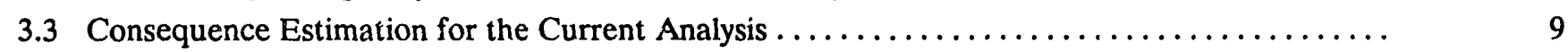

3.4 Onsite Averted Costs for the Current Analysis $\ldots \ldots \ldots \ldots \ldots \ldots \ldots \ldots \ldots \ldots \ldots \ldots \ldots \ldots \ldots$

3.5 Cost Estimating Methodology for the Current Analysis $\ldots \ldots \ldots \ldots \ldots \ldots \ldots \ldots \ldots \ldots \ldots$

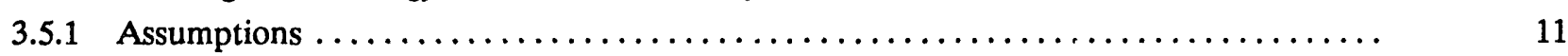

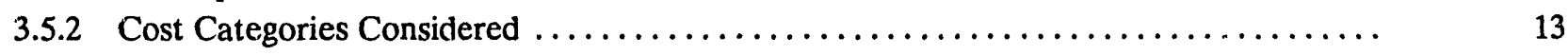

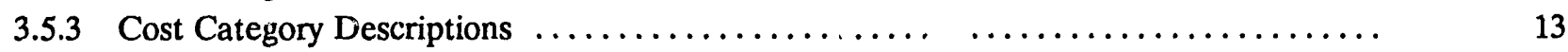

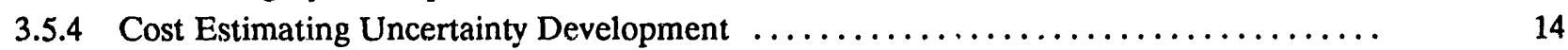

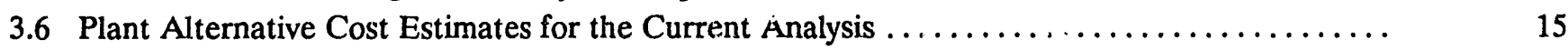

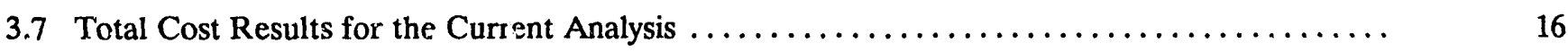

3.8 Cost/Benefit Uncertainty Discussion for the Current Analysis ..................... 19

3.9 Uncertainty Analysis Results for the Current Analysis $\ldots \ldots \ldots \ldots \ldots \ldots \ldots \ldots \ldots \ldots \ldots$

4. PREVIOUS ISLOCA COSTiBE:VEFTT ANALYSES $\ldots \ldots \ldots \ldots \ldots \ldots \ldots \ldots \ldots \ldots \ldots \ldots \ldots \ldots \ldots$

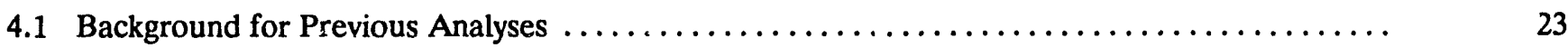

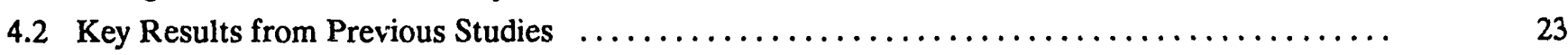

4.2.1 Risk Reduction Achievable by Periodic Testing $\ldots \ldots \ldots \ldots \ldots \ldots \ldots \ldots \ldots \ldots \ldots \ldots$ 


\section{CONTENTS (cont.)}

4.2.2 Risk Reduction Achievable by Continuous Pressur ¿ Monitoring $\ldots \ldots \ldots \ldots \ldots \ldots \ldots$

4.3 Summary of Conclusions and Key Assumptions From Previous Analyses $\ldots \ldots \ldots \ldots \ldots \ldots .28$

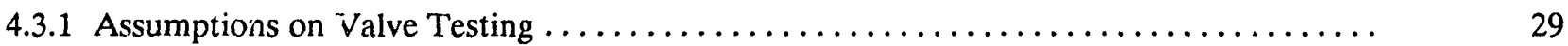

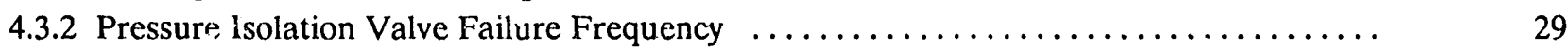

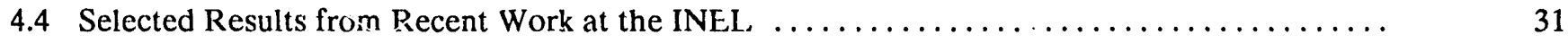

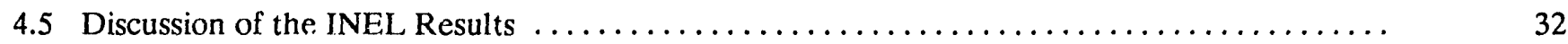

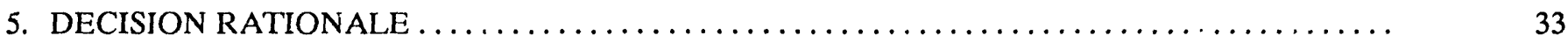

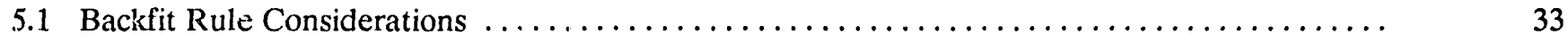

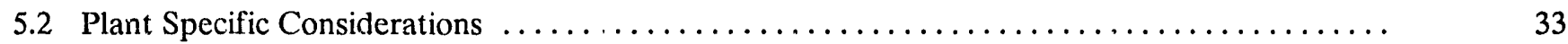

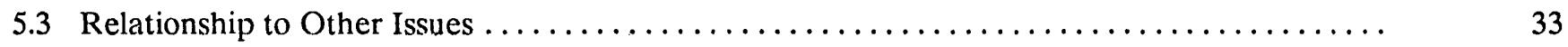

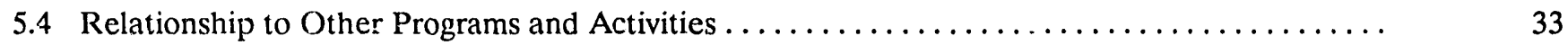

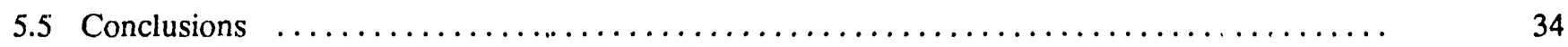

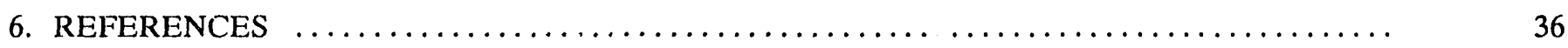

Appendix A-Alternative I Cost/Benefit Distributions $\ldots \ldots \ldots \ldots \ldots \ldots \ldots \ldots \ldots \ldots \ldots \ldots \ldots \ldots \ldots \ldots \ldots \ldots \ldots$

Appendix B-Summary of PWR Sensitivity to Alterations in the Interfacing-Systems

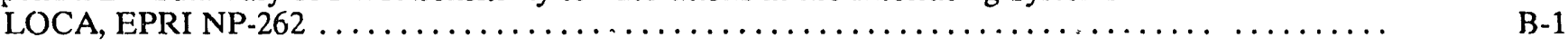

Appendix C,-Summary of Interfacing Systems LOCA: Pressurized Water Reactors $\ldots \ldots \ldots \ldots \ldots$. C-1

\section{List of Figures}

1. Approach for plant-specific evaluation of ISLOCA $\ldots \ldots \ldots \ldots \ldots \ldots \ldots \ldots \ldots \ldots \ldots \ldots \ldots, 4$

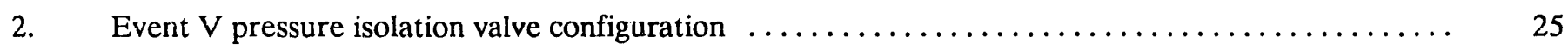

3. Pressure isolation valve corfigurations evaluated in NUREG $-0677 \ldots \ldots \ldots \ldots \ldots \ldots \ldots \ldots .26$

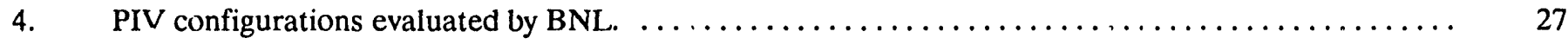

A-1. CDF of DPR ratio for B\&W plant (Case 1, 20 years without OSAC) $\ldots \ldots \ldots \ldots \ldots \ldots \ldots \ldots \ldots$ A-2

A-2. CDF of DPR ratio for B\&W plant (Case 1,20 years with $\mathrm{OSAC}$ ) $\ldots \ldots \ldots \ldots \ldots \ldots \ldots \ldots \ldots \ldots$

A-3. CDF of DPR ratio for $B \& W$ plant (Case 1,40 years without $\mathrm{OSAC}$ ) $\ldots \ldots \ldots \ldots \ldots \ldots \ldots \ldots$

A-4. CDF of DPR rativ for B\&W plant (Case 1,40 years with $\mathrm{OSAC}$ ) $\ldots \ldots \ldots \ldots \ldots \ldots \ldots \ldots \ldots \ldots$

A-5. CDF of DPR ratic for B\&W plant (Case 2, 20 years without OSAC) $\ldots \ldots \ldots \ldots \ldots \ldots \ldots \ldots$ A-4

A-6. CDF of DPR ratio for B\&W plant (Case 2, 20 years with $\mathrm{OSAC}$ ) $\ldots \ldots \ldots \ldots \ldots \ldots \ldots \ldots \ldots \ldots$

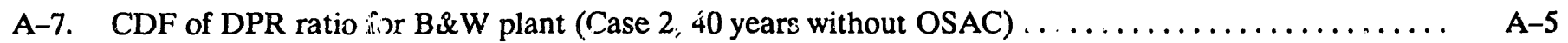

A-8. CDF of DPR ratio for B\&W plant (Cøse 2, 40 years with $\mathrm{OSAC}) \ldots \ldots \ldots \ldots \ldots \ldots \ldots \ldots \ldots \ldots$

A-9. CDF of DPR ratio for Westinghouso plant (Cace 1,20 years without OSAC) $\ldots \ldots \ldots \ldots \ldots \ldots$ A-6

A-10. CDF of DPR ratio for Westinghouse plant (Case 1, 20 years with OSAC) $\ldots \ldots \ldots \ldots \ldots \ldots \ldots$ A-6 


\section{CONTENTS (cont.)}

\section{List of Figures (cont.)}

A-11. CDF of DPR ratio for Westinghouse plant ; Case 1,40 years without OSAC) $\ldots \ldots \ldots \ldots \ldots \ldots$ A-7

A-12. CDF of DPR ratio for Westinghouse plant (Case 1,40 years with $\mathrm{OSAC}$ ) $\ldots \ldots \ldots \ldots \ldots \ldots \ldots$ A-7

A-13. CDF of DPR ratio for Westinghouse plant (Case 2, 20 years without OSAC) $\ldots \ldots \ldots \ldots \ldots \ldots$ A-8

A-14. CDF of DPR ratio for Westinghouse plant (Case 2, 20 years with OSAC) $\ldots \ldots \ldots \ldots \ldots \ldots \ldots$ A-8

A-15. CDF of DPR ratio for Westinghouse plant (Case 2, 40 years without OSAC) $\ldots \ldots \ldots \ldots \ldots \ldots$

A-16. CDF of DPR ratio for Westinghouse plant (Case 2, 40 years with OSAC) $\ldots \ldots \ldots \ldots \ldots \ldots \ldots$ A-9

A-17. CDF of DPR ratio for CE plant (Case 1, 20 years without $\mathrm{OSAC}$ ) $\ldots \ldots \ldots \ldots \ldots \ldots \ldots \ldots \ldots$

A-18. CDF of פPR ratio for CE plant (Case 1, 20 years with $\mathrm{OSAC}$ ) $\ldots \ldots \ldots \ldots \ldots \ldots \ldots \ldots \ldots \ldots$

A-19. CDF of DPR ratio for CE plant (Case 1, 40 years without $\mathrm{OS} . \mathrm{AC}) \ldots \ldots \ldots \ldots \ldots \ldots \ldots \ldots \ldots$

A-20. CDF of DPR ratio for CE plant (Case 1, 40 years with OSAC) $\ldots \ldots \ldots \ldots \ldots \ldots \ldots \ldots \ldots \ldots \ldots$ A-11

A-21. CDF of DPR ratio for CE plant (Case 2, 20 years without $\mathrm{OSAC}) \ldots \ldots \ldots \ldots \ldots \ldots \ldots \ldots \ldots$

A-22. CDF of DPR ratio for CE plant (Case 2, 20 years with OSAC) $\ldots \ldots \ldots \ldots \ldots \ldots \ldots \ldots \ldots \ldots$ A-12

A-23. CDF of DPR ratio for $\mathrm{CE}$ plant (Case 2, 40 years without $\mathrm{OSAC}$ ) $\ldots \ldots \ldots \ldots \ldots \ldots \ldots \ldots \ldots$

A-24. CDF of DPR ratio for CE plant (Case 2, 40 years with $\mathrm{OSAC}$ ) $\ldots \ldots \ldots \ldots \ldots \ldots \ldots \ldots \ldots \ldots$ A-13

B-1. Event $\mathrm{V}$ pressure isolation valve configuration $\ldots \ldots \ldots \ldots \ldots \ldots \ldots \ldots \ldots \ldots \ldots \ldots \ldots \ldots \ldots \ldots \ldots \ldots \ldots$

\section{List of Tables}

ES-1 Cost/benefit results. Probability that the DPR ratio is less than $\$ 1,000 /$ person-rem $\ldots \ldots \ldots \ldots \ldots \ldots \quad x$

1. Core damage frequency parameters for the ISLOCA plants (per reactor year) for Alternative I ... 10

2. Core damage fr $\mathrm{r}^{\prime}$ quency parameters for the ISLOCA plants (per reactor year) for Alternative II ... $\quad 10$

3. Total offsite person-rem reduction (benefits) for the ISI_OCA plarts for Aiternative I . ........ 11

4. Total offsite person-rem reduction (benefits) for the ISLOCA plants for Alternative II ......... 11

5. OSAC calculated values for the ISLOCA plants for Altcrnative i $\ldots \ldots \ldots \ldots \ldots \ldots \ldots \ldots \ldots \ldots$

6. OSAC calculated values for the ISLOCA plants for Alternative II $\ldots \ldots \ldots \ldots \ldots \ldots \ldots \ldots \ldots . . \ldots$

7. ISLOCA Alternative I cost breakdown per plant $(20$ year case $) \ldots \ldots \ldots \ldots \ldots \ldots \ldots \ldots \ldots \ldots$

8. ISLOCA Alternative $I$ cost breakdown per plant $(40$ year case) $\ldots \ldots \ldots \ldots \ldots \ldots \ldots \ldots \ldots \ldots . \ldots \ldots$

9. ISLOCA Alternative II cost breakdown per plant $(20$ year case $) \ldots \ldots \ldots \ldots \ldots \ldots \ldots \ldots \ldots . \ldots \ldots$

10. ISLOCA Alternative II cost breakdown per plant (40 year case) $\ldots \ldots \ldots \ldots \ldots \ldots \ldots \ldots \ldots \ldots$

11. Cost minus OSAC values for the ISLOCA plants (Alteruative I) $\ldots \ldots \ldots \ldots \ldots \ldots \ldots \ldots \ldots . .18$

12. Cest minus OSAC values for the ISLOCA piants (Aiternative iii) $\ldots \ldots \ldots \ldots \ldots \ldots \ldots \ldots \ldots \ldots$ 


\section{CONTENTS (cont.)}

\section{List of Tables (cont.)}

13. Cost/benefit DPR ratio results for the ISLOCA plants for Alternative I (all values in \$/person-rem).

14. Cost/benefit results for the ISLOCA plants for Alternative II (all values in $\$$ /person-rem) .......

15. Estimated ISLOCA initiator frequencies from NUREG $-0677 \ldots \ldots \ldots \ldots \ldots \ldots \ldots \ldots \ldots$

16. Summary of cost/benefit data for increased frequency of PIV testing from NUREG/CR-5102 (all dollar values inflated to 1992 dollars)

17. Summary of cost/benefit data for continuous prcssure montoring from NUPEG/CR-5102 (all dollar values inflated to 1992 dollars)

18. Bay esian update of catastrophic failure rate of PIV check valves $\ldots \ldots \ldots \ldots \ldots \ldots \ldots \ldots \ldots$ 


\section{EXECUTIVE SUMMARY}

An interfacing systems loss of cooiant accident (ISLOCA) is defined as a breach of the pressure boundary between the reactor coolant system (RCS) and any one of several low pressure systems. Breaching the pressure boundary consists of the failure or improper operation of two or more pressure isolation valves (typically check valves and/ or motor operated valyes) that compose the boundary. If high-pressure RCS coolant enters the relatively low pressure interfacing system, the possibility exits of overpressurizing and rupturing the system, which typically extends outside containment. This break results in a situation where primary coolant is being lost outside the containment. If the break is not isolated, core damage is likely with subsequent release of radioactive material bypassing the containment. Although there has never been an unrecovered incident of release of RCS inventory through an interfacing system, many actual operational events have occurred that could be termed "precursors" to such events. In addition, these precursors have characteristics much different than the ISLOCA events typically analyzed in Probabilistic Risk Assessments (PRAs). For example, the precursor events comprised human errors and plant mode changes, neither of which are included in ISLOCA analyses typically found in PRAs. As a result, a user request letter ${ }^{a}$ was transmitted that instigated a reorientation of the Generic Issue (GI)-105 program designed to investigaie all aspects of ISLOCAs.

The ISLOCA program examined ISLOCA risks for three pressurized water reactors (PWRs) (one of each veitdor). In each case, the core damage frequency (CDF) attributed to ISLOCA sequerices was approximately 2 E-6/year. In the case of Babcock and Wilcox (B\&W), human error was found to be the dominant contributor to CDF and risk in addition to the hardware failure of the low pressure injection, pressure isolation valves (PIVs) (two check valves). For the Westirighouse and Combustion Engineering (CE) plants, human errors were found to be much less important. For all plants, the hardware necessary for isolating a rupture was in place. However, specific procedures that would facilitate rupture isolation were not available. Typically, at least 2 hours would be available after a rupture occurred before core uncovery would begin. However, in some auxiliary building designs, local flooding of the emergency core cooling systems (ECCS) equipment would occur faster and could significantly shorten this time.

A cost/benefit evaluation was performed utilizing the three PWR analyses. This study calculated the benefit $i .1$ two potential modifications to the p. ants. The first, re-

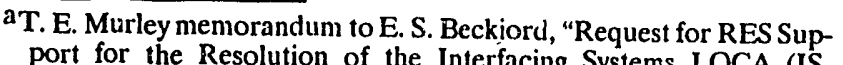
port for the Resolution of the Interfacing Systems IOCA (ISLOCA)," June 7, 1989. ferred to as Alternative I, entails unspeci: red improvements to the operations of the plants so that performance of the human operators is optimized. In this case, Alternaiive I means reducing the human error probabilities to a lower bound estimate of $1 \mathrm{E}-4$. Alternative II comprises adding pressure sensing devices and related cabling and instrumentation batween the two PIVs to provide the control room operators with continuous monitoring of the first, or inboard, PIV. In addition, these two alternatives were evaluated for both the base case plants (relerred to as Case 1) and for each plant, assuming the plarits had a particular auxiliary butding design in which severe flooding would be a problem, given a ISLOCA. The auxiliary building design (referred to as Case 2) was selected from a survey that revealed a number of designs with features thought to provide less than optimal resistance to ECCS equipment loss from subjection to an ISLOCA-induced environment. The consequence of the severe flooding is that control room operators have less time to recover from an ISLOCA sequence. The severe flooding results in the failure of all ECCS equipment and failure of all priman system injection faster than in Case 1 in which time to core uncovery is determined by the depletion of the water source (i.e., the refueling water storage tank). This time difference is reflected in the analysis through estimating failure probability for the operators to dicignose the accident as an ISLOCA. The cost/benefits for these two alternatives are quantified by the calculation of the dollar-to-person-rem (DPR) averted ratio, which is calculated as the cost of the alternative divided by the offsite person-rem averted. This ratio is calculated iwo ways, buth with and without onsite averted costs (OSAC). Lastly, the calculations are presented assuming a 20-ycar plant life remaining and 40-year plant life (a 20 year lifc remaining and 20-year life extension). 'the measure of alternatives value is whether or not the DPR ratio is less than $\$ 1000 /$ person-rem. If it is, the modification is judged to be cost beneficial. Because of uncertainties in the cal"culations, the absol"te measure is not warranted Consequently, the cost/benefit is calculated in terms of the probability that the "true" value is less than $\$ 1000$ iperson-rem. Table ES-1 displays the results of the cost/benefit analysis.

From Table ES-1, the results indicated as cost beneficial are the B\&'N Case 2 for both Alternatives (I and II) with OSAC, and Westinghouse Case 2 for Alternative $Y$ with OSAC. However, the B\&W Case 2 is artificial because of all the auxiliary buildings with questionable characteristics identified by the survey, none belonged to a $B \& W$ piant. This result illustrates that sysiem design and cperation could combine with auxiliary building characteristics to produce ISLOCA vulnerabilities that are worth considering for correction. The fact whether or not such combinations exist is verifiable only through plant specific 
Table ES-1. Cost/benefit results. Probability that the DPR ratio is less than $\$ 1,007 / p$; $:$ son-rem

\begin{tabular}{|c|c|c|c|c|}
\hline Plant & $\begin{array}{c}\text { Plant life } \\
\text { (years) }\end{array}$ & OSAC & Alternative I & Alternative II \\
\hline \multirow[t]{2}{*}{$\begin{array}{l}\text { B\&W } \\
\text { (Case 1) }\end{array}$} & 20 & $\begin{array}{l}\text { Without } \\
\text { With }\end{array}$ & $\begin{array}{l}20 \% \\
37 \%\end{array}$ & $\begin{array}{l}5.2 \% \\
5.8 \%\end{array}$ \\
\hline & 40 & $\begin{array}{l}\text { Without } \\
\text { With }\end{array}$ & $\begin{array}{l}26 \% \\
46 \%\end{array}$ & $\begin{array}{l}9.9 \% \\
11 \%\end{array}$ \\
\hline \multirow[t]{2}{*}{$\begin{array}{l}\text { B\&W } \\
\text { (Case 2) }\end{array}$} & 20 & $\begin{array}{l}\text { Without } \\
\text { With }\end{array}$ & $\begin{array}{l}69 \% \\
100 \%\end{array}$ & $\begin{array}{l}24 \% \\
60 \%\end{array}$ \\
\hline & 40 & $\begin{array}{l}\text { Without } \\
\text { With }\end{array}$ & $\begin{array}{l}77 \% \\
100 \%\end{array}$ & $\begin{array}{l}35 \% \\
32 \%\end{array}$ \\
\hline \multirow[t]{2}{*}{$\begin{array}{l}\text { Westinghouse } \\
\text { (Case 1) }\end{array}$} & 20 & $\begin{array}{l}\text { Without } \\
\text { With }\end{array}$ & $\begin{array}{l}14 \% \\
28 \%\end{array}$ & $\begin{array}{l}5.6 \% \\
5.9 \%\end{array}$ \\
\hline & 40 & $\begin{array}{l}\text { Without } \\
\text { With }\end{array}$ & $\begin{array}{l}18 \% \\
33 \%\end{array}$ & $\begin{array}{l}8.4 \% \\
9.1 \%\end{array}$ \\
\hline \multirow[t]{2}{*}{$\begin{array}{l}\text { Westinghouse } \\
\text { (Case 2) }\end{array}$} & 20 & $\begin{array}{l}\text { Without } \\
\text { With }\end{array}$ & $\begin{array}{l}17 \% \\
56 \%\end{array}$ & $\begin{array}{l}7.2 \% \\
8.3 \%\end{array}$ \\
\hline & 40 & $\begin{array}{l}\text { Without } \\
\text { With }\end{array}$ & $\begin{array}{l}21 \% \\
63 \%\end{array}$ & $\begin{array}{l}11 \% \\
13 \%\end{array}$ \\
\hline \multirow[t]{2}{*}{$\begin{array}{l}\mathrm{CE} \\
\text { (Case 1) }\end{array}$} & 20 & $\begin{array}{l}\text { Without } \\
\text { With }\end{array}$ & $\begin{array}{l}12 \% \\
11 \%\end{array}$ & $\begin{array}{l}\text { Not calculated } \\
\text { Not calculated }\end{array}$ \\
\hline & 40 & $\begin{array}{l}\text { Without } \\
\text { With }\end{array}$ & $\begin{array}{l}15 \% \\
19 \%\end{array}$ & $\begin{array}{l}\text { Not calculated } \\
\text { Not calculated }\end{array}$ \\
\hline \multirow[t]{2}{*}{$\begin{array}{l}\mathrm{CE} \\
\text { (Case 2) }\end{array}$} & 20 & $\begin{array}{l}\text { Wirthout } \\
\text { With }\end{array}$ & $\begin{array}{l}9 \% \\
11 \%\end{array}$ & $\begin{array}{l}\text { Not calculated } \\
\text { Not calculated }\end{array}$ \\
\hline & 40 & $\begin{array}{l}\text { Without } \\
\text { With }\end{array}$ & $\begin{array}{l}12 \% \\
15 \%\end{array}$ & $\begin{array}{l}\text { Not calculated } \\
\text { Not calculated }\end{array}$ \\
\hline
\end{tabular}

analyses. The Westinghouse Case 2, Alternative I results indicare that marginal benefits versus cost can be expected. Moreover, the risk studies supporting Table ES-1 entries were judged to be conservative in their estimate of frequency of failure of the two check valves in the series. The dominant sequence from the Westinghouse study was initiated by this type of failure. It was concluded that the results for the Westinghouse Case 2 do not provide an indication that ary alternatives are worth pursuing. Alternative II for the CE plant was not calculated because the hardware comprising that alternative is already installed at that plant.

The most important irsight gleaned from the ISLOCA studies is the highly plant-specific nature of the issue. Rather than similarities being identified, marked differcnces were noted in low pressure sysiems and auxiliary building designs and in the procedures. Based on these results, ir is concluded that the most meaningful and viable course of action for resolution of GI-105 is partic:pation of licensees in the ongoing individual plant examination (IPE) process. This action would be supported by issuing a supplement to Nuclear Regulatory $(-m m i s s i o n$ Information Notice (IN) 92-36 to all PWRs and boiling water reactors that would promulgate the GI-105 program insights and final results provided in IN 92-36. Of particuiar use to licensees would be the ISLOCA screening criteria and final ISLOCA analysis proceciures. For licensees not havirig completed this ISLOCA portion of their IPE, the screening criteria would be a useful preanalysis check on where emphasis might be needed. The ISLOCA procedures provide guidance on performing a comprehensive ISLOCA analysis. Licensees with completed IPEs could use the screening criteria as a quick confirmatory check on ISLOCA analysis results. 


\section{ACKNOWLEDGEMENTS}

The contributions of C. L. Smith, R. L. Van Horn, J. A. Shroeder, and D. L. Kelly, EG\&G Idaho, Inc., to Sections 3,4 , and the appendices are gratefully acknowledged. W.
J. Galyean, EG\&G Idaho, Inc., contributed to Section 4.4.2. 


\section{ACRONYMS}

$\begin{array}{llll}\text { ALWR } & \text { Advanced light water reactor } & \text { LPI } & \text { Low pressure injection } \\ \text { B\&W } & \text { Babcock and Wilcox } & \text { LWR } & \text { Light water reactor } \\ \text { BNL } & \text { Brookhaven National Laboratory } & \text { MOV } & \text { Motor operated vaive } \\ \text { BWR } & \text { Boiling water reactor } & \text { NIC } & \text { Nuclear industry check } \\ \text { CDF } & \text { Core damage frequency } & \text { NRC } & \text { Nuclear Regulatory Conmission } \\ \text { CE } & \text { Combustion Engineering } & \text { NRR } & \text { Nuclear Reactor Regulation } \\ \text { DPR } & \text { Dollari-to-person-rem } & \text { OSAC } & \text { Onsite averted costs } \\ \text { ECCS } & \text { Emergency Core Cooling System } & \text { PIB } & \text { Pressire isolation boundary } \\ \text { EEDB } & \text { Energy Economic Data Base } & \text { PIV } & \text { Pressure isolation valve } \\ \text { EPRI } & \text { Electric Power Research Institute } & \text { PRA } & \text { Probabilistic risk assessment } \\ \text { GI } & \text { Generic Issue } & \text { PWR } & \text { Pressurized water reactor } \\ \text { HEP } & \text { Human error probability } & \text { QA } & \text { Quality assurarice } \\ \text { HPI } & \text { High pressure injection } & \text { QC } & \text { Quality control } \\ \text { IN } & \text { Information Notice } & \text { RCS } & \text { Reactor coolant system } \\ \text { INEL } & \text { Idaho National Engineering Laboratory } & \text { RHR } & \text { Residual heat removal } \\ \text { IFE } & \text { Individual plant evaluation } & \text { RWST } & \text { Refueling water storage tank } \\ \text { ISLOCA } & \text { Interiacing systems loss-of-coolant accident } & \text { R. }\end{array}$




\section{STATEMENT OF THE PKOBLEM}

An in terfacing systems loss of coolant accident (ISLOCA) is defined as a breach of the pressure boundary between the reactor coclant system (RCS) and any one of several low pressure systems. This class of accidents necessarily involves failures of or improper operation of pressure isolation valves (PIVs) comprising the ooundary. PIVs can be any combination of two or more of either check valves or motor-operated valves (MOVs). Following a pressure boundary breach, overpressure in the low pressure system could cause lifting of relief valves, rupture of the low pressure systems, or loss of RCS iriventory through inadvertently opened pathways. Some ISLOCAs have the potential to bypass containment resulting in a direct release of fission products to the environment. Those ISLOCA sccnarios involving containment bypass are also complicated by loss of the recirculation mode of core cooling because the RCS effluent does not find its way to the containment sump that acts as a reservoir. If break isclation actions are unsuccessful, emergency injection sources could be depieted resulting in core damage and potentially high release of fission products. Effluents from excontainment ISLOCAs have the potential by flooding to disable injection equipment. Disabling of all injection equipment would almost certainly result in core damage and large release.

These scenarios have been included in probabilistic risk assessments (PRAs) dating to the Reactor Safety StudyAn Assessment of Accidents Risks in U.S. Commercial Nuclear Power Plants (Ref. 1) in 1975. The PRA results typically indicate little risk contribution from ISLOCAs in boiling water reactors (BWRs) but significant to dominant risk contribution in pressurized water reactors (PWRs). These results seem to hold for LOCA sequences in general because". . most BWRs have many more systems than PWRs for injecting water directly into the reactor coolant system to provide makeup. For BWRs, this includes two low-pressure emergency core cooling systems (ECCS) [low pressure injection (LPI) and lowpressure core spray], each of which is multitrain; two high pressure injection (HPI) systems (reactor core isolation cooling and either high-pressure coolant injection or high-pressure core spray); and usually several other alternative injection systems, such as the control rod drive hydraulic system, condensate, service water, and firewater. PWRs generally have one high-pressure and one low-pressure ECCS (both multitrain), plus a set of accumulators. The PWR ECCS does have considerable redundancy but not as much as that of most BWRs" (Ref. 2). With respect to ISLOCAs, some PRAs (Refs. 3 and 4) founci that BWRs have relatively low $(<1.0 \mathrm{E}-8)$ core damage frequency (CDF) due to additional combinations of low initiating event (check valve failure) frequency and low pipe or other component rupture probability together with a high degree of ECCS compartmentalization. Lower BWR operating pressure can reasonably be expected to contribute significantly to fewer valve failure initiators and lower rupture frequencies. By contrast, the NUREG-1150 studies (Ref. 2) derived mean ISLOCA CDFs one to two orders in magnitude $(1.1 \mathrm{E}-7,6.5 \mathrm{E}-7$, 1.6E-6) higher for the three PWRs than for the BWRs. The resulting risk contributions for these bypass sequences ranged from significant (Zion) to dominant (Sequoyah and Surry). Because these sequences bypass containment and have the potential for a direct large release to the atmosphere, a modest underestimate of the actual CDF could mean the real risk from ISLOCA events is much greater than indicated by past PRAs. Such underestimated ISLOCA risk was thought by some staff members to be indicated by a disparity between the content and perceived higher frequency of actual ISLOCA operational events and by the way PRAs moreled and quantified ISLOCA scenarios.

Although therc has never been an unrecovered incident of release of RCS inventory through a low pressure system, many of the actual operational events appeared to staff members to be "precurscrs" to such events. If conditions had been somewhat different in the same event or if the event had occurred in a different system, perhaps a truly serious ISLOCA would have resulted. Reference 5 describes 19 such - vents selected from licensee event reports submitted before 1989. Since 1989 there have been several others. If the PRA estimated frequency of about 1.0E-6 or less per reactor year was accurate, the number of precursors seemed to be high given the 1,400 reactor years of operation of U.S. plants by mid-1989.

With "espect to disparity between PRA ISLOCA models and actual event content, there were a number of concerns. Some PRA ISLOCA CDF estimates have been derived considering: (1) only LPI systems, (2) failure of check valves only as initiators, (3) subsequent rupture of piping or unspecified components, (4) no possibility of recovery, and (5) events were postulated to occur during cperation (Kef. 6). By comparison, actual ISLOCA events (1) iriv slved a variety of interfacing systems, (2) had a high human error content in many initiating events and subsequent events, (3) most releases of RCS fluid did not involved ruptures, (4) recovery was effected in all cases, and (5) several events occurred during transition between operating modes, not during power operation.

The foregoing considerations resulted in the user request 
of June 7, $1989^{\mathrm{a}}$ and subsequent reorientation of the research program in support of resolution of Generic Issue (GI)-105, ISLOC.A in light water reactors (LWRs). The program to that time had focused on the value of increased PIV leak testing as a means to resolve the issue.
The new program was comprehensive and designed to investigate all aspects of ISLOC $A$ s. The aspects were to be investigated in a level-three PRA context is include transitions between operating modes.
aT. E. Mútiey, memolansium to E. S. Beckjord, "Request for RES Support for the Resolution of the Interfacing Systems LOCA (ISLOCA)," June 7, 1989. 


\section{RESEARCH PROGRAM DESCRIPTION}

\subsection{Operating Reactors Objectives}

The GI-105 program, which was reformulated in mid-calendar year 1989, had a netv set of objectives as delineated in Reference 7. Six objectives are summarized as follows:

1. Develop a PRA framework to evaluate human and hardware contributions io ISLOCA.

2. Identify specific human actions and root causes im. portant to ISLOCA for recommending risk reduction actions.

3. Evaluate low pressure systems fragilities under high pressure/temperatures to identify likely failure locations.

4. Determine ISLOCA sequence timing, flow rates, accident management strategies, and ISLOCA effects on other equipment.

5. Estimate ISLOCA consequences and important factors for consequence reduction.

Because PWRs were perceived to be at higher risk from ISLOCA than BWRs, these objectives were first pursued through PWR information and analyses as detailed in References 5, 7, and 8. These are ISLOCA analyses of Babcock and Wilcox (B\&W), Westinghouse, and Combustion Engineering (CE) plants, respectively. The BWR analysis is described in Reference 9. The BWR phase of the program had additional impetus from $a$ user request $b$ that expressed concern about ISLOCAs induced by inadvertent emergency safety feature actuations in BWRs. An assessment of the risk from these events was within existing programmatic objectives.

Information generated and insights gained from activities in support of the five stated objectives were intended to support two decisions with respect to ISLOCA. First was a decision on what agency action was appropriate for the near term. This decision is embodied in Nuclear Regulatory Commission (NRC) Information Notice (IN) 92-36 (Ref. 10). The second decision concerned the longer term resolution of GI-105. Thus, the final programmatic objective with respect to operating reactors is

5. Perform a cost/benefit analysis for identified licensee activities to reduce risk from ISLOCAs.

The cost/benefit analysis results from this program appear in Section 3. For completeness, results from other ISLOCA studies are presented in Section 4.

bA. C. Thadani, memorandum to W. Minners, "Research User Needs for Safety Issue 105-Interfacing Systems LOCA it BWR," May 15. 1991.

\subsection{Advanced Reactors}

For evolutionary and advanced designed reactors, the insight gained from resolution of GI-105 for operating reactors was to be examined for regulatory implications for future plants. The sole objective for advanced reactors was to

- Develop a draft standard review plan for advanced light water reactor (ALWR) interfacing Systems.

Other events overtook the GI-105 program in the advanced reactor arena. The staff's recommendations with respect to evolutionary LWRs (Ref. 11) were approved by the NRC in June $1990 .^{c}$ These recommendations are found in Refcrences 12 and 13. Interfacing systems satisfying those design requirements, as well as all other existing requirements, are expected to pose minuscule risk from ISLOCA. The adva.aced designs have features enhancing prevention and alleviation of breaches of the pressure boundary between the RCS and interfacing systems whether human error or hardware faults are considered. Details are covered in References 12 and 13.

\subsection{Programmatic Approach for Operating Reactors}

Three PWR and one BWR ISLOCA analyses were performed as illustrated by the flow chart in Figure 1 and described in detail in References 5, 7, and 8. The analysis approach was basically a standard PRA with two notable exceptions that were necessary to meet the objectives stated in Section 2.1. These exceptions will be discussed briefly in Sections 2.3.1 and 2.3.2 to aid in understanding the overall approach and use of the results in the cost/ benefit analysis in Section 3.

\subsubsection{Human Errors}

The ISLOCA initiating events (Block 3 of Figure 1) considered in References 5, 7, and 8 consisted of both hardware and human errors. This portion of the analysis included commission errors among human errors that needed to be identified and quantificd. Human error probabilities (HEPs) contributing significantly to risk were identified as candidates for HEP optimization. The performance shaping factors contributing to the significant HEPs were examined for improvements, such as

\footnotetext{
CS. J. Chilk, menorandum to J. M. Taylor, "SFCY-90-16 Evolutionary Iight Water Reactor Certification Issues and Their Relationships to Current Regulatory Requirements," June 26, 1990.
} 


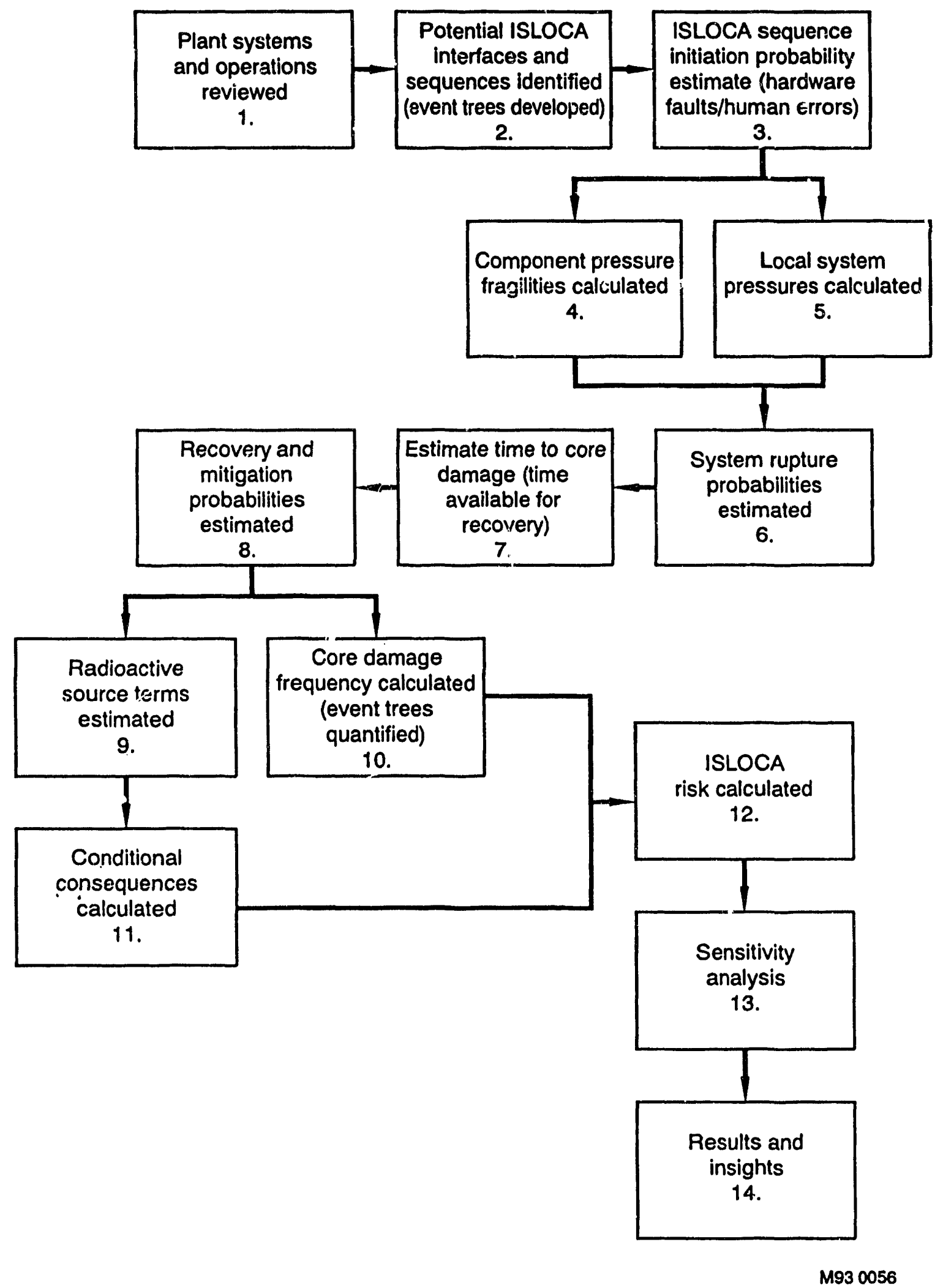

Figure 1. Approach for plant-specific evaluation of ISLOCA 
additiona! iraining, and modified procedures, that would reduce HEPs. FEP optimization was part of the overall cost/benefit analysis. Human errors were again considered in the post-rupture phase of the ISLOCA. Consideration was given for the ability of operators to detect, diagnose, and isolate the break (Block 8, Figure 1) in relation to control room indicators, training, as-written procedures, and time available for recovery (Block 7, Figure 1).

\subsubsection{Break Location Identification}

The location of the break in the low-pressure interfacing system (Block 6, Figure 1) is important because it determines break size and flow rate of fluid from the primary system. Injection system flow rates and refueling water storage tank (RWST) volume then determine time to core damage, provided injection systems are availaule. If the break location causes injection equipment to be lost because of flooding or other effects from the rupture, time available for recovery could be a functior. of the time to loss of all injection equipment, including charging pumps. In this case, knowledge of a likely break location would be important in cost/benefit analyses of equipment qualification improvements, equipment relocations, and erection of barriers. The approach to determining break locations, provided in References 5, 7, and 8, was also a departure from past PRA practice. Probability distributions for low-pressure system component, pressure fragilities (Block 4, Figure 1) were used with local system pressure distribution (Block 5, Figure 1) in a Monte Carlo sampling procedure to determine component likelihood of failure. Component fragility information has been compiled in References 14 and 15.

\subsection{ISLOCA PWR Results}

This section provides a general summary of the insights from the PWR ISLOCA assessments (Refs. 5, 7, and 8), and text has been taken verbatim from Reference 9. Extrapolating these results to other plants without further analysis would be highly speculative.

\subsubsection{B\&W Plant Results}

1. The mean ISLOCA CDF was estimated to be $2 \mathrm{x}$ $10^{-6 / \text { reactor-year. }}$

2. Potential human errors during mode changes were found to be the dominant contributors to ISLOCA CDF and risk. ISLOCA initiating events driven by human error were composed of commission errors that could occur during execution of normal procedural tasks, such as entering shutdown cooling.
3. Scenarios initiated primarily by hardware failures of PIVs were also important contributors to ISLOCA $\mathrm{CDF}$ and risk.

4. Break isolation would be required to prevent core damage because the makeup capacity to the borated water storage tank was insulficient to maintain an adequate reactor coolant inventory for breaks larger than 2 inches in diameter. Although the analysis indicated that hardware would probably be available to isolate these breaks, specific procedures and training were not in place at the time of the plant visit to ensure that this hardware was used.

5. Operational experience related to ISLOCA made credible the specific human error of commission that was the dominant contributors to ISLOCA risk.

All of the auxiliary building rooms that were evaluated experienced periods of $100 \%$ relative humidity. The flooding results are summarized with two general statements:

1. For the large-break sequences [residual heat removal (RHR) letdown line interface], flooding will occur in the break compartment and in adjacent compartments at a rate that will cover essential ECCS components within 1 hour.

2. For the small-break sequences HPI and LPI interfaces, flooding will occur slowly and could be delayed by operation of the compartment sump pumps. Many hours would pass before essential ECCS components would be threatened.

Of the various factors controlling pool formation, two dominate. The first is the rate of discharge of unflashed fluid from the break. The second is the extent to which firewater and condensate from balance-of-plant areas find their way into rooms housing ECCS equipment. For the large-break sequences, the principal contributor to pool formation is the discharged liquid that does not flash to steam. For large-break sequences, as the RCS cools down, it becomes the runout flow of the surviving ECCS. In small-break sequences, th'; discharge of fire protection sprays provides a greater flooding hazard than the accumulation of condensate or unflashed break discharge.

The results from the steam propagation analysis show that operator entry into the auxiliary building would be prohibited by the live steam environment that forms within minutes of system rupture. The results also show that the most limiting environmental factor is water pool formation in the ECCS compartments. When the pools reach a depth of 2 feet, the ECCS pump motors will be submerged, failing the ECCS pumps. The time at which this failure occurs becomes the limiting time available for operator recovery of the plant. The temperature and humidity effects were not important at the $B \& W$ study 
plant because the ECCS equipment was qualified for the postulated environment produced by a high energy line break, which is a more severe environment than predicted here.

\subsubsection{Westinghouse Plant Results}

1. The mean ISLOCA CDF was estimated to be $2 \mathrm{x}$ $10^{-6 / \text { reactor-year. }}$

2. Human errors that occurred during startup and shutdown of the plant were negligible contributors to ISLOCA CDF and risk and a direct result of the high quality of the administrative controls and safety culture at the Westinghouse plant.

3. Sequences initiated by hardware failures of pressure isolation check valves were the only significant contributors to ISLOCA CDF and risk.

4. As in the B\&W plant, 'reak isolation would be an important recovery action because the makeup capacity from the RWST is insufficient to maintain an adequate reactor coolant inventory for breaks that are larger than approximately 2 inches in diameter. The analysis indicates that hardware would be available to isolate these ISLOCA breaks. Adequate pro. cedires and training are generally available to ensure that this hardware is used correctly.

5. At the time of the plant visit, a general survey was made of the interfacing system flow paths to qualitatively estimate the impact on equipment from ruptures in various locations. This survey could not verify that the ECCS components are adequately separated so that any postulated rupture would not affect redundant ECCS trains. In the case of the RHR system, the pumps for units 1 and 2 (the analyzed plant is located at a two-unit site) are located in the basement of the auxiliary building, and a common corridor runs outside of the individual pump rooms. If there were a pipe break and blowdown of steam and liquid from the RCS into one of the RHR pump rooms, this configuration may not ensure that at least one train of ECCS would still be available following the rupture. In other words, because of the common corridor, a rupture in the RHR pump room of one unit could conceivably disable the RHR pumps for the other unit.

6. A significant reduction in ISLOCA risk through relatively simple changes to procedures, training, and instrumentation does not appear to be achievabiè.

\subsubsection{CE Plant Results}

1. The mean ISLOCA CDF was estimated to be $2 \mathrm{x}$ $10^{-6} /$ reactor-year.

2. As at the Westinghouse plant, human errors that occurred during startup and shutdown of the plant were negligible contributors to ISLOCA CDF and risk. Again, this is a direct result of the high quality of the administrative controls and safety culture visible at the plant.

3. Sequences initiated by hardware failures of pressure isolation check valves were the dominant contributors to ISLOCA CDF and risk. Howev'er, at the CE plant, exposure of the low-pressure interfacing system is precipitated by stroke testing of a normally closed injection flow control valve.

4. As in the other two plants, break isolation would be an important recovery action because makeup capacity to the refueling water storage pool is insufficient to maintain an adequate reactor coolant inventory for breaks that are larger than approximately 2 inches in diameter. The analysis indicated that hardware would be available to isolate these ISLOCA breaks; however, procedures were not available at the time of the plant visit to ensure that this hardware was used in all sequences.

5. At the time of the plant visit, a general survey was made of the interfacing system flow paths to qualitatively estimate the impact on equipment from ruptures in various locations. As for the Westinghouse plant, this survey could not verify that the ECCS were adequately separated so that any postulated rupture would not affect redundant ECCS trains.

6. It appears that relatively simple changes to procedures and training could reduce ISLOCA risk by reducing the initiator frequency and by increasing the likelihood of successfully isolating an intersystem break.

\subsection{BWR Results}

An ISLOCA analysis was performed as part of the GI-105 research program and is documented in NUREG/ CR-5928 (Ref. 9). The work consisted of screening analyses and bounding calculations on the systems identified as potentially susceptible to an ISLOCA. A BWR/4 was examined, and the following systems were explicitly addressed: reactor core isolation cooling, high pressure coolant injection, core spray, RHR, reactor water clean up, and control rod drive. The study concluded that ISLOCA is not a risk concern. Although portions of the interfacing systems are susceptible to rupture if exposed to fuil primary system pressure, these are typicaily pump 
suction lines that are not directly connected to the primary system and thus protected by multiple valves. In addition, these suction lines are directly connected to atmospheric or near atmospheric pressure (i.e., either the condensate storage tank or suppression pool, respec- tively), which limits the degree of pressurization that can cake place. Finally, the lower pressure of the primary syst:=a in BW/Rs (1000 psi contrasted to 2000 psi for PWRs) resulti in a greater safoty margin for the BWR systems (contrasted to the PWR systezns). 


\section{ISLOCA COST/BENEFIT ANALYSIS}

This section covers the current GI-105 program cost/ benefit evaluation using the guidelines of Reference 16, $A$ Handbook for Yalue-Impact Assessment, and Reference 17, Generic Cost Estimates. This current cost/benefit analysis is comprehensive and includes treatment of the uncertainty through Monte Carlo simulation. Section 4 summarizes results from previous studies that investigated how reductions in ISLOC.A initiator frequency and risk can be achieved by periodically leak testing the PIVs at the boundary between the RCS and the low-pressure interfacing system.

To assess the cost effectiveness of a particular plant aliernative, a dollar-to-person-rem ratio (DPR) is generated. A value of $\$ 1000 /$ person-rem is usually used by the NRC as an upper bound in deciding whether corrective measures may be appropriate. The DPR is calculated as the cost of the alternative divided by the offsite person-rem averted:

$$
D P R=\frac{\text { cost of alternative }}{\text { offsite person-rem averted }}
$$

When onsite averted costs (OSAC) (i.e., a potential reduction of onsite accident costs) are included as a cost offset in the expression for the DPR, the ratio becomes

$$
D P R=\frac{\text { cost of alternative-onsite averted cost }}{\text { offsite person-rem averted }}
$$

\subsection{Alternatives for the Current Analysis}

The alternatives considered for the $\mathrm{B} \& \mathrm{~W}$, Westinghouse, and CE ISLOCA plants include

- Alternative I The development of ISLOCA mitigation procedures, plant personnel training on the new procedures, and recurring training for yearly requalification. These three modifications are consolidated into one overall alternative that is assumed to minimize HEPs for ISLOCA events.

- Alternative II The installation of eight Class I pressure sensing devices with associated tubing, fittings, supports, and cables located inside containment on the reactor coolant system. In addition, this alternative will require a control board modification to install an alarm or other indicating device, technical specification changes, engineering and quality assurance, health physics support, recordkeeping, train- ing, and rewriting procedures. This alternative is not applicable to the $\mathrm{CE}$ plant because the $\mathrm{CE}$ plant already hasi installed pressure-sensing devices. It is also assumed that this alternative will reduce the risk from leak events/sequences but will not reduce the risk from operator error.

For Alternatives I and II, it is assumed that each of the three plants investigated in the ISLOCA program (B\&W, Westinghouse, and CE) have two possible cases for evaluation. The first case evaluates the effect by modifying ihe existing plant-specific base case. (The term "base case" signifies the actual plant, without modifications.) The second case is for the reduction in CDF by modifying the plant to reflect the incorporation of Alternatives I and II, but assuming the plant has an auxiliary building that has the potential for severe flooding. The cases will be referred to in this report as Case 1 and Case 2, respectively.

Optimized HEPs refers to minimizing the probability of human error to a realistic lower bound for detection, diagnosis, and isolation of an ISLOCA. For Case 1, the error probabilities for detection, diagnosis, and isolation were set to $10-4$. This value is assumed to be an achievable lower bound for an optimized HEP.

For Case 2, auxiliary building flooding limits the time available for operator action. Consequently, detection and isolation error probabilities were set to $10^{-4}$ (these actions require little time), while the diagnosis error probability was estimated using a time-reliability correlation (the time available for diagnosis is a constraint when flooding is a problem) from the Electric Power Research Institute (EPRI)-sponsored Human Cognitive Reliability Project (Ref. 18). The salient entry condition for the ISLOCA procedure at the Westinghouse plant (Ref. 8) is an auxiliary building high radiation alarm. Because the operators initially will be involved in carrying out the immediate actions required for responding to a large LOCA, and because the control room high radiation alarm is rather inconspicuously located, the analysts estimated that about 15 minutes would elapse before the alarm could be received and acknowledged. Once the alarm is acknowledged, it is estimated that another 5 minutes would be required for the operators to enter the correct procedure and carry out the actions to isolate the break. Therefore, the available time for diagnosing the ISLOCA is 30 minutes, and the median time required to complete the diagnosis and isolate the break is 20 minutes, leaving 10 minutes leeway. Westinghouse personnel were judged to be expert and well-trained. The quality of the operatormachine interface was judged to be good. The stress level was taken io be that of a potential emergency. The result- 
ing probability of diagnosis error was calculated to be 0.14 .

\subsection{Core Damage Frequency Results for the Current, sinalysis}

The calculated plant CDFs are assumed to be the contribution exclusively from the ISLOCA analysis. For the cost/benefit uncertainty analysis, the CDFs are assumed to be distributed lognormally. From the plant ISILOCA analysis [using the Idaho National Engineering Laboratory (INEL) developed IRRAS 4.0 computer code], the $\mathrm{CDF}_{\text {before }}$ parameters, $\mathrm{CDF}_{\text {after }}$ parameters, and $\mathrm{CDF}_{\text {delta }}$ parameters are shown in Tables 1 and 2. The $\mathrm{CDF}_{\text {delta }}$ parameter was found by subtracting the $\mathrm{CDF}_{\text {affer }}$ from the $\mathrm{CDF}_{\text {before }}$ using a Taylor series expansion. This delta parameter (assumed to be lognormally distributed) was used to evaluate the cost/benefit uncertainty.

\subsection{Consequence Estimation for the Current Analysis}

The offsite dose consequence was evaluated in the ISLOCA base case analysis. The offsite dose per accident event was calculated to be $2.8 \times 10^{6}$ person-rem/event for the $B \& W$ plant and $6.12 \times 10^{6}$ person-rem/event for the Westinghouse and CE plants. The total offsite dose (person-rem per year) from an ISLOCA event is calculated by multiplying the base case reduction in $\mathrm{CDF}\left(\mathrm{CDF}_{\text {delta }}\right)$ by the total offsite dose per event. This value is then calculated for the remaining life of the plant. For the analysis in this report, it is assumed that a plant has 20 years left on its operating license. For example, the $\mathrm{B} \& \mathrm{~W}$ plant has approximately 20 years left on its operating license (it expires on March 24, 2011). But, if the plant applies for and receives a 20 -year license extension, a 40 -year pointestimate dose reduction is applicable. Both a 20 and 40-year cost/benefit analysis are performed in this report.

Tables 3 and 4 shows the best estimate total offsite dose reduction for both 20 and 40 years for each plant. The dose reduction is the change in dose (dose before-dose after) that is expected from implementation of the alternative. This dose reduction is the benefit that may be realized.

\subsection{Onsite Averted Costs for the Current Analysis}

In addition to the costs associated with the alternative, the potential reduction of onsite accident costs as a cost offset was evaluated. A Handbook for Value/Impact Assessment (Ref. 16) was used as the reference for this tvaluation. This reference calculates the OSAC using Equation (1):

$V_{o p}=N U\left(F_{o}-F_{N}\right)$

where

$\mathrm{V}_{o p}=$ cost of avoided onsite property damage (OSAC)

$\mathrm{N}=$ number of affected facilities

$\mathrm{U}=$ present worth of onsite property damage given a release

$\mathrm{F}_{O}=$ original $\mathrm{CDF}$ (base case)

$\mathrm{F}_{N}=\mathrm{CDF}$ after implementing an option.

The present worth of onsite property damage given a release, $\mathrm{U}$, is calculated by

$$
U=\frac{C}{m r^{2}}\left(e ^ { - r t _ { i } ) } \left(1-e^{\left.-r^{(t} f^{t} i\right)}\left(1-e^{-r m}\right)\right.\right.
$$

where

$\mathrm{C}=$ cleanup, repair, and replacement power costs per severe accident per plant

$\mathrm{t}_{f}=$ years remaining unîil end of plant life

$\mathrm{t}_{i}=$ years before reactor begins operation

$\mathrm{m}=$ period of time over which damage costs are paid out

$\mathrm{r}=$ discount rate (for $5 \%, \mathrm{r}=0.05$ ) per year.

When an uncertainty in the calculation of $\mathrm{V}_{O P}$ is considered, it is appropriate to calculate a low, best, and high estimate for the worth of $U$. These values can then be multiplied by the best estimate of the $\mathrm{CDF}_{\text {dett }}$ to yield a low, best, and high cost for $V_{o p}$. The cost handbook (Ref. 16) recommends low, best, and high estimate values for input to calculate $U$ (present value of onsite property damage given a release). The inputs that were used to evaluate the $U$ equation above are 
Table 1 Core damage frequency parameters for the LSLOCA piants (per reactor year) for Alternative I.

\begin{tabular}{llll}
\hline Plant & CDF & Mean & $\begin{array}{c}\text { Standard } \\
\text { deviation }\end{array}$ \\
\hline B\&W & Before & $2.4 \times 10^{-6}$ & $1.5 \times 10^{-5}$ \\
(Case 1) & After & $3.5 \times 10^{-8}$ & $6.0 \times 10^{-7}$ \\
& Delta & $2.3 \times 10^{-6}$ & $1.5 \times 10^{-5}$ \\
B\&W & Before & $2.2 \times 10^{-5}$ & $9.7 \times 10^{-5}$ \\
(Case 2) & After & $1.0 \times 10^{-6}$ & $1.5 \times 10^{-5}$ \\
& Delta & $2.1 \times 10^{-5}$ & $9.8 \times 10^{-5}$ \\
Westinghouse & Before & $2.3 \times 10^{-6}$ & $1.3 \times 10^{-4}$ \\
(Case 1) & After & $4.3 \times 10^{-9}$ & $3.1 \times 10^{-7}$ \\
& Delta & $2.3 \times 10^{-6}$ & $1.3 \times 10^{-4}$ \\
Westinghouse & Before & $5.2 \times 10^{-6}$ & $2.9 \times 10^{-4}$ \\
(Case 2) & After & $1.3 \times 10^{-6}$ & $6.3 \times 10^{-5}$ \\
& Delta & $3.9 \times 10^{-6}$ & $3.0 \times 10^{-4}$ \\
CE & Before & $1.3 \times 10^{-6}$ & $5.5 \times 10^{-5}$ \\
(Case 1) & After & $4.1 \times 10^{-10}$ & $2.7 \times 10^{-8}$ \\
& Delta & $1.3 \times 10^{-6}$ & $5.5 \times 10^{-5}$ \\
CE & Before & $1.3 \times 10^{-6}$ & $5.5 \times 10^{-5}$ \\
(Case 2) & After & $2.4 \times 10^{-7}$ & $2.1 \times 10^{-5}$ \\
& Delta & $1.1 \times 10^{-6}$ & $5.9 \times 10^{-5}$ \\
\hline
\end{tabular}

Table 2 Core damage frequency parameters for the ISLOCA plants (per reactor year) for Alternative II.

\begin{tabular}{llll}
\hline Plant & CDF & \multicolumn{1}{l}{ Mean } & \multicolumn{1}{c}{$\begin{array}{c}\text { Standard } \\
\text { deviation }\end{array}$} \\
\hline B\&W & Before & $2.4 \times 10^{-6}$ & $1.5 \times 10^{-5}$ \\
(Case 1) & After & $3.5 \times 10^{-8}$ & $6.0 \times 10^{-7}$ \\
& Delta & $2.3 \times 10^{-6}$ & $1.5 \times 10^{-5}$ \\
B\&W & Before & $2.2 \times 10^{-5}$ & $1.3 \times 10^{-5}$ \\
(Case 2) & After & $5.6 \times 10^{-6}$ & $2.5 \times 10^{-5}$ \\
& Delta & $1.6 \times 10^{-5}$ & $2.8 \times 10^{-5}$ \\
Westinghouse & Before & $2.3 \times 10^{-6}$ & $1.3 \times 10^{-4}$ \\
(Case 1) & After & $4.3 \times 10^{-9}$ & $3.1 \times 10^{-7}$ \\
& Delta & $2.3 \times 10^{-6}$ & $1.3 \times 10^{-4}$ \\
Westinghouse & Before & $5.2 \times 10^{-6}$ & $2.9 \times 10^{-4}$ \\
(Case 2) & After & $1.3 \times 10^{-6}$ & $6.3 \times 10^{-5}$ \\
& Delta & $3.9 \times 10^{-6}$ & $3.0 \times 10^{-4}$ \\
& & & \\
\hline
\end{tabular}


Table 3 Total offsite person-rem reduction (benefits; for the ISLOCA plants for Aiternative $I$.

\begin{tabular}{llc}
\hline Plant & $\begin{array}{c}\text { Number } \\
\text { of } \\
\text { years }\end{array}$ & $\begin{array}{c}\text { Dose } \\
\text { Reduction } \\
\text { (best estimate) }\end{array}$ \\
\hline B\&W & 20 & 129 \\
(Case 1) & 40 & 258 \\
B\&W & 20 & 1176 \\
(Case 2) & 40 & 2352 \\
Westinghouse & 20 & 282 \\
(Case 1) & 40 & 563 \\
Westinghouse & 20 & 477 \\
(Case 2) & 40 & 954 \\
CE & 20 & 159 \\
(Case 1) & 40 & 318 \\
CE & 20 & 135 \\
(Case 2) & 40 & 269 \\
\hline
\end{tabular}

Table 4 Total offsite person-rem reduction (benefits) for the ISLOCA plants for Alternative II.

\begin{tabular}{|c|c|c|c|}
\hline \multicolumn{2}{|c|}{ Plant } & $\begin{array}{c}\text { Number } \\
\text { of } \\
\text { years }\end{array}$ & $\begin{array}{c}\text { Dose } \\
\text { Reduction } \\
\text { (best estimate) } \\
\text { (person-rem) }\end{array}$ \\
\hline \multicolumn{2}{|c|}{$\begin{array}{l}\text { B\&W } \\
\text { (Case 1) }\end{array}$} & $\begin{array}{l}20 \\
40\end{array}$ & $\begin{array}{l}129 \\
258\end{array}$ \\
\hline \multicolumn{2}{|c|}{$\begin{array}{l}\text { B\&W } \\
\text { (Case 2) }\end{array}$} & $\begin{array}{l}20 \\
40\end{array}$ & $\begin{array}{r}896 \\
1792\end{array}$ \\
\hline \multicolumn{2}{|c|}{$\begin{array}{l}\text { Westinghouse } \\
\text { (Case 1) }\end{array}$} & $\begin{array}{l}20 \\
40\end{array}$ & $\begin{array}{l}282 \\
563\end{array}$ \\
\hline \multicolumn{2}{|c|}{$\begin{array}{l}\text { Westinghouse } \\
\text { (Case 2) }\end{array}$} & $\begin{array}{l}20 \\
40\end{array}$ & $\begin{array}{l}477 \\
954\end{array}$ \\
\hline $\mathrm{C}$ & \multicolumn{2}{|c|}{$\begin{array}{l}\text { Low }-\$ 1.035 \times 10^{9} \\
\text { Best }-\$ 1.65-10^{9} \\
\text { High }=\$ 4.95 \times 10^{9}\end{array}$} & \\
\hline $\mathbf{m}$ & \multicolumn{2}{|c|}{$\begin{array}{l}\text { Low }-7.5 \text { years } \\
\text { Best }-10 \text { years } \\
\text { High }-12.5 \text { years }\end{array}$} & \\
\hline $\mathbf{r}$ & \multicolumn{2}{|l|}{0.05} & \\
\hline & \multicolumn{2}{|l|}{0 ry } & \\
\hline & \multicolumn{2}{|c|}{20 or 40 ry. } & \\
\hline
\end{tabular}

Sometimes the $U$ value is mistaken to be the future costs inclurred in the event of an accident. This interpretation of $U$ is incorrect. Reference 16 gives a correct explanation
of $U$ as

...the quantity, $U$, must be interpreted carefully to avoid misunderstandings. It does not represent the expected onsite property damage due to a single accident. Rather, it is the present value of a stream of potential losses extending over the remaining lifetime of the reactor. Thus, it reflects the expected loss due to a single accident; the possibility that such an accident could occur, with some small probability, at any time over the remaining reactor life; and the effects of discounting these potential future losses to present value. When the quantity, $U$, is multiplied by the accident frequency, the result is the expected loss over the reactor life, discounted to present value.

The low, best, and high present onsite property damage costs (including cleanup cost, repair or refurbishment cost, and replacement energy cost) given a release were calculated and used to calculate the OSAC values. The OSAC values were calculated using the mean value of the $\mathrm{CDF}_{\text {delta }}$ distribution. This $\mathrm{CDF}_{\text {delta }}$ value represents a best estimate for the change in CDF given implementation of an alternative. The mean $\mathrm{CDF}_{\text {delta }}$ was multiplied by the low, best, and high estimates of the $U$ values to yield the low, best, and high OSAC. These calculated OSAC values are shown in Tables 5 and 6 for the 20 and 40 year cases for all three ISLOCA plants.

\subsection{Cost Estimating Methodology for the Current Analysis}

This section presents the general methodology used in performing the cost analysis for the ISLOCA alternative. All plant cost estimates are presented in 1992 dollars and represent implementation costs for the specific improvement and any recurring costs associated with the plant alternative.

\subsubsection{Assumptions}

The following assumptions were made in developing cost estimates for the alternatives considered:

- The alternative will be made during normal plant operations.

- Socioeconomic impacts will be considered minimal and will not be included as an additional cost.

- Since the plant will not be shut down to implement the alternative, no shutdown costs are included. 
Table 5 OSAC calculated values for the ISLOCA plants for Alternative I.

\begin{tabular}{lcccr}
\hline & & & \multicolumn{3}{c}{$\begin{array}{c}\text { OSAC } \\
(\$)\end{array}$} \\
\cline { 5 - 5 } Plant & $\begin{array}{c}\text { Number of } \\
\text { years }\end{array}$ & Low & Best & High \\
\hline B\&W & 20 & 25,100 & 37,800 & 107,000 \\
(Case 1) & 40 & 34,300 & 51,600 & 146,000 \\
& & & & \\
B\&W & 20 & 229,000 & 345,000 & 977,000 \\
(Case 2) & 40 & 313,000 & 472,000 & $1,340,000$ \\
& & & & \\
Westinghouse & 20 & 25,100 & 37,800 & 107,000 \\
(Case 1) & 40 & 34,300 & 51,600 & 146,000 \\
& & & & \\
Westinghouse & 20 & 42,600 & 64,000 & 181,000 \\
(Case 2) & 40 & 58,200 & 87,600 & 248,000 \\
& & & & \\
CE & 20 & 14,200 & 31,300 & 60,500 \\
(Case 1) & 40 & 19,400 & 29,200 & 82,700 \\
& & & & \\
CE & 20 & 12,000 & 18,100 & 51,200 \\
(Case 2) & 40 & 16,400 & 24,700 & 70,000 \\
& & & & \\
\hline
\end{tabular}

Table 6 OSAC calculated values for the ISLOCA plants for Alternative II. OSAC

(\$)

\begin{tabular}{lcccr}
\cline { 4 - 5 } Plant & $\begin{array}{c}\text { Number of } \\
\text { years }\end{array}$ & Low & Best & High \\
\hline B\&W & 20 & 25,100 & 37,800 & 107,000 \\
(Case 1) & 40 & 34,300 & 51,600 & 146,000 \\
& & & & \\
B\&W & 20 & 175,000 & 262,000 & 744,000 \\
(Case 2) & 40 & 239,000 & 359,000 & $1,020,000$ \\
Westinghouse & 20 & 25,100 & 37,800 & 107,000 \\
(Case 1) & 40 & 34,300 & 51,600 & 146,000 \\
& & & & \\
Westinghouse & 20 & 42,600 & 64,000 & 181,000 \\
(Case 2) & 40 & 58,200 & 87,600 & 248,000 \\
& & & & \\
\hline
\end{tabular}


- An escalation rate of $5 \%$ was used for all recurring costs.

- No waste disposal or record keeping costs are required.

- For Alternative I, installation or removal costs are not necessary because the alternative does not include any application of equipment.

- For Alternative I, the technical specifications will not be impacted by either the procedure changes or the training. Thus, no technical specification related cosis will be incurred.

- Since the procedure changes (i.e., Alternative I) will not effect the plant technical specifications, it is assumed that no NRC or NRC related (e.g., computer time or other miscellaneous technical costs) will be incurred for Alternative I.

- For Alternative I, no radiation/health physics costs are needed because no work is required in radiation areas.

- Although equipment/component locations for Alternative II are specific to the reference plant, the environmental factors chosen to estimate worker prociuctivity reductions are appropriate for the entire PWR plant population.

\subsubsection{Cost Categories Considered}

All costs were computed using FORECAST 2.1 (Ref. 19) and based on the input provided by the cost analyst and the assumptions in Section 3.5.1. Using the assumptions above, the cost analyses were limited to the following:

\section{Alternative I}

- Licensee costs for rewriting procedures, staff training, and other technical subtasks

- Licensee recurring costs

- OSAC that represent the averted onsite property damages, including allowances for cleanup, repair, and replacement energy costs.

\section{Alternative II}

- Cost of equipment, materials, and structures

- Installation costs .nd associated overhead

- Engineering ard quality assurance costs

- Radiation exposure costs
- Health physics support costs

- Licensee costs for rewriting procedures, staff training, technical specification changes, and other technical subtasks

\section{- Licensee recurring costs}

- NRC implementation costs associated with the review of the plant alternative

- NRC technical specification change

- OSAC that represent the averted onsite property damages, including allowances for cleanup, repair, and replacement energy costs.

The cost evaluation in this analysis follows the general methodology and parameters used by FORECAST 2.1. For example, costs incurred by the utility as a result of implementing the alternative considered included the costs of rewriting procedures, training the staff, and changing recordkeeping or reporting requirements. For each of the above-stated cost categories, the costs were derived following the guidelines presented in Reference 18, Abstracts 2.2.2, 2.2.3, and 2.2.4.

Areas addressed by Alternative I include (1) changing shutdown procedures concerning jumpering interlocks, (2) inserting warnings about stroke testing of HPI valves, with instructions in the emergency operating procedures that address leaks outside of containment, (3) training operators to identify and isolate ISLOCAs, and (4) revising training material to address the ISLOCA concerns.

\subsubsection{Cost Category Descriptions}

Labor and Equipment/Materials Costs._Pricing was obtained for the pressure indicator and associated remote and local transmitters from several vendors. The energy economic data base (EEDB) (Refs. 19 and 20) built into the FORECAST 2.1 cude provided the basis for the labor estimate. The EEDB incorporates "as-built" cost information (installation labor hours) for nuclear plant construction activities. Additionally, for operating nuclear power plants, there are a number of workplace characteristics that significantly reduce the level of productivity and increase the number of labor hours required to accomplished a task. These characteristics, discussed in detail in FORECAST 2.1, $\mathrm{i}^{-}$- ude access, congestion and interference, radiation, and task management. Since EEDB reflects only new (or as-built) plant conditions, the installation labor hours were adjusted to properly consider actual conditions existing at operating nuclear plants.

Total labor costs. The total labor costs associated with the alternative considered include overhead charges to account for contractor management, administrative support, rent, and insurance. 
Engineering and Quality Assurance/Control Costs. Engineering and quality assurance costs reflect the cost of engineering ard design, as well as quality assurance/quality control (QA/QC) activities associated with implementing the requirements. For requirements affecting structures/systems already in place (operating plants) the guidelines in Reference 17, Abstract 6.4, recommend a $25 \%$ engineering and QA/QC factor be applied to the direct cost (i.e., labor and materials cost but without any overhead charges). All cost estimates developed in this study include this engineering and QA/QC cost component wheri applicable.

Radiation Exposure. Worker radiation exposure estimates were derived based on guidelines presented in Reference 17, Abstract 4.3. The collectiv? radiation exposure associated with the implementatiori of an alternative considered is estimated by taking the product of the in-field labor hours necessary to perform the task and the work area dose rate associated with that particular task.

Health Physics Support Costs. Health physics requirements for the alternative considered were developed based on information and guidelines presented in Reference 17, Abstract 2.1.6. Two factors were considered: the size of the work crew and the magnitude of the radiation field. Plant health prysics personnel perform radiological surveys, that are conducted throughout the performance of the alternative, staff radiological checkpoints, set up anticontamination clothing removal areas, and determine badging requirements.

Other Licensee Costs. Other costs incurred by the utility as a result of implementing the alternatives considered included the costs of rewriting procedures, technical specification changes, staff training, and changing recordkeeping or reporting requirements. For each of the cost categories, the costs were derived following the guidelines presented in Reference 17, Abstracts 2.2.2, 2.2.3, and 2.2 .4 , respectively.

NRC Costs. NRC implementation costs account for onetime NRC activities such as developing inspection guidelines and procedures, ensuring compliance with the regulatory action, technical specification changes, and other technical tasks.

\subsubsection{Cost Estimating Uncertainty Development}

The areas of uncertainty associated with the cost estimating model for this study included the following:

- Contingency allowance

- Licensee analytical, procedure writing, and training costs
- OSAC

- Labor rate variations due to plant site location

- Variability of in-plant work environment conditions

- NRC procedural/administrative/analytical cost.

Each cost estimate was evaluated to determine all applicable areas of uncertainty. Specific numerical values were used for each individual cost analysis; however, the following general assumptions were made:

- The contingency factor provides the user with a means for including an allowance for uncertainty and cost variations at the summary cost level. A contingency percentage can be applied to some or all of the applicable licensee cost categories (i.e., physical alternative costs, replacement energy costs, recurring costs, and procedural/analytical costs). For this analysis, the following contingency factors were applied to all cost categories:

\section{Cost contingency input}

Low cost estimate-no contingency factor

Best cost estimate $-5 \%$ contingency factor

High cost estimate $-10 \%$ contingency factor.

- The licensee procedural/administrative/analytical cost module in FORECAST 2.1 allows alternatives to reflect uncertainty in the following cost categories: technical specification changes, writing new procedures, staff training, recordkeeping, and other miscellaneous technical costs. In the case of technical specification changes, writing procedures, and recordkeeping, the FORECAST 2.1 package allows a change from "routine" to "complex" depending on the plant specific situation. The FORECAST code assumes a cost of $\$ 800$ for each routine procedure, while each complex procedure costs $\$ 3600$. For this analysis, it was assumed that two new procedures will be written. Thus, the following conditions were used for the low, best, and high estimates:

\section{Initial, one-time procedure writing cost input}

Low cost estimat -2 routine procedures

Best cost estimate-1 routine, 1 complex procedure

High cost estimate -2 complex procedures

- For staff training, uncertainty is reflected by varying the number of hours required for the training or evaluation. The FORECAST code breaks training down into four categories (with associated costs): 
simulator training ( $\$ 44 /$ hour), classroom training (\$26/hour), on-the-job training (\$8/hour), and development of training information and materials (\$112/page). It was assumed that each plant had approximately 85 operators that will need to be trained. Also, it was assumed that hourly salary costs would not be combined with the hourly training costs because the actual training time is small compared to the overall number of hours vorked during the year. This training will incur an initial cost as well as yearly recuu ring costs. Thus, two separate cases were developed for the low, best, and high scenarios:

\section{Initial, one-time training cost input}

Low cost estimate -1 hour simulator, 2 hour classroom, no on-the-job training, and 5 pages of training material

Best cost estimate -2 hour simulator, 4 hour classroom, no on-the-job training, and 5 pages of training material

High cost estimate -4 hour simulator, 8 hour classroom, no on-the-job trainine and 10 pages of training material

\section{Recurring training cost input}

- Low cost estimate-0 hour simulator, 1 hour classroom, no on-the-job 'raining, and no pages of training material

Best cost estimate $-1 / 2$ hour simulator, 2 hour classroom, no on-the-job training, and no pages of training material

High cost estimate -1 hour simulator, 4 hour classroom, no on-the-job training, and no pages of training material

- In the recurring cost modules for the licensee, all future costs considered are discounted to reflect the present value using the chosen discount rate. A 5\% discount rate was used for the low, best, and high cases. This discount rate was the same as that chosen for the OSAC calculation.

- Labor rate variations due to plant site location are a consideration when calculating labor costs.

\section{Labor rate input}

Low cost estimate-88\% factor

Best cost estimate $-100 \%$ factor

High cost estimate-112\% factor
- The working environment characteristics are reflected in the labor productivity factor. Radiation, congestion, and access and handling conditions in the area where the alternative is being performed increase the amount of time spent for that task. For the best estimate cost calculation, the labor productivity factor for typical work conditions (as derived by the FORECAST 2.1 coỏe) was used. A labor productivity factor for an environment reflecting less radiation and congestion was used for the low cost estimate calculation. Conversely, a higher value for the labor productivity factor, (an environment reflecting more radiation and congestion) was used for the high cost estimate calculation.

\section{Radiation level input}

Low cost estimate-high radiation, high temperature (31-50 mrem/hour, 2 hour stay time)

Best cost estimate-high radiation, high temperature (51-100 mrem/hour, 1 hour stay time)

High cost estimate-high radiation, high temperature ( $>100 \mathrm{mrem} /$ hour, $1 / 2$ hour stay time).

- The NRC procedural/administrative/analytical cost module in FORECAST 2.1 allows alternatives to reflect uncertainty in the following cost categories: implementation, technical specification changes, and other technical costs. For the technical specification changes, the FORECAST 2.1 package allows a change from "simple" to "complex" depending on the plant specific situation.

Initial, one-time technical specification changes

Low cost estimate-routine procedure

Best cost estimate-routine procedure

High cost estimate-complex procedure.

\subsection{Plant Alternative Cost Estimates for the Current Analysis}

In this study, the cost estimates were primarily derived from guidelines and input provided in NUREG/CR-3568 (Ref. 16) and NUREG/CR-4627, Rev. 2 (Ref. 17). Low, best, and high range of cost estimates were developed using this guidance. Table 7 shows the cost breakdown per plant for Alternative I for the 20 year case. The cost values are $\$ 34,600$ for the low estimate, $\$ 97,900$ for the best estimate, and $\$ 210,300$ for the high estimate. This is a range difference from the low to the high cost estimate of $\$ 175,700$. A main contributor to this difference is the contingency factor (10\% included in the high cost estimate) and the cost of recurring training. 
Table 7 ISLOCA Alternative I cost breakdown per plant (20 year case).

\begin{tabular}{|c|c|c|c|}
\hline \multirow[b]{2}{*}{ Category } & \multicolumn{3}{|c|}{ Cost estimate } \\
\hline & $\begin{array}{l}\text { Low } \\
(\$)\end{array}$ & $\begin{array}{c}\text { Best } \\
(\$)\end{array}$ & $\begin{array}{c}\text { High } \\
\text { (\$) }\end{array}$ \\
\hline $\begin{array}{l}\text { Licensee procedural/analytical (one-time) } \\
\text { Licensee contingency (one-time) }\end{array}$ & $\begin{array}{r}10,600 \\
0 \\
\end{array}$ & $\begin{array}{r}21,800 \\
1,100\end{array}$ & $\begin{array}{r}42,000 \\
4,200 \\
\end{array}$ \\
\hline Total licensee one-time cost & 10,600 & 22,900 & 46,200 \\
\hline $\begin{array}{l}\text { Licensee procedural/analytical (recurring) } \\
\text { Licensee contingency (recurring) }\end{array}$ & $\begin{array}{r}24,000 \\
0\end{array}$ & $\begin{array}{r}71,500 \\
3,500\end{array}$ & $\begin{array}{r}149,200 \\
14,900\end{array}$ \\
\hline Total licensee recurring cust & 24,000 & 75,000 & 164,100 \\
\hline Total (without onsite averted cost) & 34,600 & 97,900 & 210,300 \\
\hline
\end{tabular}

The cost estimates for the 40 year case (Alternative I) are shown in Table 8. The cost estimates are $\$ 43,400$ for the low estimate, $\$ 125,700$ for the best estimate, and $\$ 271,700$ for the high estimate. This is a range difference from the low to the high cost estimate of $\$ 228,300$. The main contributors to this difference are the same as those for the 20 year case above.

Table 9 shows the cost breakdown for Alternative II for the 20 year case. The cost values are $\$ 312,000$ for the low estimate, $\$ 488,000$ for the best estimate, and $\$ 651,000$ for the high estimate. This is a range difference from the low to the high cost estimate of $\$ 339,000$. A main contributor to this difference is the contingency factor $(10 \%$ included in the high cost estimate) and the cost of recurring training.

The cost estimates for the 40 year case (Alternative II) are shown in Table 10. The cost estimates are $\$ 333,000$ for the low estimate, $\$ 511,000$ for the best estimate, and $\$ 671,000$ for the high estimate. This is a range difference from the low to the high cost estimate of $\$ 338,000$. The main contributors to this difference are the same as those for the 20 year case above.

Alternative II requires the placement of eight Class I pressure sensing devices with associated tubing, fittings, supports, and cables located inside containment on the reactor coolant system. The cost of a pressure sensing device is approximately $\$ 3300$ each, and the average cost of the associated wiring and brackets is approximately $\$ 100$. It was estimated to require 320 person-hours for installation in the containment area and 80 person-hours for installation of the remote alarms in the control room. The hourly labor rate from the EEDB data base in FORECAST 2.1 was used. The associated licensee procedural costs will include 100 staff hours as well as that discussed in the cost estimating uncertainty section above. Licensee recurring costs include $\$ 4000 /$ year for test and maintenance (because of the high radiation area). All costs were adjusted according to the workplace characteristics and included overhead charges.

In this study, the cost estimates associated with the NRC were primarily derived from guidelines and input provided in NUREG/CR-3568 (Ref. 16) and NUREG/ CR-4627, Rev. 2 (Ref. 17). For NRC one-time activities, the best cost estimate assumed that the NRC implementation costs per plant would include 40 person-hours to develop guidelines, costs as discussed in the cost estimating uncertainty section above, and one person-day for initial plant inspection.

\subsection{Total Cost Results for the Current Analysis}

NRC policy recommends inclusion of the OSAC. As stated in the introduction to Section 3.4, the OSAC is a cost offset in the cost/benefit equation. Occasionally, the OSAC value is larger than the cost estimate for an alternative, and the resulting total cost estimate is a negative number (i.e., an overall cost savings). The best estimate costs minus the best estimate OSAC values for Alternative I are listed below in Table 11. Table 12 lists the best estimate costs minus the best estimate OSAC values for Alternative II. 
Table 8 ISLOCA Alternative I cost breakdown per plant (40 year case).

\begin{tabular}{|c|c|c|c|}
\hline \multirow[b]{2}{*}{ Category } & \multicolumn{3}{|c|}{ Cost estimate } \\
\hline & $\begin{array}{l}\text { Low } \\
(\$)\end{array}$ & $\begin{array}{c}\text { Best } \\
\text { (\$) }\end{array}$ & $\begin{array}{c}\text { High } \\
\text { (\$) }\end{array}$ \\
\hline Licensee procedural/analytical (one-time) & 10,600 & 21,800 & 42,000 \\
\hline Licensee contingency (one-rime) & $\underline{0}$ & 1,100 & 4,200 \\
\hline Total licensee one-time cost & 10,600 & 22,900 & 46,200 \\
\hline Licensee procedural/analytical (recurring) & 32,800 & 97,900 & 205,000 \\
\hline Licensee contingency (recurring) & 0 & 4,900 & 20,500 \\
\hline Total licensee recurring cost & 32,800 & 102,800 & 225,500 \\
\hline Total (without onsite averted cost) & 43,400 & 125,700 & 271,700 \\
\hline
\end{tabular}

Table 9 ISLOCA Alternative II cost breakdown per piant (20 year case).

\begin{tabular}{|c|c|c|c|}
\hline \multirow[b]{2}{*}{ Category } & \multicolumn{3}{|c|}{ Cost estimate } \\
\hline & $\begin{array}{l}\text { Low } \\
(\$)\end{array}$ & $\begin{array}{c}\text { Best } \\
(\$)\end{array}$ & $\begin{array}{c}\text { High } \\
\text { (\$) }\end{array}$ \\
\hline Licensee hardware and equipment (one-time) & 34,000 & 34,000 & 34,000 \\
\hline Licensee installation labor (one-time) & 79,000 & 118,000 & 147,000 \\
\hline Licensee engineering/QA-QC & 19,000 & 24,000 & 27,000 \\
\hline Licensee health physics & 75,000 & 140,000 & 189,000 \\
\hline $\begin{array}{l}\text { Licensee procedural/analytical (one-time) } \\
\text { Licensee contingency (one-time) }\end{array}$ & $\begin{array}{r}36,000 \\
0 \\
\end{array}$ & $\begin{array}{l}77,000 \\
20,000 \\
\end{array}$ & $\begin{array}{r}102,000 \\
50,000 \\
\end{array}$ \\
\hline Total licensee one- time cost & 243,000 & 413,000 & 549,000 \\
\hline Licensee recurring costs & 52,000 & 54,000 & 62,000 \\
\hline Licensee contingency (recurring) & 0 & 3,000 & 6,000 \\
\hline Total licensee recurring cost & 52,000 & 57,000 & 68,000 \\
\hline Total NRC cost & 17,000 & 18,000 & 34,000 \\
\hline Total (without onsite averted cost) & 312,000 & 488,000 & 651,000 \\
\hline
\end{tabular}


Table 10 ISLOCA Alternative II cost breakdown per plant (40 year case).

\begin{tabular}{|c|c|c|c|c|c|}
\hline & & & \multicolumn{3}{|c|}{ Cost estimate } \\
\hline \multicolumn{3}{|l|}{ Category } & $\begin{array}{l}\text { Low } \\
(\$)\end{array}$ & $\begin{array}{c}\text { Best } \\
(\$)\end{array}$ & $\begin{array}{c}\text { High } \\
\text { (\$) }\end{array}$ \\
\hline \multicolumn{3}{|c|}{ Licensee hardware and equipment (one-time) } & 34,000 & 34,000 & 34,000 \\
\hline \multicolumn{3}{|c|}{ Licensee installation labor (one-time) } & 79,000 & 118,000 & 147,000 \\
\hline \multicolumn{3}{|c|}{ Licensee engineering/QA-QC } & 19,000 & 24,000 & 27,000 \\
\hline \multicolumn{3}{|c|}{ Licensee health physics } & 75,000 & 140,000 & 189,000 \\
\hline \multicolumn{3}{|c|}{ Licensee procedural/analytical (one-time) } & 36,000 & 77,000 & 102,000 \\
\hline \multicolumn{3}{|c|}{ Licensee contingency (one-time) } & 0 & 20,000 & 50,000 \\
\hline \multicolumn{3}{|c|}{ Total licensee one-time cost } & 243,000 & 413,000 & 549,000 \\
\hline \multicolumn{3}{|c|}{ Licensee recurring costs } & 73,000 & 76,000 & 80,000 \\
\hline \multicolumn{3}{|c|}{ Licensee contingency (recurring) } & $\mathbf{0}$ & 4,000 & 8,000 \\
\hline \multicolumn{3}{|c|}{ Total licensee recurring cost } & 73,000 & 80,000 & 88,000 \\
\hline \multicolumn{3}{|c|}{ Total NRC cost } & 17,000 & 18,000 & 34,000 \\
\hline \multicolumn{3}{|c|}{ Total (without onsite averted cost) } & 333,000 & 511,000 & 671,000 \\
\hline \multicolumn{3}{|c|}{$\begin{array}{l}\text { Table } 11 \text { Cost minus OSAC values for the } \\
\text { ISLOCA plants (Alternative I). }\end{array}$} & \multicolumn{3}{|c|}{$\begin{array}{l}\text { Table } 12 \text { Cost minus OSAC values for the } \\
\text { ISLOCA plants (Alternative II). }\end{array}$} \\
\hline Plant & $\begin{array}{c}\text { Number } \\
\text { of } \\
\text { Years }\end{array}$ & $\underset{\text { (best estimate } \$ \text { ) }}{\text { Cost-OSAC }}$ & Plant & $\begin{array}{c}\text { Number } \\
\text { of } \\
\text { Years }\end{array}$ & $\underset{\text { (best estimate \$) }}{\text { Cost-OSAC }}$ \\
\hline $\begin{array}{l}\text { B\&W } \\
\text { (Case 1) }\end{array}$ & $\begin{array}{l}20 \\
40\end{array}$ & $\begin{array}{l}60,120 \\
74,100\end{array}$ & $B \& W$ & 20 & 450,000 \\
\hline $\begin{array}{l}\text { R\&W } \\
\text { (Case 2) }\end{array}$ & $\begin{array}{l}20 \\
40\end{array}$ & $\begin{array}{l}-247,000 \\
-346,000\end{array}$ & (Case 1) & 40 & 459,000 \\
\hline \multirow{2}{*}{$\begin{array}{l}\text { Westinghouse } \\
\text { (Case 1) }\end{array}$} & \multirow{2}{*}{$\begin{array}{l}20 \\
40\end{array}$} & \multirow{2}{*}{$\begin{array}{l}60,100 \\
74,100\end{array}$} & $\mathrm{~B} \& \mathrm{~W}$ & 20 & 226,000 \\
\hline & & & (Case 2) & 40 & 152,000 \\
\hline $\begin{array}{l}\text { Westinghouse } \\
\text { (Case 2) }\end{array}$ & $\begin{array}{l}20 \\
40\end{array}$ & $\begin{array}{l}33,900 \\
38,100\end{array}$ & Westinghouse & 20 & 450,000 \\
\hline \multirow{2}{*}{$\begin{array}{l}\text { CE } \\
\text { (Case 1) }\end{array}$} & \multirow{2}{*}{20} & \multirow{2}{*}{$\begin{array}{l}66,600 \\
96,500\end{array}$} & (Case 1) & 40 & 459,000 \\
\hline & & & Westinghouse & 20 & 424,000 \\
\hline (Case 2) & $\begin{array}{l}20 \\
40\end{array}$ & $\begin{array}{r}79,800 \\
101,000\end{array}$ & (Case 2) & 40 & 423,000 \\
\hline
\end{tabular}




\subsection{Cost/Benefit Uncertainty Discussion for the Current Analysis}

The Handbook for Value/Impact Assessment (Ref. 16) states that the estimation and presentation of uncertainties are vital parts of a value/impact assessment. The PRA Procedures Guide - A Guide to the Performance of Probabilistic Risk Assessments for Nuclear Power Plants (Ref. 21) and NUREG/CR-5197 (Ref. 22) discuss two contributors to the uncertainty: model uncertainty and data uncertainty. The model uncertainty is related to the model's accuracy and completeness for core damage sequence, containment failure, and consequence. Only the data uncertainty was addressed in this analysis.

Data uncertainty is important to any analysis of this type. If only the point estimate results are given, much information about the data is lost, and an unjustified opinion about the precision of the result may occur. The larger the standard error or the statistical confidence intervals, the point estimate becomes less reliable. The distribution of the data also communicates a greater amount of information for the decision-making process than the point estimates alone. For the cost/benefit uncertainty analysis, the uncertainties in the cost estimate calculations and benefit calculations were addressed.

The cost/benefit ratio uncertainty is calculated using the DPR equations shown in the introduction to Section 3. A DPR ratio was calculated for both equations, including and excluding the OSAC. The @RISK (Ref. 23) computer program was used for evaluation of the uncertainty in the cost/benefit analysis. The @RISK program uses a Monte Carlo sampling method to determine a resultant cost/benefit distribution by random sampling over many iterations of the contribution risk and cost data distribution functions. Input to the @RISK program included the cost (the cost of the alternative), benefit (offsite dose averted), and OSAC.

The cost variable was modeled using a triangular distribution with the low, best, and high value (see Section 3.6) as input modeled to @RISK. A triangular distribution is frequently used in cost applications where only three points, a low, best, and high cost estimate, are known. When randomly sampled, all the cost values will lie in a range from the low cost estimate to the high cost estimate.

As discussed in Sections 3.2 and 3.3, the benefit values were calculated using the CDF parameters from the ISLOCA plant analysis. The $\mathrm{CDF}_{\text {detr }}$ is modeled by assuming a lognormal distribution in the @RISK program. The lognormal CDFdelta distribution is then multiplied by the point estimate dose $\left(2.8 \times 10^{\varepsilon}\right.$ person-remievent for the B\&W plant or $6.12 \times 10^{6}$ person-rem/event for the Westinghouse and CE plants) and the total number of years (either 20 or 40 ) to obtain the total benefit.

The OSAC values are calculated by multiplying the point estimate $\mathrm{CDF}_{\text {delta }}$ by the low, best, and high estimates of $U$ values to develop a triangular distribution as discussed in Section 3.4 and presented in Tables 3 and 4. This triangular distribution is used in the DPR ratio uncertainty analysis.

\subsection{Uncertainty Analysis Results for the Current Analysis}

The cost, benefit, and OSAC uncertainty distributions are entered in the final DPR ratio calculations (with and without OSAC) as shown in the introduction to Section 3. The results of the DPR ratio (with and without OSAC) uncertainty analyses are shown in Table 13 for Alternative I. The Alternative II DPR ratios are shown in Table 14. The resulting DPR ratio cumulative density graphs are presented in Figures A-1 through A-24 (in Appendix A) for the Alternative I cases. The CDFs for the Alternative II cases are not displayed because the Alternative II cases are much less cost beneficial than the associated Alternative I cases. The DPR uncertainty calculations were performed using the @RISK program with 4000 iterations.

The last column in Tables 13 and 14 contains the probability that the DPR $<1000$. This column gives the probability that an alternative will produce less than $\$ 1000$ /person-rem. For the B\&W plant (Case 1) for 20 years.including the OSAC, the alternative only has a $37 \%$ chance of the DPR ratio being $\$ 1000 /$ person-rem or less. This percentage implies that the alternative has a $63 \%$ chance of being greater than $\$ 1000 /$ person-rem.

All of the point estimate values are less than $\$ 1000 /$ person-rem while most of the associated mean (and median) values are greater than the $\$ 1000$ value. This difference can be attributed primarily to the probabilistic nature of the resulting DPR distribution to be skewed to the right. For a distribution that is skewed to the right, the mean is always larger than the median and, consequently, may be much larger than the point estimate.

One inherent assumption for Alternative $I$ is that the actual in-plant hardware and instrumentation is adequate enough to allow a reduction of the ISLOCA risk through an improvement in procedures or training. It may be possible to postulate other alternatives where instrumentation or hardware is added to the plant to better alleviate ISLOCA scenarios. But, these additional alternatives will simply add additional cost (for hardware and installation) to the Ailternative İ case, making it less cost beneficial. 
Table 13 Cost/benefit DPR ratio results for the ISLOCA plants for Alternative I (all values in \$/person-rem).

\begin{tabular}{|c|c|c|c|c|c|c|c|}
\hline \multirow[b]{2}{*}{ Plant } & \multirow{2}{*}{$\begin{array}{l}\text { Total } \\
\text { years }\end{array}$} & \multirow[b]{2}{*}{ Mean } & \multirow{2}{*}{$\begin{array}{c}\text { Point } \\
\text { estimate }\end{array}$} & \multicolumn{3}{|c|}{ Percentiles } & \multirow{2}{*}{$\begin{array}{r}\text { Probability } \\
\text { (DPR }<1000)\end{array}$} \\
\hline & & & & 5th & 50th & 95th & \\
\hline B\&W & 20 Without OSAC & 43,000 & 780 & 220 & 5,600 & 140,000 & $20 \%$ \\
\hline \multirow[t]{3}{*}{ (Case 1) } & With OSAC & 22,000 & 480 & -210 & 2,100 & 66,000 & $37 \%$ \\
\hline & 40 Withol: SAC & 26,000 & 500 & 140 & 3,700 & 94,000 & $26 \%$ \\
\hline & With OSAC & 13,000 & 290 & -300 & 1,300 & 46,000 & $46 \%$ \\
\hline \multirow{4}{*}{$\begin{array}{l}\text { B\&W20 } \\
\text { (Case 2) }\end{array}$} & Without OSAC & 2,100 & 83 & 23 & 420 & 8,000 & $69 \%$ \\
\hline & With OSAC & $-7,500$ & -210 & $-28,000$ & $-1,400$ & -72 & $100 \%$ \\
\hline & 40 Without OSAC & 1,300 & 53 & 13 & 275 & 5,200 & $77 \%$ \\
\hline & With OSAC & $-5,000$ & -150 & $-20,000$ & $-1,000$ & -52 & $100 \%$ \\
\hline \multirow{4}{*}{$\begin{array}{l}\text { Westinghouse } \\
\text { (Case 1) }\end{array}$} & 20 Without OSAC & $1,400,000$ & 348 & 200 & 23,000 & $3,100,000$ & $14 \%$ \\
\hline & With OSAC & 680,000 & 214 & -600 & 7,800 & $1,500,000$ & $28 \%$ \\
\hline & 40 Without OSAC & 850,000 & 223 & 120 & 15,000 & $2,000,000$ & $18 \%$ \\
\hline & With OSAC & 350,000 & 130 & $-1,100$ & 4,700 & 750,000 & $33 \%$ \\
\hline \multirow{4}{*}{$\begin{array}{l}\text { Westinghouse } \\
\text { (Case 2) }\end{array}$} & 20 Without OSAC & $1,600,000$ & 205 & 130 & 17,000 & $2,200,000$ & $17 \%$ \\
\hline & With OSAC & 370,000 & 71 & $-100, v 00$ & 470 & 380,000 & $56 \%$ \\
\hline & 40 Without OSAC & 940,000 & 130 & 77 & 11,000 & $1,400,000$ & $21 \%$ \\
\hline & With OSAC & 170,000 & 40 & $-110,000$ & 120 & 190,000 & $63 \%$ \\
\hline \multirow{4}{*}{$\begin{array}{l}\text { CE } \\
\text { (Case 1) }\end{array}$} & 20 Without OSAC & $4,400,000$ & 620 & 300 & 29,000 & $2,800,000$ & $12 \%$ \\
\hline & With OSAC & $3,500,000$ & 480 & 160 & 19,000 & $1,900,000$ & $16 \%$ \\
\hline & 40 Without OSAC & $2,200,000$ & 400 & 180 & 19,000 & $1,700,000$ & $15 \%$ \\
\hline & With OSAC & $1,300,000$ & 300 & 80 & 12,000 & $1,200,000$ & $19 \%$ \\
\hline $\mathrm{CE}$ & 20 Without OSAC & $2,100,000$ & 730 & 420 & 43,000 & $5,300,000$ & $9 \%$ \\
\hline \multirow[t]{3}{*}{ (Case 2) } & With OSAC & $1,600,000$ & 590 & 270 & 32,000 & $3,800,000$ & $11 \%$ \\
\hline & 40 Without OSAC & $1,500,000$ & 470 & 250 & 28,000 & $3,400,000$ & $12 \%$ \\
\hline & With OSAC & $1,100,000$ & 380 & 170 & 20,000 & $2,400,000$ & $15 \%$ \\
\hline
\end{tabular}


Table 14 Cost/benefit results for the ISLOCA plants for Alternative II (all values in \$/person-rem).

\begin{tabular}{|c|c|c|c|c|c|c|c|c|}
\hline \multirow[b]{2}{*}{ Plant } & \multirow{2}{*}{\multicolumn{2}{|c|}{$\begin{array}{l}\text { Total } \\
\text { years }\end{array}$}} & \multirow[b]{2}{*}{ Mean } & \multirow{2}{*}{$\begin{array}{c}\text { Point } \\
\text { estimate }\end{array}$} & \multicolumn{3}{|c|}{ Percentiles } & \multirow{2}{*}{$\begin{array}{r}\text { Probability } \\
(\text { DPR }<1000)\end{array}$} \\
\hline & & & & & 5th & 50th & 95th & \\
\hline $\mathrm{B} \& \mathrm{~W}$ & 20 & Without OSAC & 160,000 & 3800 & 980 & 24,000 & 610,000 & $5.2 \%$ \\
\hline \multirow[t]{3}{*}{ (Case 1) } & & With OSAC & 138,000 & 3500 & 900 & 22,000 & 540,000 & $5.8 \%$ \\
\hline & 40 & Without OSAC & 81,000 & 2000 & 530 & 13,000 & 330,000 & $9.9 \%$ \\
\hline & & With OSAC & 70,000 & 1800 & 430 & 11,000 & 270,000 & $11.4 \%$ \\
\hline \multirow{4}{*}{$\begin{array}{l}\text { B\&W } \\
\text { (Case 2) }\end{array}$} & 20 & Without OSAC & 27,000 & 415 & 140 & 3,800 & 110,000 & $24.2 \%$ \\
\hline & & With OSAC & 6,800 & 192 & $-2,400$ & 490 & 30,000 & $59.9 \%$ \\
\hline & 40 & Without OSAC & 14,000 & 217 & 77 & 2,000 & 60,000 & $35.3 \%$ \\
\hline & & With OSAC & -84 & 65 & $-6,800$ & 9 & 6,900 & $82.1 \%$ \\
\hline \multirow{4}{*}{$\begin{array}{l}\text { Westinghouse } \\
\text { (Case 1) }\end{array}$} & 20 & Without OSAC & $6,100,000$ & $17 n 0$ & 860 & 110,000 & $10,000,000$ & $5.6 \%$ \\
\hline & & With OSAC & $5,300,000$ & 1600 & 730 & 95,000 & $9,400,000$ & $5.9 \%$ \\
\hline & 40 & Withoי't OSAC & $3,500,000$ & 910 & 450 & 58,000 & $5,400,000$ & $8.4 \%$ \\
\hline & & With OSAC & $3,000,000$ & 820 & 400 & 47,000 & $4,500,000$ & $9.1 \%$ \\
\hline \multirow{4}{*}{$\begin{array}{l}\text { Westinghouse } \\
\text { (Case 2) }\end{array}$} & 20 & Without OSAC & $6,000,000$ & 1000 & 520 & 72,000 & $9,200,000$ & $7.2 \%$ \\
\hline & & With OSAC & $4,700,000$ & 890 & 410 & 57,000 & $7,400,000$ & $8.3 \%$ \\
\hline & 40 & Without OSAC & $2,900,000$ & 540 & 270 & 37,000 & $4,700,000$ & $10.9 \%$ \\
\hline & & With OSAC & $2,400,000$ & 440 & 190 & 28,000 & $3,400,000$ & $13.2 \%$ \\
\hline
\end{tabular}




\section{PREVIOUS ISLOCA COST/BENEFIT ANALYSES}

The potential benefits of leak testing PIVs have been reported in References 24, 25, and 26. Results from this past work indicate that plants not currently testing their PIVs can achieve reductions in the frequency of ISLOCAs by performing periodic testing. An additional reduction can be achieved by implementing continuous pressure monitoring on the low pressure side of the highpressure system boundary valves. A cost benefit/analysis (Ref. 26) showed that the value of periodic testing and continuous pressure monitoring may depend strongly on whether the necessary modifications can be made without incurring replacement power costs. For plants already performing leak tests, increasing the frequency of the leak tests or implementing continuous pressure monitoring may not be cost effective. Reference 26 indicates that for plants not doing any leak testing or testing only those valves making up the Event $\mathrm{V}$ configuration, the calculated potential benefit is significant. However, there are conservatisms (discussed in Section 4.4.2) involved in the benefit calculations in Reference 26.

This section summarizes the important results from the past analyses. A discussion is provided of how increasing the frequency of periodic leak testing or implementing continuous pressure monitoring would affect the ISLOCA initiator frequency for three plants analyzed by the INEL (Refs. 5, 7, and 8).

\subsection{Background for Previous Analyses}

Before publication of the reactor safety study (Ref. 1), PIV leak testing was being addressed as part of the inservice inspection/in-service testing program. The reactor safety study showed that a significant portion of the risk from operating nuclear power plants could be attributed to an accident sequence that became known as Event $V$. This sequence involved the failure of two check valves at the high pressure isolation boundary (PIB) between the RCS and LPI system. Failure of these PIVs resulted in overpressurization and rupture of the LPI system outside containment. The severity of the fission product release that accompanied core damage under these conditions accounted for a disproportionate amount of the total plant risk calculated by the stury.

Because of concerns about the potential risk from this type of sequence, the Acting Director of the Division of Operating Reactors issued a letterd ordering all nuclear plant licensees to determine if the Event $V$ valve configuration existed in their plants. The Event $V$ valve configuration was defined as either two check valves in series or

dD. G. Eisenhut, Nuclear Regulatory Commission, letter to LWR Licensees, "LWR Primary Coolant System Pressurc Isolation Values," Feabruary 23, 1980 two check valves in series with a MOV. This valve configuration is used to connect the Class 1 boundary of the RCS to low-pressure system piping. Figure 1 shows the Event $V$ configuration as described in footnote $d$. If the Event $V$ arrangement was present, the licensees were to indicate whether continuous or periodic PIV leak tests were being performed and whether the PIVs were known or had been found to lack integrity. Finally, the licensees were asked to determine whether plant procedures should be revised or if plant modifications should be made to increase PIV reliability.

After considering the responses received to Reference 26, the NRC ordered specific licensees with the Event V valve configuration to implement PIV leak testing procedures. Some plants that received the Event V order, but with different configurations, may have boundaries that are not subject to periodic testing. This cannot be determined without perusal of the technical specifications of all Event $V$ orders plants and without reviewing the piping and instrumentation diagrams for each of those plants. Plants licensed after the Event $V$ order were required to implement leak testing for a broader range of PIV configurations than required by the Event $\mathrm{V}$ order.

\subsection{Key Results from Previous Studies}

A number of reports have been written on reducing ISLOCA risk through modification of plant designs or procedures (Refs. 24, 25, and 26). The two most promising methods of reducing risk, from Reference 26 , were periodic leak testing of the PIVs and continuous pressure monitoring to detect leakage. Other methods of reducing risk, such as improved operator training and formalized refueling water storage tank makeup procedures, have been shown to be relatively ineffective (Ref. 26).

\subsubsection{Risk Reduction Achievable by Periodic Testing}

Examples of periodic testing methods considered acceptable by the NRC include periodic leak testing, ultrasonic examination, or radiographic examination of each valve every time the plant is shutdown and whenever either check valve is moved from the fully closed position (see footnote d).

Brookhaven National Laboratory (BNL) evaluated the cost of implementing acceptable leak testing procedures at PWRs that currently do not have them (Ref. 26). In their evaluation, BNL assumed the plant would have a PIV configuration similar to that of the Oconee plant. An Oconee-like plant implementing leak testing procedures was assumed to incuir one-time costs for cieveioping new test procedures (700 labor-hours at $\$ 40 /$ hour), and instal- 
lation of the necessary hardware (test taps, valves, and test tubing) at a cost of $\$ 150,000$. The plant would also incur periodic costs including labor for testing (50 laborhours at $\$ 40 /$ hour), radiation exposure to plant personnel (1 person-rem at $\$ 1000 /$ person-rem), and replacement power ( 5 hours at $\$ 16,700 /$ hour). The periodic costs were discounted over the remaining plant life using the following expression:

$$
C_{d}=\frac{C\left(1-e^{-r t}\right)}{r}
$$

where

$$
\begin{aligned}
& \mathrm{C}_{\mathrm{d}}=\text { discounted cost } \\
& \mathrm{C}=\text { present cost } \\
& \mathrm{t}=\text { time to end of plant life (31 years) } \\
& \mathrm{r}=\text { discount rate }(10 \%) .
\end{aligned}
$$

The discounted periodic costs are then $\$ 3000 \times 9.6$ or $\$ 28,800$. The replacement power costs were discounted using the following expression:

$$
C^{d}=\left(\frac{C}{r}\right)\left(\frac{1-e^{-r t}}{r}-e^{-r t} t\right)
$$

The discounted replacement power costs are then $\$ 83,800 \times 81.5$ or $\$ 6,790,000$. The total costs for an 18 -month test interval are given by

total costs $=\quad \begin{aligned} & \text { hardware }+ \text { procedures }+ \\ & (12 / 18)(\text { periodic testing }+ \\ & \text { replacement power })\end{aligned}$
$=\quad \begin{aligned} & \$ 150,000+\$ 28,000+ \\ & (12 / 18)(\$ 28,800+\$ 6,790,000)\end{aligned}$
$=\quad \$ 4,720,000$.

This value is reduced to $\$ 197,000$ if the installation and testing can be performed without incurring replacement power costs.

Reference 24 evaluated the ISLOCA initiator frequencies for the valve configuration displayed in Figure 2, with and without periodic testing. The effect of yearly testing the two check valves was to reduce the initiator frequency from $5.8 \times 10^{-6} /$ year to $5.5 \times 10^{-9} /$ year. These values are averages based on a 40 -year plant lifetime, assuming four shutdowns per year. The analysis assumed the test verifies that both check valves are neither ruptured nor leaking. This study did not assess the CDF or consequences of an ISLOCA. The main result was a calculated reduction in initiator frequency by three orders of magnitude achieved by periodic PIV testing. The analysis from Reference 24 is summarized in further detail (including potential failure modes of the interfacing system) in Appendix $\mathbf{B}$.

Reference 25 evaluated the ISLOCA initiator frequencies, both with and without periodic testing, for the valve configurations shown in Figure 3. The results for each configuration are shown in Table 15. A calculated two to three order of magnitude reduction in ISLOCA initiator frequency results when testing is implemented with a 2 year period. Increasing the frequency of testing to once per year provides a relatively small additional reduction in initiator frequency. The study in Reference 25 (like Reference 24) did not address CDF or the consequences, and the result on initiator frequency is similar to the result from Reference 24 and provides data on some additional valve configurations not considered by Reference 24 .

Reference 26 provides an analysis of three plants (Indian Point 3, Oconee 3, and Calvert Cliffs 1) with the PIV configurations shown in Figure 4. The analysis estimated the reduction in ISLOCA initiator frequency, CDF, and risk associated with increasing the frequency of PIV leak testing at the plants. The existing PIV testing requirements are different at each of these plants. At Indian Point 3 , the practice is to test at each cold shutdown, which Reference 26 assumes to occur every 4 months. However the PIVs at the HPI system interface currently are not tested. Therefore, increased frequency of testing was taken to mean including these valves under the current test program. At Oconee, the PIVs are tested at 9 month intervals. In this case, increased frequency of testing was taken to mean testing after each cold shutdown, two of which were assumed to occur during the current 9-month test interval. At Calvert Cliffs, there is a permanent pressure sensor at the LPI/HPI/accumulator inlet. However, the RHR suction line MOVs are not tested. Therefore, at Calvert Cliffs increased frequency of testing was taken to mean testing these valves at each cold shutdown (assuming four shutdowns occur per year). The results of increasing the testing frequency (or scope) are summarized in Table 16 (see Appendix $\mathrm{C}$ for additional details of the analysis contained in Reference 26). The benefit of the modifications is also provided based on the risk reduction resulting from the test program. The benefits are calculated for two categories and then summed. The first category assumes the interfacing system is overpressurized but that core damage is avoided. In this case, the consequences included in the risk equation include replacement power costs, cleanup costs, and occupational doses. The second category assumes that core damage occurs. In this case, the consequences tc offsite personnel are calculated using a generic CRAC $2 \mathrm{n}$ 'ndel. The conse- 
quence measures used are person-rem, acute fatalities, occupational health effects, onsite cleanup costs, and

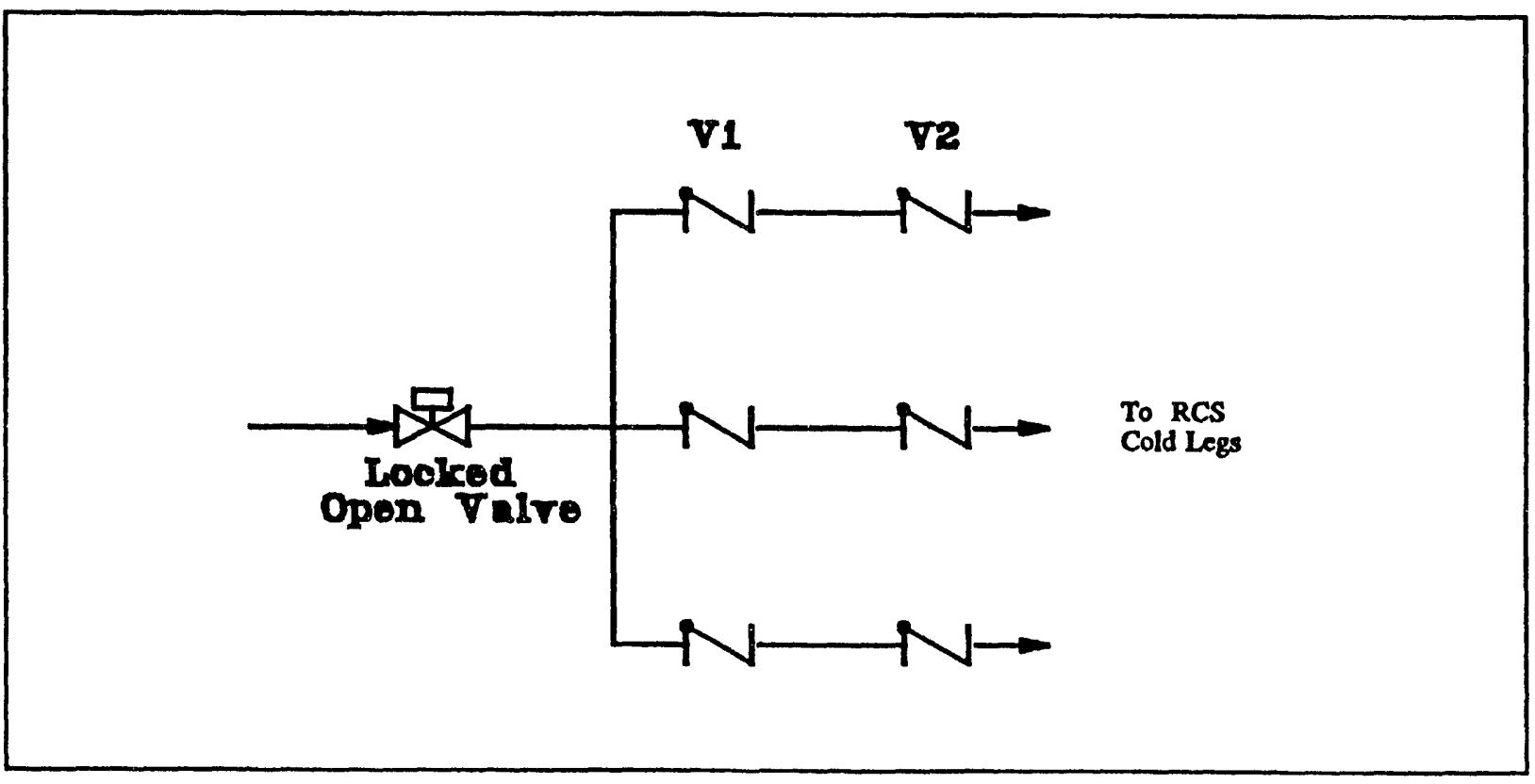

Figure 2. Event V pressure isolation valve configuration.

land interdiction costs (without decontamination). The dollar value of the consequences was calculated assuming $\$ 1000$ /person-rem, $\$ 5,000,000 /$ fatality, onsite cleanup costs of $\$ 100,000,000 /$ year for 10 years, and land interdiction costs of $\$ 1.26 \times 10^{9}$ for an unsubmerged release or $\$ 2.76 \times 10^{8}$ for a submerged release. These costs were discounted over the remaining plant life. The benefits shown in Table 16 are based on an unsubmerged release, and therefore, represent an upper bound on the benefit. The dollar values presented in Table 16 were inflated (using a 5\% rate) to 1992 dollars to facilitate comparisons to the current cost/benefit analysis presented in Section 3. In each of the three study plants, the cost of increasing the test frequency is much greater than the resulting benefit. This is largely because tests at these plants include the cost of obtaining replacement power, and this cost overwhelms the benefit of increased frequency of testing.

Reference 26 also estimated the benefit of implementing test procedures at plants that currently do not test. This was done in two ways. First, the study calculated what the ISLOCA CDF would be at each of the study plants with testing not required. The resulting CDF is shown in the second column of Table 16 . Second, the study evaluated a generic no-test case with a valve configuration similar to that of Oconee. The ISLOCA CDF for an Oconee-type plant that does not have any testing requirements in place was estimated to be about $3.25 \times 10^{-4} /$ year. When such a plant implements periodic PIV testing on an 18 month interval, the ISLOCA CDF is reduced to $3.28 \times 10^{-6} /$ year. In this case, the reduction in CDF and risk is much larger, as much as two orders of magnitude, and the resulting benefit is more than three times greater than the cost of implementing the program. The results would appear even more attractive if the improvement could be implemented without incurring replacement power costs.

\subsubsection{Risk Reduction Achievable by Continuous Pressure Monitoring}

Continuous pressure monitoring involves adding pressure sensors that will allow the operators to detect leakage through the first of two or more PIVs shortly after it occurs. This would eliminate time-dependent failure modes for the second valve. The cost of installing the required instrumentation was estimated at $\$ 8200$ dollars for each line monitored (Ref. 26). This is based on the cost of parts, engineering, labor, and personnel exposure but does not include replacement power costs. There would be an additional cost of $\$ 600$ /year for maintenance of the instrumentation. Discounting the cost over the remaining life of the plant and adjusting for the number of lines that must be monitored at each of the three study plants produces the cost estimates in Table 17. 

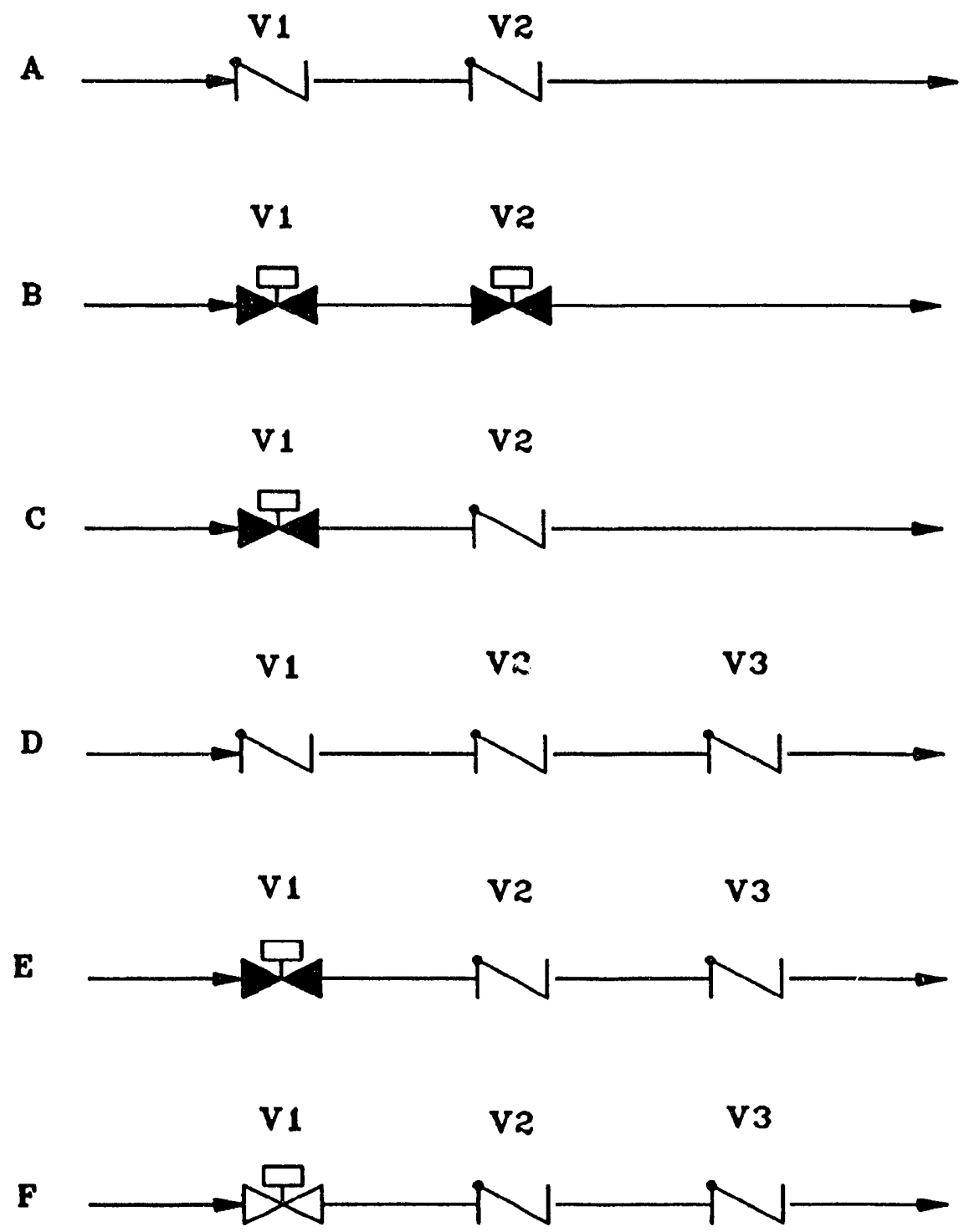

Figure 3. Pressure isolation valve configurations evaluated in NUREG-0677 (REF. 75). 
Table 15 Estimated ISLOCA initiator frequencies from NUREG-0677 (Ref. 25).

\begin{tabular}{llll}
\hline $\begin{array}{l}\text { Valve } \\
\text { configuration }\end{array}$ & $\begin{array}{c}\text { Original frequency } \\
\text { (no testing) }\end{array}$ & $\begin{array}{c}\text { Revised } \\
\text { frequency }\end{array}$ & \multicolumn{1}{c}{ Revision to procedure } \\
\hline $\mathrm{A}$ & $9.5 \times 10^{-6}$ & $\begin{array}{l}4.7 \times 10^{-7} \\
2.4 \times 10^{-7}\end{array}$ & Test every 2 years Test every year \\
$\mathrm{B}$ & $1.8 \times 10^{-4}$ & $4.2 \times 10^{-9}$ & Lock valves closed and test every 2 years \\
$\mathrm{C}$ & $1.0 \times 10^{-5}$ & $2.5 \times 10^{-7}$ & Leak test every year \\
$\mathrm{D}$ & $3.0 \times 10^{-6}$ & $7.4 \times 10^{-9}$ & Leak test every 2 years \\
$\mathrm{E}$ & $2.8 \times 10^{-4}$ & $4.7 \times 10^{-7}$ & Leak test every 2 years Leak test every year \\
& $2.4 \times 10^{-7}$ & Leak test every 2 years Leak test every year \\
$\mathrm{F}$ & $9.6 \times 10^{-6}$ & $4.7 \times 10^{-7}$ & \\
\hline
\end{tabular}

\section{LOW PRESSURE HIGH PRESSURE}

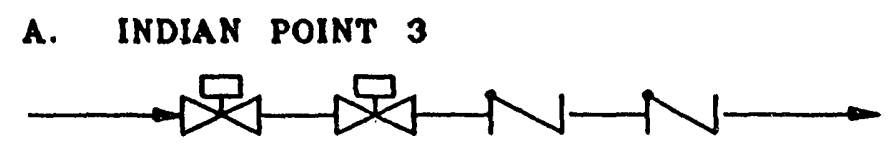

B. OCONEE 3

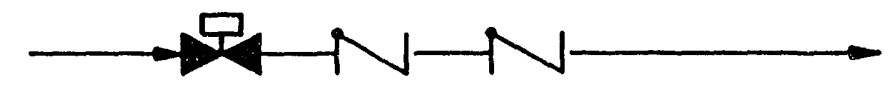

C. CALVERT CLIFFS 1

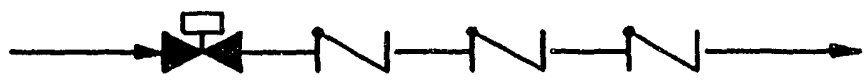

Figure 4. PIV configurations evaluated by BNL. 
Table 16 Summary of cost/benefit data for increased frequency of PIV testing from NUREG/CR-5102 (Ref. 26) (all dollar values inflated to 1992 dollars).

\begin{tabular}{lllllr}
\hline Plant & $\begin{array}{l}\text { No testing } \\
\text { (CDF/year) }\end{array}$ & $\begin{array}{l}\text { Existing } \\
\text { policy } \\
\text { (CDF/year) }\end{array}$ & $\begin{array}{l}\text { Increased } \\
\text { frequency of } \\
\text { testing } \\
\text { (CDF/year) }\end{array}$ & Cost/Year & $\begin{array}{r}\text { Benefit/ } \\
\text { Year }\end{array}$ \\
\hline Indian Point & $5.58 \times 10^{-8}$ & $2.78 \times 10^{-9}$ & $2.74 \times 10^{-9}$ & $\$ 30,000,000$ & $\$ 9,440$ \\
Ocones & $3.26 \times 10^{-4}$ & $8.42 \times 10^{-7}$ & $1.63 \times 10^{-7}$ & $\$ 17,000,000$ & $\$ 38,500$ \\
Calvert Cliffs & $9.12 \times 10^{-5}$ & $3.38 \times 10^{-6}$ & $4.70 \times 10^{-7}$ & $\$ 24,400,000$ & $\$ 176,000$ \\
No-test case & $3.25 \times 10^{-4}$ & $3.25 \times 10^{-4}$ & $3.28 \times 10^{-6}$ & $\$ 5,460,000$ & $\$ 18,100,000$ \\
\hline
\end{tabular}

Table 17 Summary of cost/benefit data for continuous pressure monitoring from NUREG/CR-5102

(Ref. 26) (all dollar values inflated to 1992 dollars).

\begin{tabular}{lllllr}
\hline Plant & $\begin{array}{l}\text { No testing } \\
\text { (CDF/year) }\end{array}$ & $\begin{array}{l}\text { Existing } \\
\text { policy } \\
\text { (CDF/year) }\end{array}$ & $\begin{array}{l}\text { Increased } \\
\text { frequency of } \\
\text { testing } \\
\text { (CDF/year) }\end{array}$ & Cost/Year & $\begin{array}{r}\text { Benefit/ } \\
\text { Year }\end{array}$ \\
\hline Indian Point & $5.58 \times 10^{-8}$ & $2.78 \times 10^{-9}$ & $1.50 \times 10^{-9}$ & $\$ 104,000$ & $\$ 6,530$ \\
Oconee & $3.26 \times 10^{-4}$ & $8.42 \times 10^{-7}$ & $6.82 \times 10^{-7}$ & $\$ 28,900$ & $\$ 9,370$ \\
Calvert Cliffs & $9.12 \times 10^{-5}$ & $3.38 \times 10^{-6}$ & $1.95 \times 10^{-6}$ & $\$ 75,600$ & $\$ 87,700$ \\
\hline
\end{tabular}

Table 17 shows that adding continuous pressure monitoring to the three study plants reduced the ISLOCA CDF. However, the resulting benefit did not justify the cost at two of the three study plants. The Calvert Cliffs benefit is large enough to justify the cost primarily because the plant has higher consequences associated with MOV failure at the RHR suction boundary. This is because Calvert Cliffs has one of the two RHR suction valves located outside of containment. Therefore, the chance of the LOCA occurring in containment is reduced, and the chance of the LOCA occurring outside of containment is increased. The benefit numbers shown in Table 17 are based on an unsubmerged release and, therefore, represent an upper limit on the benefit.

\subsection{Summiary of Conclusions and Key Assumptions From Previous Analyses}

From the studies discussed in Section 4.2, periodic leak testing of PIVs appears to substantially reduce ISLOCA initiator frequency. Large calculated reductions in fre- quency are attained by testing every 18 months as opposed to no testing. Testing yearly, or after every cold shutdown, appears to further reduce the initiator frequency. However, when the cost of implementing the increased frequency of testing is considered, the additional risk reduction may not justify the cost. Plants that are already testing as frequently as at every refueling might cost effectively implement additional risk reduction measures. However, the plant-specific analyses done by BNL show that this is unlikely if implementing such additional measures requires the purchase of replacement power. If replacement power does not figure into the cost, then increasing the frequency of testing to once every cold shutdown could be cost effective. Plant-specific analyses would be required to demonstrate this for any given plant. The BNL studies have also shown that when costs of implementing continuous pressure monitoring are compared to the resulting benefit, pressure monitoring appears not to be cost effective at plants that currently are performing periodic PIV leak tests.

The cost/benefit analysis in Reference 26, on the value of performing PIV leak testing, includes a number of as- 
sumptions that are somewhat unrealistic. One assumption in particular should be carefully considered. This is the assumption that leaking valves will only be discovered through leak testing. The base case assumption of a 30-year mission time for PIVs is also questionable as is the assumption that leak testing resets the mission clock. Leak testing may reveal nothing of wear and corrosion conditions precipitating valve failure. Whether pressure monitoring could be considered as a substitute for periodic testing is not clear from any of the Section 4.2.2 referenced analyses.

\subsubsection{Assumptions on Valve Testing}

The primary benefit of individually leak testing PIVs from a risk perspective is to ensure that both valves are closed so that if the one maintaining the pressure boundary were to fail, the redundant valve would be available for performing the task. Individual leak testing, therefore, provides assurance that redundancy does exist to guard against catastrophic failures of PIV check valves. However, there is no evidence in the available operating history of U.S. or foreign commercial nuclear power plants of an $i$...mediate and catastrophic failure of a check valve that was initially closed and maintaining a differential pressure. (The normal plant startup could not be accomplished without one of the valves closing and maintaining RCS integrity.) In addition, the available evidence suggests that check valves in this type of service fall because they develop an initial small leak that grows gradually. This type of failure mechanism would in all likelihood be detected through the routine monitoring of the RCS water inventory balance or by the interfacing system instru- mentation (i.e., pressure and temperature indicators and alarms). Typical plant practices (i.e., technical specifications) related to the RCS pressure boundary include monitoring the amount of RCS leakage. This leakage is segregated into three categories: controlled (RCP seals), identified, and unidentified leakage. Standard techncial specifications from one vendor limit the total leakage for each of these three categories to 52,10 , and $1 \mathrm{gpm}$, respectively. Controlled leakage should be monitored every 31 days. A RCS water inventory balance should be performed every 72 hours during steady state operations. Therefore, if immediate and catastrophic failures of check valves are not a concern (i.e., not credible) and leaks are detected through a number of routine plant monitoring systems, individual leak testing of PIVs provides assurance that both valves are closed and seated but does not generate a significant risk reduction. The key premise of this argument is check valves that are maintaining a differential pressure in their normal service fail by developing small leaks that grow gradually and will be detected by a plant's routine monitoring systems and do not fail by the catastrophic failure of the disk.

\subsubsection{Pressure Isolation Valve Failure Frequency}

Reference 26 used a 1985 expert opinion generated value of $1.0 \times 10^{-7}$ /hour for the frequency of valve disk rupture failure. The failure rates applied in the study were admitted to be conservative because that failure mode had never been experienced in the history of the nuclear industry. At the time of this document, 7 years of additional U.S. PWR of experience has accumulated.

Using a later expert opinion estimate (later than Reference 26), from NUREG/CR-4550 (Ref. 27) regarding check valve catastrophic failure frequency and the additional years of experience, a Bayesian estimate was made of a new rate to be assigned that failure mode.

The update information is provided in Table 18.

The new failure frequency is $2.3 \times 10^{-9} /$ hour. This value can be used to calculate the rate of failure of two untested series check valves. For this, the following assumptions apply:

1. No leak testing

2. 40-year plant life

3. Plant experiences (on average) one cold shutdown per year (i.e., plant is on RHR cooling).

4. Valves can fail either of two ways, stick open after experiencing flow through them, or catastrophically fail to maintain a differential pressure.

5. Valve can fail catastrophically only if experiencing a differential pressure.

6. Successful plant startup implies at least one check valve is closed and maintaining a differential pressure. (This assumption precludes the failure scenario of both valves sticking open.)

7. Probability of a check valve sticking open (after RHR cooling is secured) is 1E-3 per opportunity.

8. Probability of a catastrophic failure of a check valve to maintain a differential pressure is 3.9E-5/year $\left[2.3 \times 10^{-9} /\right.$ hour. (from Table 18$) * 8760$ hour/ year].

9. Failure rates of the two check valves are not correlated.

Two failure scenarios are possible. First, the inboard check valve (referred to as V1) successfully maintains pressure for all plant operations until failing via the catastrophic mechanism (i.e., it does not stick open). During this time, the outboard check valve (referred to as V2) has the potential for sticking open until V1 fails, thereafter if 
Table 18 Bayesian update of catastrophic failure rate of PIV check valves.

\begin{tabular}{|c|c|c|c|c|c|c|c|}
\hline Lambda & $\mathbf{Z}$ & $\begin{array}{l}\text { Priora } \\
\text { probability }\end{array}$ & Likelihood $^{b}$ & $\begin{array}{c}{ }_{\text {Prior }}^{\mathbf{X}} \\
\text { likelihood }\end{array}$ & $\begin{array}{l}\text { Posterior } \\
\text { probability }\end{array}$ & $\begin{array}{c}\underset{X}{\text { Lambda }} \\
\text { posterior } \\
\text { probability }\end{array}$ & $\underset{\underset{\mathbf{X}}{\text { posterior }}}{\text { Lambda }^{2}}$ \\
\hline $3.0 \mathrm{E}-10$ & -2.0123 & $2.2 \mathrm{E}-02$ & $9.0 \mathrm{E}-01$ & $2.0 \mathrm{E}-02$ & $8.4 \mathrm{E}-02$ & $2.5 \mathrm{E}-11$ & $7.6 \mathrm{E}-21$ \\
\hline $1.0 \mathrm{E}-09$ & -1.1523 & $1.0 \mathrm{E}-01$ & $7.1 \mathrm{E}-01$ & $7.3 \mathrm{E}-02$ & $3.2 \mathrm{E}-01$ & $3.2 \mathrm{E}-10$ & $3.2 \mathrm{E}-19$ \\
\hline $2.0 \mathrm{E}-09$ & -0.6572 & $1.3 \mathrm{E}-01$ & $5.0 \mathrm{E}-01$ & $6.5 \mathrm{E}-02$ & $2.8 \mathrm{E}-01$ & $5.6 \mathrm{E}-10$ & $1.1 \mathrm{E}-18$ \\
\hline $3.0 \mathrm{E}-09$ & -0.3676 & $1.0 \mathrm{E}-01$ & $3.6 \mathrm{E}-01$ & $3.6 \mathrm{E}-02$ & $1.6 \mathrm{E}-01$ & $4.7 \mathrm{E}-10$ & $1.4 \mathrm{E}-18$ \\
\hline $5.0 \mathrm{E}-09$ & -0.0027 & $1.4 \mathrm{E}-01$ & $1.8 \mathrm{E}-01$ & $2.6 \mathrm{E}-02$ & $1.1 \mathrm{E}-01$ & $5.6 \mathrm{E}-10$ & $2.8 \mathrm{E}-18$ \\
\hline $7.0 \mathrm{E}-09$ & 0.2376 & $9.1 \mathrm{E}-02$ & $9.1 E-02$ & $8.3 E-03$ & $3.6 \mathrm{E}-02$ & $2.5 \mathrm{E}-10$ & $1.7 \mathrm{E}-18$ \\
\hline $1.0 \mathrm{E}-08$ & 0.4924 & $9.7 \mathrm{E}-02$ & $3.2 \mathrm{E}-02$ & $3.1 \mathrm{E}-03$ & $1.4 \mathrm{E}-02$ & $1.4 \mathrm{E}-10$ & $1.4 \mathrm{E}-18$ \\
\hline $2.0 \mathrm{E}-08$ & 0.9875 & $1.5 \mathrm{E}-01$ & $1.1 \mathrm{E}-03$ & $1.6 \mathrm{E}-04$ & $6.9 \mathrm{E}-04$ & $1.4 \mathrm{E}-11$ & $2.7 \mathrm{E}-19$ \\
\hline 3.0E-08 & 1.2771 & $6.1 \mathrm{E}-02$ & $3.4 \mathrm{E}-05$ & $2.1 \mathrm{E}-06$ & $9.0 \mathrm{E}-06$ & $2.7 \mathrm{E}-13$ & $8.1 \mathrm{E}-21$ \\
\hline $5.0 \mathrm{E}-08$ & 1.6420 & $5.0 \mathrm{E}-02$ & $3.6 \mathrm{E}-08$ & $1.8 \mathrm{E}-09$ & $7.8 \mathrm{E}-09$ & $3.9 E-16$ & $1.9 \mathrm{E}-23$ \\
\hline $1.0 \mathrm{E}-07$ & 2.1371 & 3.3E-02 & $1.3 \mathrm{E}-15$ & $4.3 \mathrm{E}-17$ & $1.8 \mathrm{E}-16$ & $1.8 \mathrm{E}-23$ & $1.8 \mathrm{E}-30$ \\
\hline \multirow[t]{3}{*}{$3.0 \mathrm{E}-07$} & 2.9218 & $1.6 \mathrm{E}-02$ & $2.2 E-45$ & $3.6 \mathrm{E}-47$ & $1.5 E-46$ & $4.6 \mathrm{E}-53$ & $1.4 \mathrm{E}-59$ \\
\hline & & 1.00 & & 0.2320 & 1.00 & $2.3 \mathrm{E}-09$ & $9.0 \mathrm{E}-18$ \\
\hline & & & & & & $\begin{array}{c}\text { mean } \\
\text { lambda }\end{array}$ & $\underset{\text { lambda }^{\wedge} 2}{\text { mean }}$ \\
\hline
\end{tabular}
a. Prior-Lognormal
$\mathrm{mu}=-19.11(5 \mathrm{E}-9 /$ hour$)$
sigma $=1.40(\mathrm{EF}=10)$
mean $=1.3 \mathrm{E}-08 /$ hour

Taken from Reference 27, page B-6.

b. Update-Poisson
$\mathrm{f}=0.0$
$\mathrm{~T}=3.4 \mathrm{E}+08$ hour

From 978.0 years of U.S. PWR experience, and 40 check valve PIVs per PWR (Reference 27, page B-6). 10-10

it has not stuck open, it has the potential for failing catastrophically. In the second scenario, V1 sticks open sometime during the plant life, at which time V2 functions as the PIB and is subsequently susceptible to the catastrophic failure mechanism. Thus, 
Probability of PIB failure over plant lifetime =

$$
\left(\lambda_{c} * T_{1}\right) *\left[\left(\lambda * D_{1}\right)+\left(\lambda_{c} * T^{1} / 2\right)\right]+\left[\left(\lambda * D_{1}\right) *\left(\lambda_{c} * T_{1} / 2\right) ;\right.
$$

where

$\lambda_{c}=$ failure rate for catastrophic failure of a normally closed check valve

$\mathrm{T}_{1}=$ Fault e. osure time, lifetime of plant

$\lambda=$ failure rate for check valve to stick open (i.e., fails to close)

$D_{1}=$ Number of opportunities for valve to stick open (i.e., number to times valve experiences flow through it).

Probability of PIB failure over plant lifetime $=$

$(2.0 \mathrm{E}-5 /$ year * 40 year $) *$ [1E-3/demand * 40 demands $)+(2.0 \mathrm{E}-5 /$ year * 20 year $)]$

$+(1 . \mathrm{E}-3 /$ demand $* 40$ demands $) *(2.0 \mathrm{E}-5 /$ year $* 20$ year $)]$

$=3.23 \mathrm{E}-5+1.60 \mathrm{E}-5=4.83 \mathrm{E}-5$.

This is equivalent to a yearly probability of PIB failure of 1.2E-6/reactor-year.

This result rer resents an initiator frequency and does not account for possible detection or mitigating features that are likely available. Specifically, no consideration is given to means for detecting a stuck open valve, detecting the overpressure situation before rupturing the low pressure system, or recovery by the control room crew after a rupture but before core damage occurs.

For a three-train system, such as the LPI system in the Reference 25 base case analysis, the initiating event frequency is then $3.6 \times 10^{-6} /$ reactoryear.

This value for the initiating event, LPI PIB failure, is almost two orders of magnitude less than the initiator frequency, $3.2 \times 10^{-4} /$ reactoryear, for the sequence dominating the Reference 26 results. If foreign PWR experience been included in the Bayesian update, it undoubtedly would have been lower (because of the larger number for PWR experience in Table 18, note b). Thus, a revised estimate of the benefit in CDF reduction claimed for the Reference 26 base case is below the $1.0 \times 10^{-6} /$ reactoryear threshold for containment bypass sequences in Reference 28. A comparison of the initiator frequencies from References 24 and 25, in Section 4.2 , with the value calculated in this section, indicates that the values are also high and probably for the same reason; they were calculated at times of significantly less operating experience than those current for the calculations of this section.

\subsection{Selected Results from Recent Work at the INPL}

The INEL has evaluated ISLOCA risk at three reference plants. NUREG contractor reports have been issued for a
Westinghouse ice condenser plant, CE plant, and B\&W plant (Refs. 5, 7, and 8) Currently, all of these plants periodically leak test their PIVs. At the Westinghouse plant, the valve configuration involved in the dominant ISLOCA sequence corresponds to arrangement $F$ in Figure 3. At the CE plant, the dominant sequence configuration corresponds to arrangement $\mathrm{E}$. The $\mathrm{B} \& \mathrm{~W}$ plant has sequences with valve configurations corresponding to arrangements $B, E$, and $F$ in Figure 3.

The Westinghouse plant analysis produced an ISLOCA initiator frequency for one pair of boundary check valves of $4.11 \times 10^{-6} /$ year. Summing over the four similar boundaries produced an initiator frequency of $1.6 \times 10^{-5} /$ year for the plant. The INEL analyses produced higher initiator frequencies than References 24 , 25 , and 26 (see Appendix C for Reference 26 frequencies) for a given interface arrangement because correlated failure rate data were used. However, the INEL initiator frequency calculation was based on fewer failure modes than accounted for in References 25 and 26. The effect of increasing the frequency of testing would be similar to that shown in References 25 and 26, but the effect of continuous pressure monitoring would be more dramatic, essentially eliminating all ISLOCA sequences that survived the initial screening for risk significance (the frequency would fall below the screening limit used in the analysis). This is because the INEL analysis included only those failure modes supported by licensee event report data, and these would be eliminated by continuous pressure monitoring.

In the CE plant, a closed MOV backs each pair of boundary check valves. The risk-significant sequence for this plant involves operators opening the MOV during quarteriy stroke testing with the PIVs failed. The plant is equipped for continuous pressure monitoring on these boundaries. However, the alarm is often rendered inoperable (this is done to maintain a "black board" in the 
cortrol room; leakage from the xifety injection accumulators causes the alarm to be received), and the stroke testing procedures do not require the operators to verify that there is low pressure between the check valves before opening the MOV. There: rre, no credit was given for the availability of pressure monitoring equipment. If these conditions were corrected, all the remaining ISLOCA sequences would be eliminated.

From Table 13 of Section 3.9, there are two Alternative I results indicating that the benefits probably exceed the implementation costs. Th sse are the B\&W Case 2 with or without OSAC and the Westinghouse Case 2 with OSAC. Fom Table 14, Section 3.9, and the rationale in Section 3.1, Alternative II results indicate that the costs probably far exceed the benefits for that alternative with the exception of Case 2 for the B\&W plant with OSAC. These results are discussed in Section 4.5.

\subsection{Wiscussion of th iNEL Results}

Although the B\&W Case 2 results (see Section 3.9) for both alternatives appea: cost effective, none of the auxiliary buildings irer:ified by the screening nrocess as having questionable characteristics were a $3 \& W$ plant. As disclissed beluw, the CDF for the B\&W plant (Ref. 5) is likely more than an order of magnitude high. The actual
CDF is probably less than the $1 \times 10^{-6} /$ reactor-year from Reference 28 . Therefore, those analyses are more an illustration than a substantial basis for any backfit. Alternative I illustrates that front-end ISLOCA weaknesses combined with auxiliary building weaknesses might produce cost beneficial human reliability improvements. But the human errors involved are specific to the analysis for that plant. Whether there is any such other combination appears to require plant specific analyses.

One important fact is the PIV pathway ISI_OCA initiator frequency used in the INEL analyses, which is a mean value of $4.1 \times 10^{-6} /$ year. As mentioned in Section 4.4, the plants in the INEL analyses all periodically leak tested their PIVs. The INEL initiator is larger than that calculated in Section 4.3.2, which assumes no leak testing. A comparison with the ISLOCA PIV pathway initiator frequencies from the PRAs, discussed in Appendix C, indicates that the INEL value is about an order of magnitude or more higher. The INEL value is slightly more than an order of magnitude higher than that of Reference 28, which is a mean value of $3.8 \times 10^{-7} /$ year. The INEL results from References 5,7 , and 8 are judged to be conservative, therefore, by about an order of magnitude. The reduction in CDF to be gained from the Westinghouse case 2 result for Alternative $I$ is below the $1 \times 10^{-6} /$ year threshold as stated in footnote $d$. 


\section{DECISION RATIONALE}

The objectives of the Gl-105 program as delineated in Section 2 are considered to be achieved although not with results that resolve the issue by a few well-defined backfits. In considering the results of the program and arriving at the resolution, some previous investigations of PIV failure probability and the GI-105 issue were reviewed and critiqued (Section 4), and additional PIV failure probabilities derived in some past PRAs were examined (Appendix $\mathrm{C}$ ). The body of work examined in ti:e current program is small in comparison to the riuriber of operating plants. Nevertheless, the plant specific examinations including this issue are underway through the individual plant evaluation (IPE) program and will soon be completed for all plants. The resolution will be accomplished because the current GI-105 program (Refs. 5, 7, and 8) and other results, as critiqued in this report, provide sufficient depth when considered together with a program that includes examination of this issue at specific plants. This is discussed further in Section 5.5.

\subsection{Bach..it Rule Considerations}

Two cost/benefit analyses for PWRs were considered in this regulatory analysis: Reference 26 , Section 3 , and Appendix A of this report, which is based on results from References 5, 7, and 8.

Seven years of additional PWR operating experience have ensued since the Reference 26 ISLOCA initiating event of PIVs catastrophic failure was calculated. A re-estimation of the frequency of that event (Section 4.3.2) indicates that the Reference 26 calculation of the effectiveness of leak testing versus no leak testing was conservative by two orders of magnitude. Other conservatisms in the analysis include a 30 -year mission time assumed for PIVs, and no credit was given for in-service testing programs, RCS inventory monitoring, or preventive or corrective maintenance actions that would shorten valve mission time. Reference 26 is judged not to provide a best estimate basis for determining requirements for PWRs. A similar companion study of ISLOCA at BWRs (Ref. 29) also provides bounding estimates of initiating event frequencies like Reference 26 as discussed in Section 4.3.2. The conditional prcbabilities of low-pressure system rupture, given overpressure, estimated in Reference 29 are also conservative based on the use of a more recent comprehensive rupture analysis in Reference 9 that utilized low-pressure system component pressure dependent fragilities devcloped for the GI-105 program and tabulated in References 14 and 15. References 9 and 29 (interpreted with uncerstanding of its conservatısms) are case studies not supporting ISLOCA backfits at BWRs.

\subsection{Plant Specific Considerations}

The major insight learned from the GI-105 program is the plant specific nature of the issue. Interfacing systems designs are varied; operating procedures differ; test and maintenance practices and equipment qualification levels vary; and auxiliary building designs differ greatly in compartment numbers, sizes, elevations, and in atmospheric and fluid pathways among compartments. Other items affecting ISLOCA scenarios also differ from plant to plant such as auxiliary buildings sump locations and volumes, sump pump capacity, and locations of drain lines to sumps. Fire suppression system activation set points and system volume rate of flow can also be a consideration. The safety culture, ISLOCA training, and sensitivity to the issue also vary from plant to plant. Whether any of these concerns bear additional attention or improvement at a given plant and how any improvement should be accomplished can only be identified by plant specific examination such as an IPE.

\subsection{Relationship to Other Issues}

GI-96, "RHR Suction Valve Testing," was subsumed by GI-105 because the latter issue was broadened to include RHR systems.

\subsection{Relationship to Other Programs and Activities}

There are a number of ongoing NRC staff and industry activities regarding performance of MOVs and check valves. Within NRC, Nuclear Reactor Regulation (NRR) office has assumed lead responsibility and with the assistance of the other offices has developed plans of action to ensure proper MOV and check valve performance (Ref. 30). NRR is working directly with the American Society of Mechanical Engineers to inject NRC concepts into a check valve testing standard (Ref. 30) and has issued generic letterse,f about developing acceptable in-service testing programs and MOV testing and surveillance. The Office of Analysis and Evaluation of Operational Data issued case studies on valve performance (Ref. 31), and RES has sponsored a valve testing program (Ref. 32) and an aging program (Ref. 33) that includes valves. NRC maintenance team inspections evaluate plant valve programs.

\footnotetext{
"Nuclear Regulaotyr Commission. "(iuidance on Aceptable In-Service 'Iesting Program." (ieneric l eller 89014. Nuclear Reactor Regulation, April 3. 1989

${ }^{f}$ Nuclear Regulatory Commission. "Sifety-Related MotorOperatcd Vaive "Tesiing and Surveillance," Generic letter 89-10, Nuclear Reactor Regulation, June 28, 1989.
} 
As summarized in Reference 30, the nuclear power industry has also undertaken a number of activities concerned with valve performance. The Institute of Nuclear Power Operations has conducted valve inspections at several plants, monitors valve performance, and issues reports (Ref. 34) on valve problems. EPRI has been developing guidance on MOVs and check valves (Ref. 35). Several utilities formed the Nuclear Industry Check (NIC) valve groupg to develop procedures to assess check valve condition.

\subsection{Conclusions}

In regard to BWRs, the current ISLOCA program results support the conclusion in most past PRAs that CDF from ISLOCA at BWRs is very low. This low risk is caused in great measure by equipment separation and by the low susceptibility to rupture from overpressure in BWR interfacing systems. Low initiating event frequencies add to the case for concluding that GI-105 should be considered resolved for BWRs with no new requirements.

For PWRs, while it is also true that the GI-105 program did not produce results that identified a significant CDF from ISLOCA, it is less clear that this finding would apply across the board for PWRs. Given all the plant specific facets affecting ISLOCA risk (Section 5.2, and Refs. 5, 7, 8 ), it is not guaranteed that undesirable factors cannot combine to produce an outlier situation at some plant(s).

Four options were considered for resolution of GI-105:

1. No regulatory action beyond publishing the technical findings from the GI-105 program.

2. Issue a supplement to IN 92-36 to all PWRs and BWRs. The information notice would promulgate the GI-105 program insights and final results alluded to in IN 92-36. The ISLOCA screening criteria and final ISLOCA analysis procedures would be of use to licensees. For licensees not having completed the ISLOCA portion of their IPEs, the screening criteria would be a useful preanalysis check on where emphasis might be needed. The ISLOCA procedures provide guidance on performance of a comprehensive ISLOCA analysis. Licensees with completed IPEs could use the screening criteria as a quick confirmatory check on ISLOCA analysis results. Participation in the IPE program would be sufficient licensee action to resolve the issue.

3. Issue a generic letter under 10 CFR 50.54(f), "Conditions of Licenses," to all BWRs and PWRs. The generic letter would not prescribe cost-effective ge-

BSteve Marsh, Nuclear Industry Check (NIC) Chrirman, Ontariu hyudro, letier to NIC members, "NIC Summer 1992 Mvecting Minutes, September 14, 1992. neric fixes because none could be identified. As with the IN (option 2), the generic letter would promulgate the ISLOCA program insights and results. In addition, the generic letter would require application of the screening criteria, with in-depth analyses of units not satisfying the criteria. The GI-105 program final ISLOCA evaluation procedures (Ref. 9) would provide an analysis approach that licensees could use in performing in-depth analyses. The screening criteria and analysis would apply only to PWRs and would require each licensee to report analysis results, identified problems, and any proposed remedial action. Participation in the IPE program would be sufficient for resolution of GI-105 at BWRs.

4. Issue an ISLOCA rule. The rule could vary in content and prescriptiveness from something similar to the generic letter (option 3) to one that delineated new design features, maintenance tests, and operating requirements.

The pros and cons of each of these options were considered as follows:

No Regulatory Action

Pros

- This option would place no additional burden on NRC resources, NRC staff, or licensees.

\section{Cons}

- Doing nothing may be misinterpreted as a statement that there could be no problem with respect to ISLOCA. The GI-105 program did not demonstrate an absence of outliers.

- This option would not contribute to ISLOCA outlier identification or risk reduction.

- This option could engender complacency and increase ISLOCA risk.

- Useful results from the GI-105 program would be limited to routine distribution of reports.

\section{Supplement to IN 92.36}

Pros

- Continuing agency concern with outliers would be voiced by this option.

- IPEs can be considered sufficient licensee action to resoive Gi-105. IPEs aireaúy inciucie ISLOCA analyses. 
- This is the most timely option to affect IPEs.

- Information promulgated by the supplement would be useful to licensees whether or not their IPEs were completed.

Cons

- It would be difficult to judge overall industry analyses depth and completeness.

\section{Generic Letter}

Pros

- This option would also voice continuing agency concern with outliers.

- Licensee responses would be more uniformly scrutable.

- GI-105 program information would be promulgated with regulatory requirements as opposed to disseminated for information.

- There could be a more positive affect on IPEs not yet completed.

\section{Cons}

- This option would take longer than an IN supplement to promulgate information.

- It is less timely for affecting the IPE process.

- This option would cause duplication of effort by some PWR licensees (those with completed IPEs).
- Agency resources would be required for review of response to the generic letter.

- The GI-105 program has not identified sufficient risk to justify a generic letter under the backfit rule.

\section{ISLOCA Rule}

Pros

- This option wo ld have the same attractive features as the generic lttter option with greater enforcement potential.

Cons

- This option entails more delicy in information promulgation than for the generic letter.

- The time involved in rulemaking causes this option to be disjunctive with the IPE process.

- Since all IPEs would be completed by the completion of rulemaking, there would be duplication of effort by all PWR licensees.

- Additional agency resources would be consumed by the rulemaking process.

- The technical basis is extremely weak for this option.

It is concluded that the most meaningful and viable course of action for resolution of GI-105 is part:cipation of licensees in the ongoing IPE process. This conclusion with the results of the GI-105 program used in ISLOCA analyses should be promulgated by a supplement to IN 92-36, "Intersystem LOCA Outside Containment." Therefore, option 2 is recommended. 


\section{REFERENCES}

1. Nuclear Regulatory Commission, "Reactor Safety Study-An Assessment of Accident Risks in U.S. Commercial Nuclear Power Plants," WASH-1400 (NUREG 75/014), October 1975.

2. Nuclear Regulatory Commission, "Severe Accident Risks: An Assessment for Five U.S. Nuclear Power Plants," NiIREG-1150, December 1990.

3. M. T'. Drouir, et al., "Analysis of Core Damage Frequency: Grand Gulf, Unit 1 Internal Events," NUREG/CR-4550, Vol. 6, Rev. 1, Part 1, September 1989 .

4. A. M. Kolaczkowski et al., "Analysis of Core Damage Frequency: Peach Bottom, Unit 2 Internal Events," NUREG/CR-4550, Vol. 4, Rev. 1, Part 1, August 1989.

5. W. J. Galyean and D. L. Gertman, “Assessment of ISLOCA Risk-Methodology and Application to a Babcock and Wilcox Nuclear Power Plant," NUREG/CR-5604, April 1992.

6. R. C. Bertucio and J. A. Julius, "Analysis of Core Damage Frequency: Surry, Unit 1 Internal Events," NUREG/CR-4550, Vol. 3, Rev. 1, Part 1, April 1990.

7. D. L. Kelly et al., "Assessment of ISLOCA RiskMethodology and Application to a Westinghouse Four-Loop Ice Condenser Plant," NUREG/ CR-5744, April 1992.

8. D. L. Kelly et al., "Assessment of ISLOCA RiskMethodology and Application to a Combustion Engineering Plant," NUPEG/CR-5745, April 1992.

9. W. J. Galyean et al., "ISLOCA Research Program Final Report," NUREG/CR-59?8, June 1993.

10. IN 92-36, "Intersystem L.OCA Outside Containment," May 7, 1992.

11. SECY-90-016, "Evolutionary Light Water Reactor Certification Issues and Their Relationship to Current Regulatory Requirements," January 12, 1990.

12. Electric Power Research Institute, Advanced Light Water Reactor Utility Requirements Document, ALWR Evolutionary Plant, Rev. 3, November 1991.
13. Electric Power Research Institute, Advanced Light Water Reactor Utility Requirements Document, ALWR Passive Plant, Rev. 2, December 1991.

14. D. A. Wesley et al., "Pressure Dependent Fragilities for Piping Components, Pilot Study on DavisBesse Nuclear Power Station," NUREG/CR-5603, October 1990.

15. D. A. Wesley, "Sureening Methods for Developing Internal Pressure Capacities for Components in Systems Interfacing with Nuclear Power Plant Reactor Coolant Systems," NUREG/CR-5862, May 1992.

16. S. Heaberlin et al., "A Handbook for Value/Impact Assessment," NUREG/CR-3568, December 1983.

17. E. Claiborne et al., "Generic Cost Estimates," NUREG/CR-4627, Revisions 1 and 2, February 1989.

18. G. W. Hannaman, A. Spurgin, and Y..Lukic, Human Cognitive Reliability Model for PRA Analysis, Electric Power Research Institute, NUS-4531, 1984.

19. B. Lopez and F.W. Sciacca, FORECAST 2.1 User Manual, SEA Report No. 89-461-04-A:1, April 1990.

20. United Engineers and Constructors, Phase VIII Update (1986) Report for the Energy Economic Data Base Program, DOE/NE-OO51/1, August 1986.

21. Nuclear Regulatory Commission, "PRA Procedures Guide-A Guide to the Performance of Probabilistic Risk Assessments for Nuclear Power Plants," NUREG/CR-2300, Section 5, January 1983.

22. D. A. Reny et al., "Evaluation of Generic Issue 115, Enhancement of the Reliability of Westinghouse Solid State Protection System," NUREG/ CR-5197, EGG-2456, January 1989.

23. "Risk Analysis and Simulation Add-In for Lotus 1-2-3,"@RISK, Version 2, Palisades Corporation, Newfield, NY, August 1991.

24. F. L. Leverenz, Jr. et al., PWR Sensitivity to Alterations in the Interfacing-Systems LOCA, Electric Power Research Institute, EPRI NP-262, September 1976 . 
25. M. P. Rubin, "The Probability of Intersystem LOCA: Impact Due to Leak Testing and Operational Changes," NUREG-0677, May 1980.

26. G. Bozoki et al., "Interfacing Systems LOCA: Pressurized Water Reactors," NUREG/CR-5102, February 1989.

27. T. A. Wheeler et al., "Analysis of Core Damage Frequency From Internal Events: Expert Judgement Elicitation,"NUREG/CR-4550, Vol. 2, April 1989.

28. SECY-91-270, "Interim Guidance on Staff Implementation of the Commission's Safety Goal Policy," August 27, 1991.

29. T.L. Chu et al., "Interfacing Systems LOCA: Boiling Water Reactors," NUREG/CR-5124, February 1989.

30. SECY-90-112, "Staff Activities Regarding MotorOperated Valves and Check Valves," March 22, 1990.
31. Nuclear Regulatory Commission, "A Review of Motor-Operated Valve Performance," Case Study Report C603, Office for Analysis and Evaluation of Operational Data, December 1986.

32. R. Steele, Jr. et al., "Generic Issue 87, Flexible Wedge Gate Valve Test Program," Idaho National Engineering Laboratory, NUREG/CR-5558, January 1991.

33. N. N. Kondic, "NRC Research Program on Plant Aging: Listing and Summaries of Reports Through July 1992," NUREG-1377, Rev. 3, August 1992.

34. Institute of Nuclear Power Operations, Check Valve Failure or Degradation," Significant Operating Experience Report (SOER) 86-3, Atlanta, Georgia, October $15,1986$.

35. Electric Power Research Institute, Application Guidelines for Check Valves in Nuclear Power Plants, Electric Power Research Institute, EPRI NP-5479, Palo Alto, California, January 1988. 


\section{Appendix A}

\section{Alternative I Cost/Benefit Distributions}




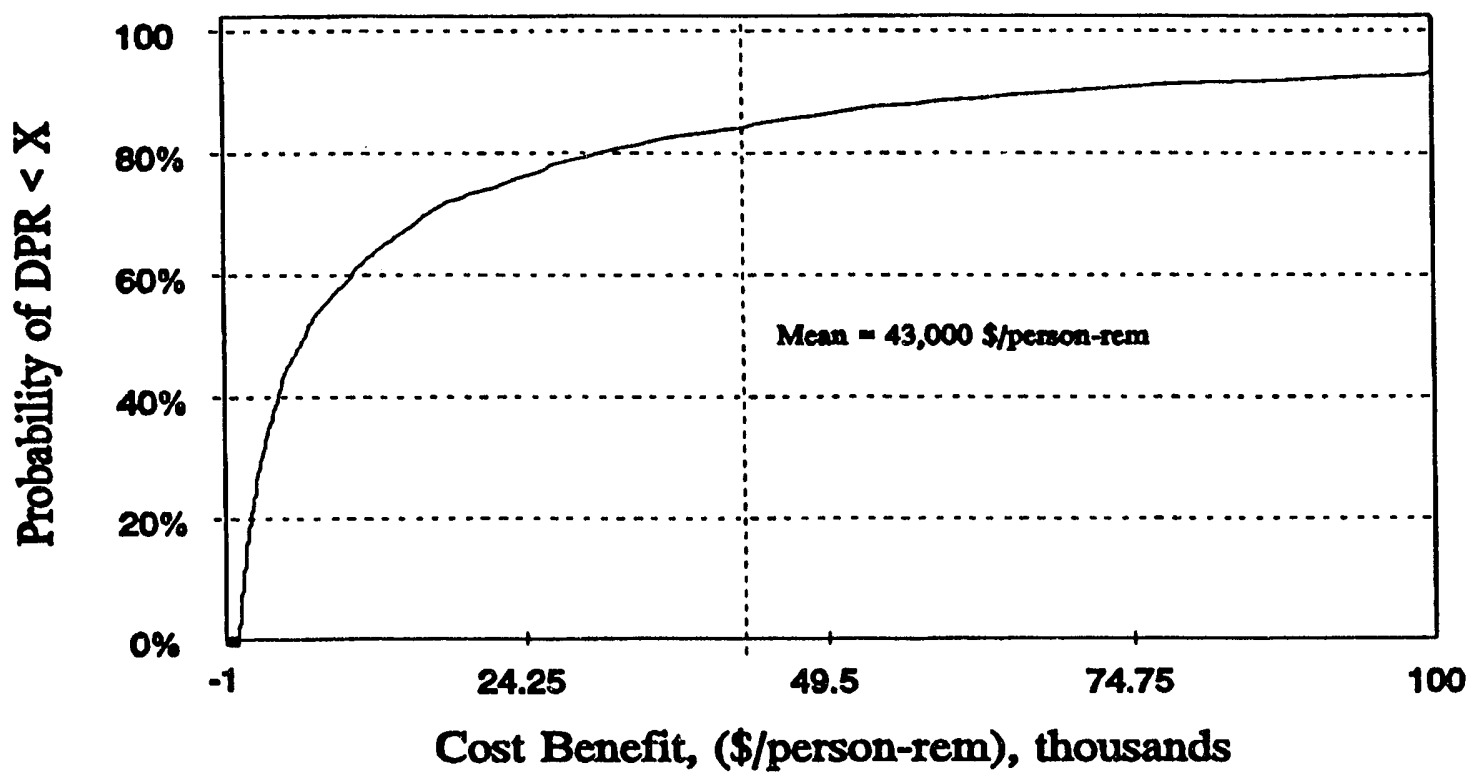

Figure A-1. CDF of DPR ratio for B\&W plant (Case 1, 20 years without OSAC).

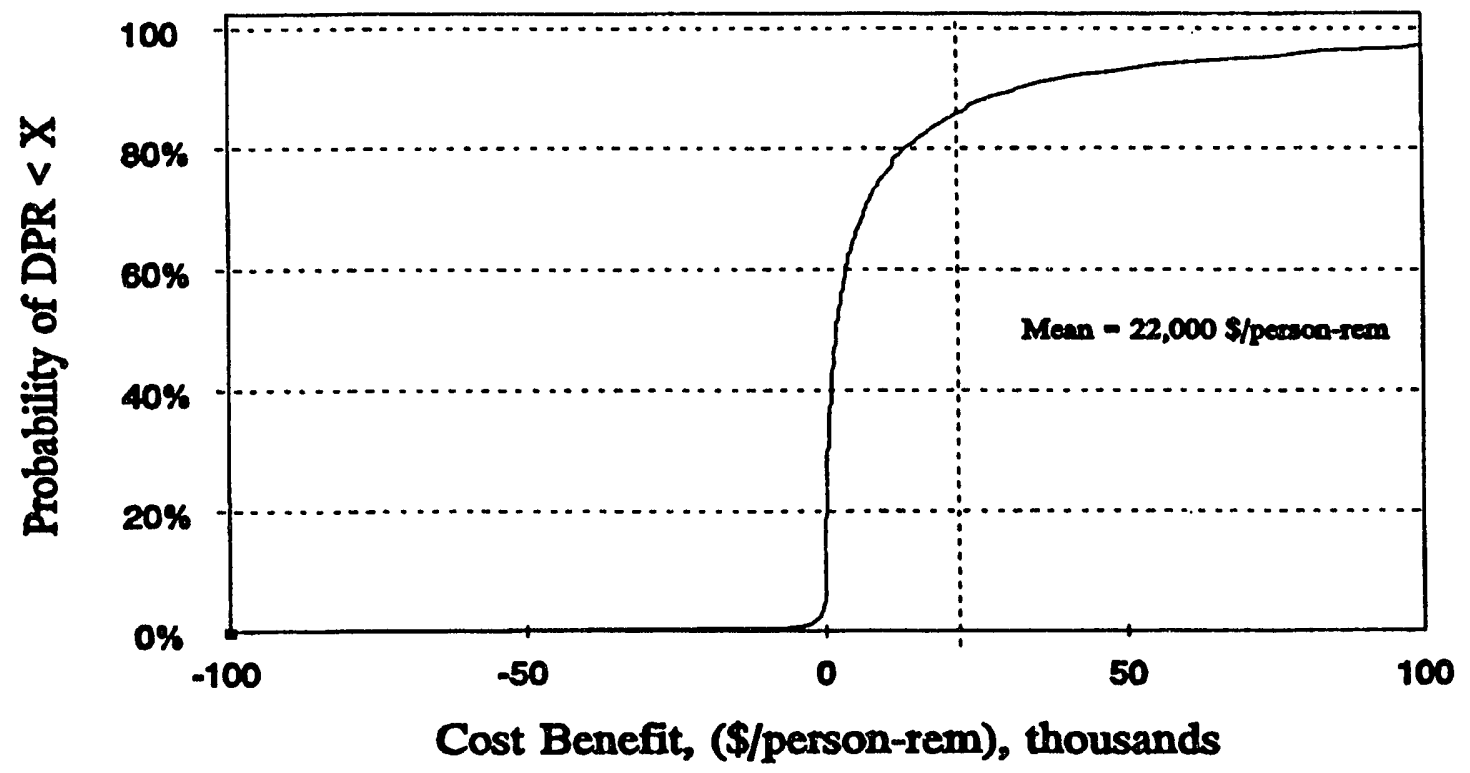

Figure A-2. CDF of DPR ratio for B\&W plant (Case 1, 20 years with OSAC). 


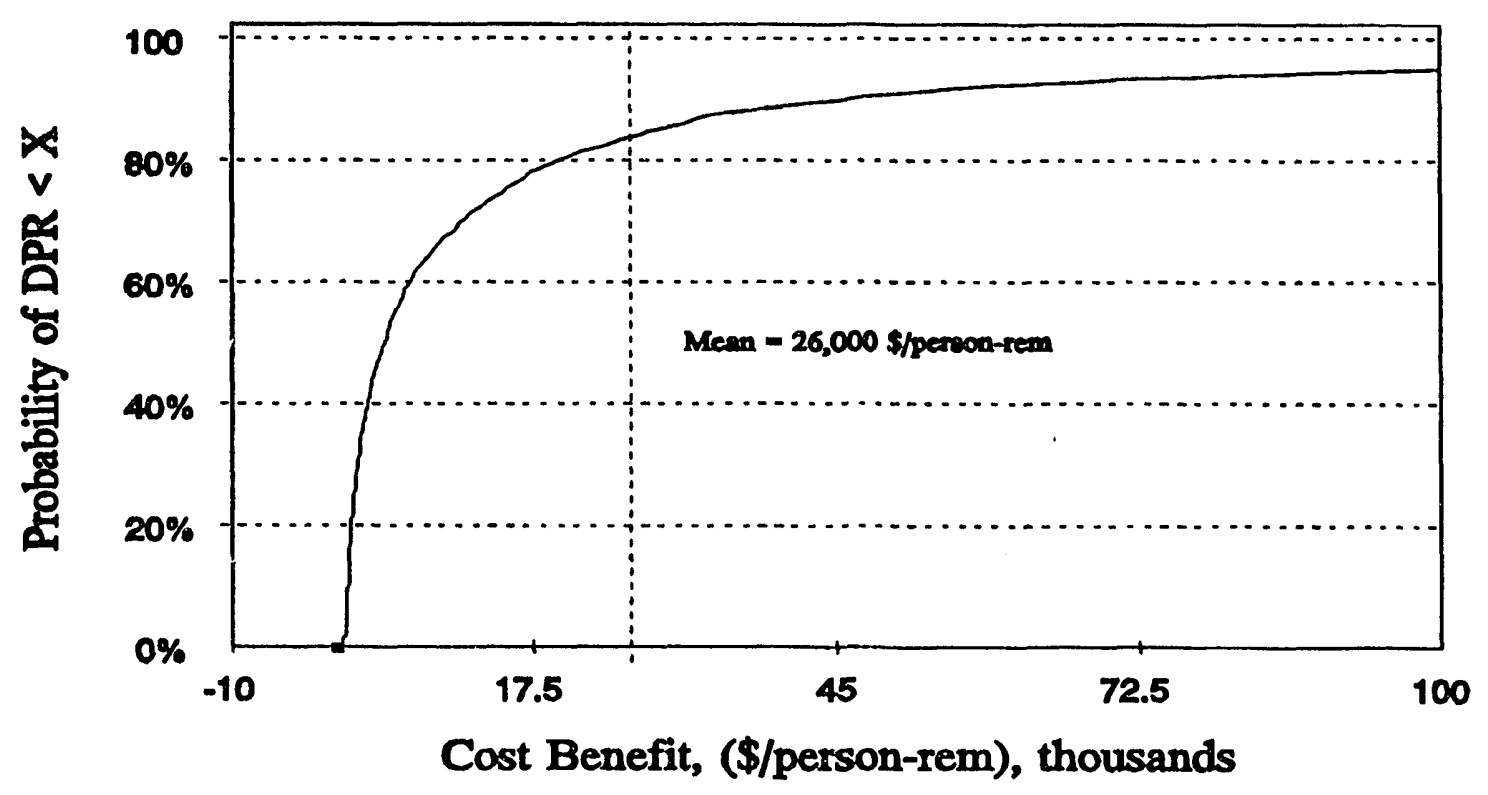

Figure A-3. CDF of DPR ratio for B\&W plant (Case 1, 40 years without OSAC).

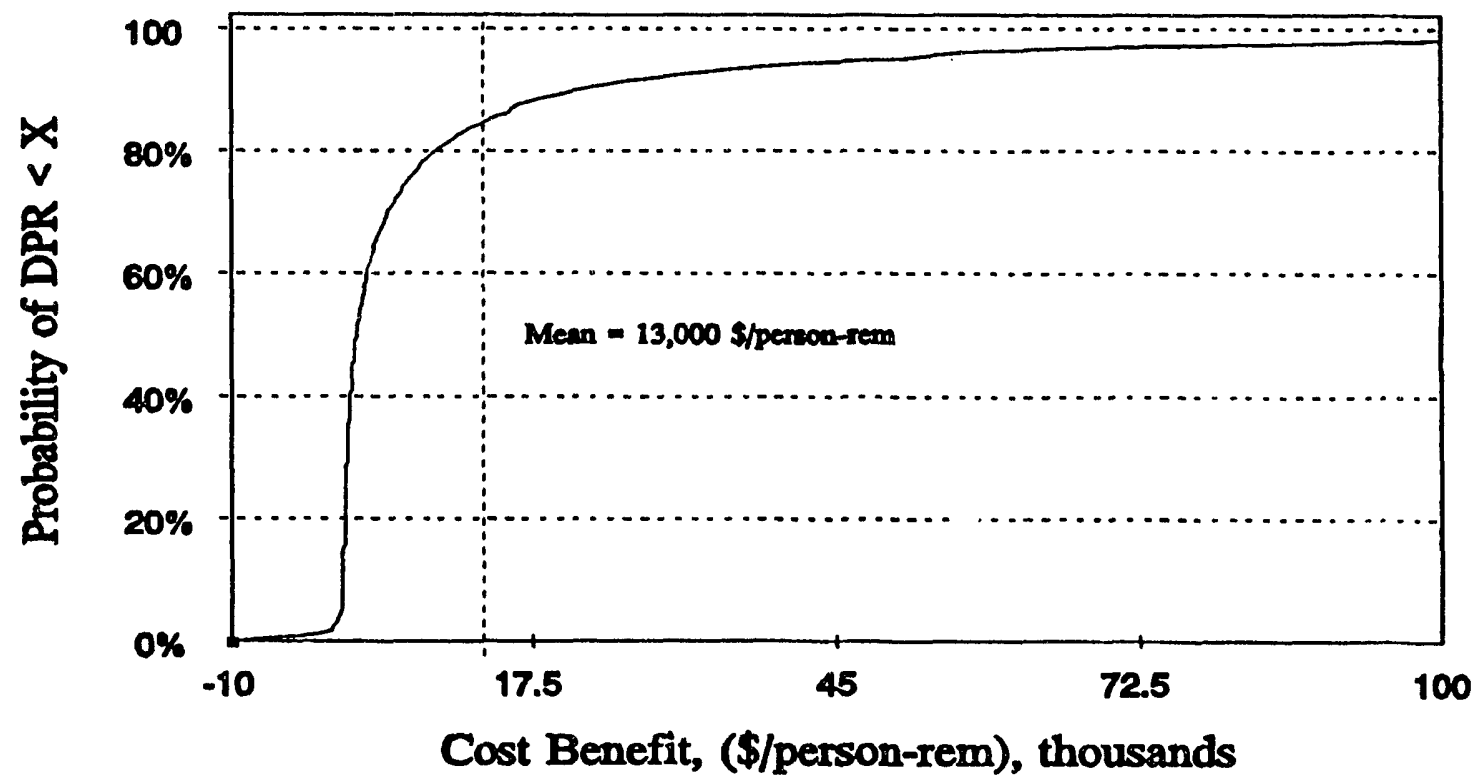

Figure A-4. CDF of DPR ratio for B\&W plant (Case 1, 40 years with OSAC). 


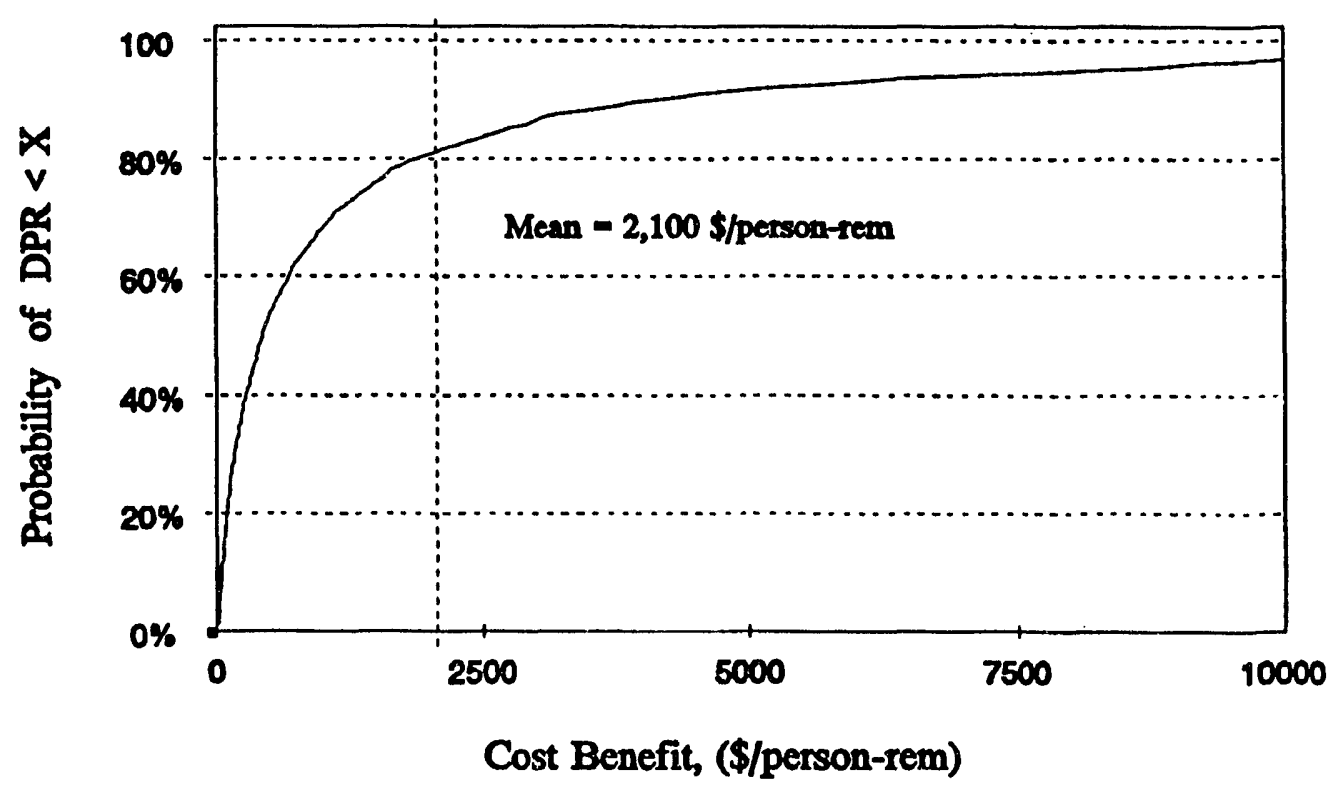

Figure A-5. CDF of DPR ratio for B\&W plant (Case 2, 20 years without OSAC).

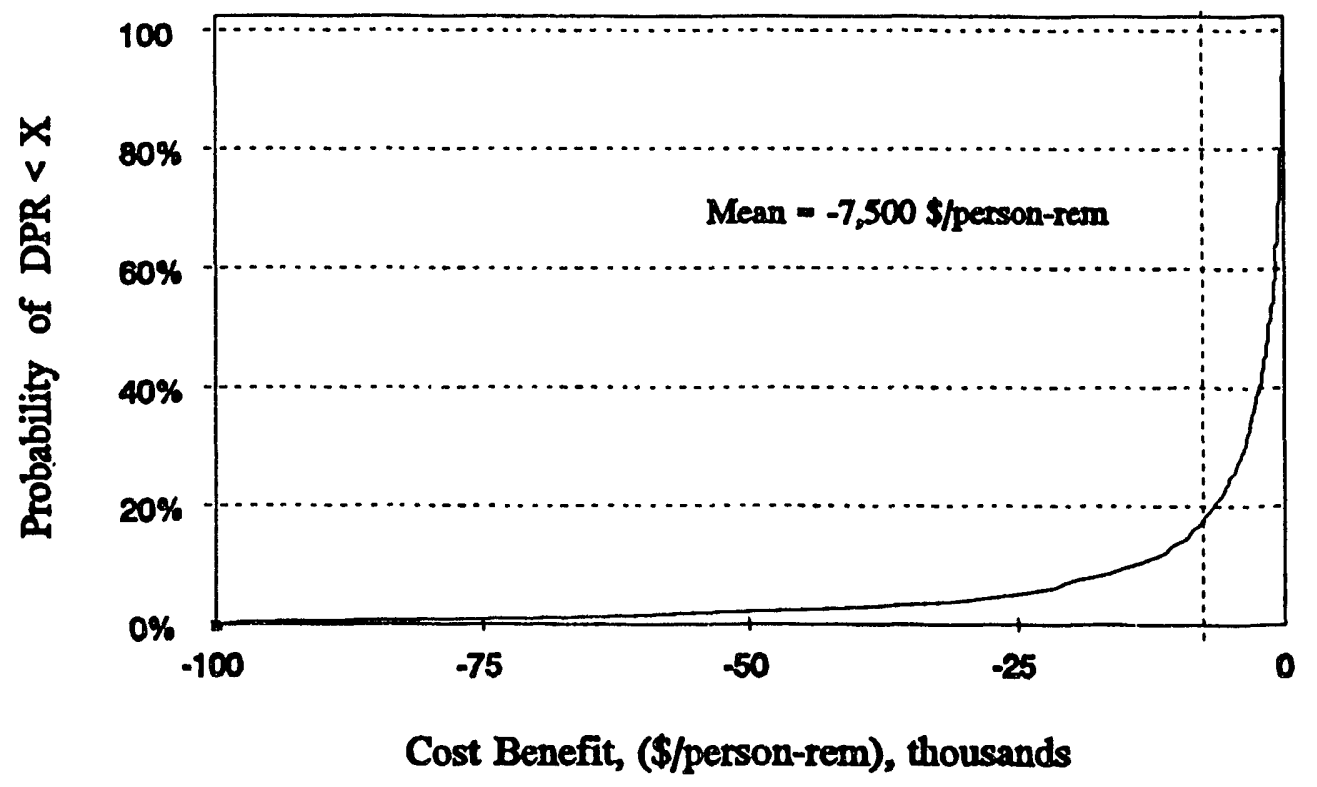

Figure A-6. CDF of DPR ratio for B\&W plant (Case 2, 20 years with OSAC). 


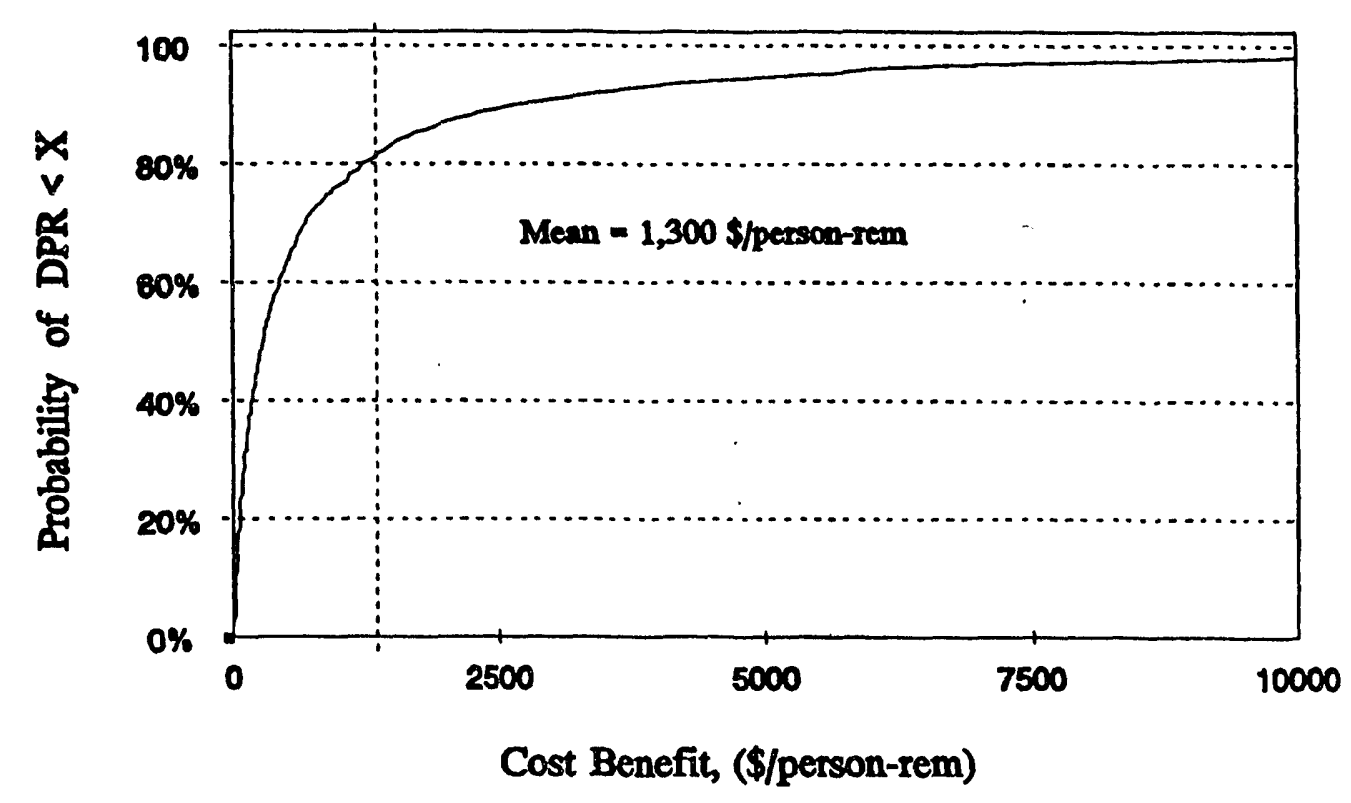

Figure A-7. CDF of DPR ratio for B\&W plant (Case 2, 40 years without OSAC).

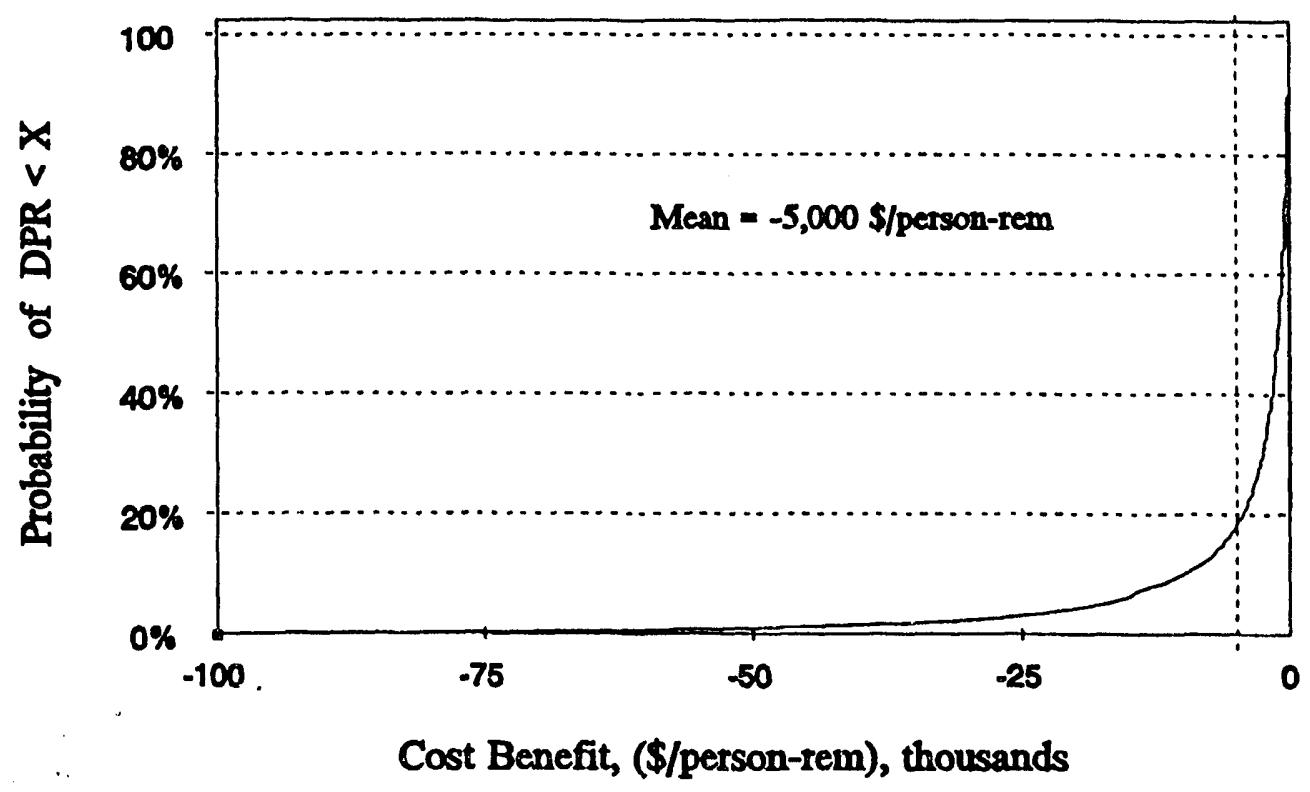

Figure A-8. CDF of DPR ratio for B\&W plant (Case 2, 40 years with OSAC). 


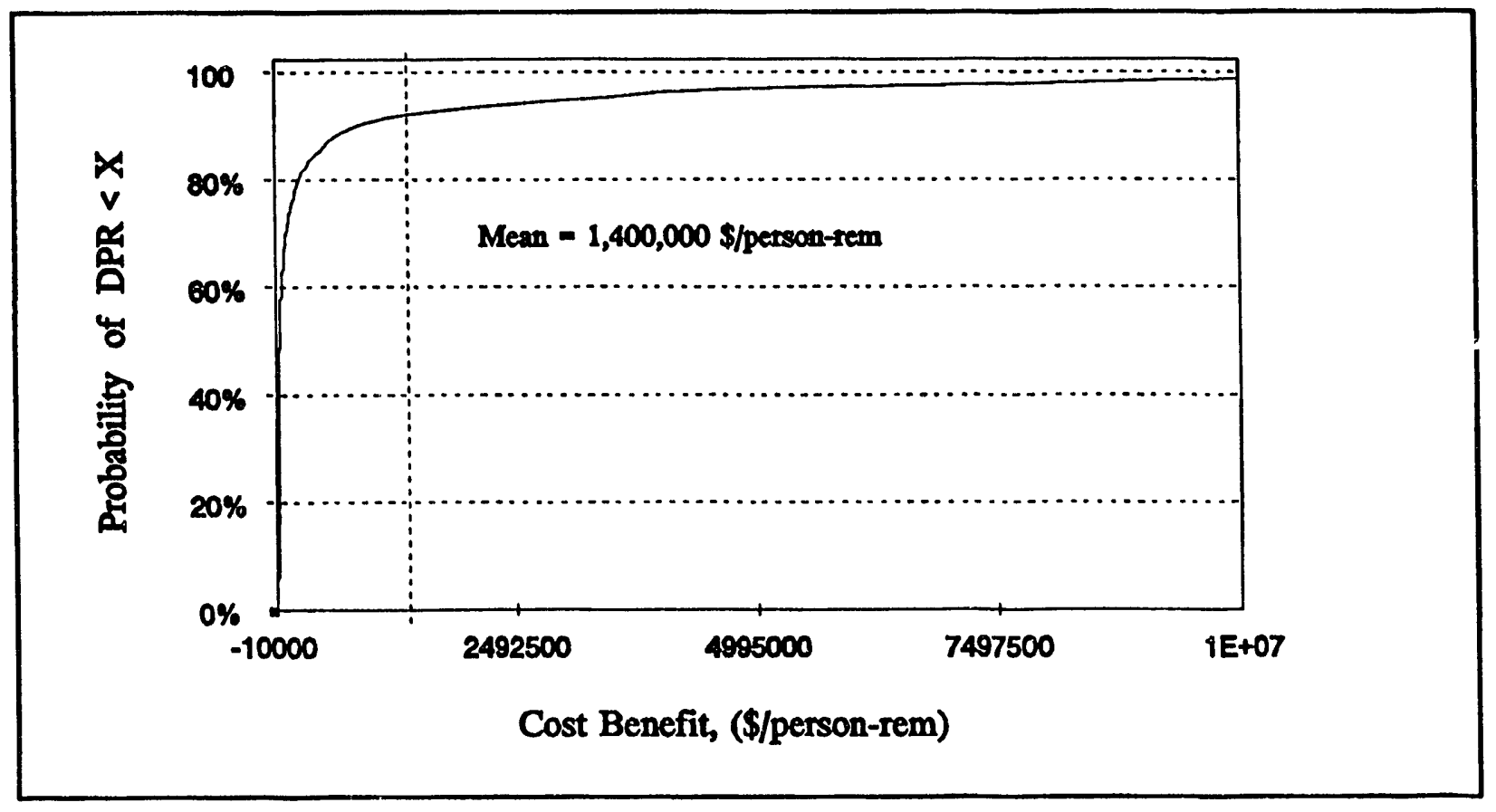

Figure A-9. CDF of DPR ratio for Westinghouse plant (Case 1, 20 years without OSAC).

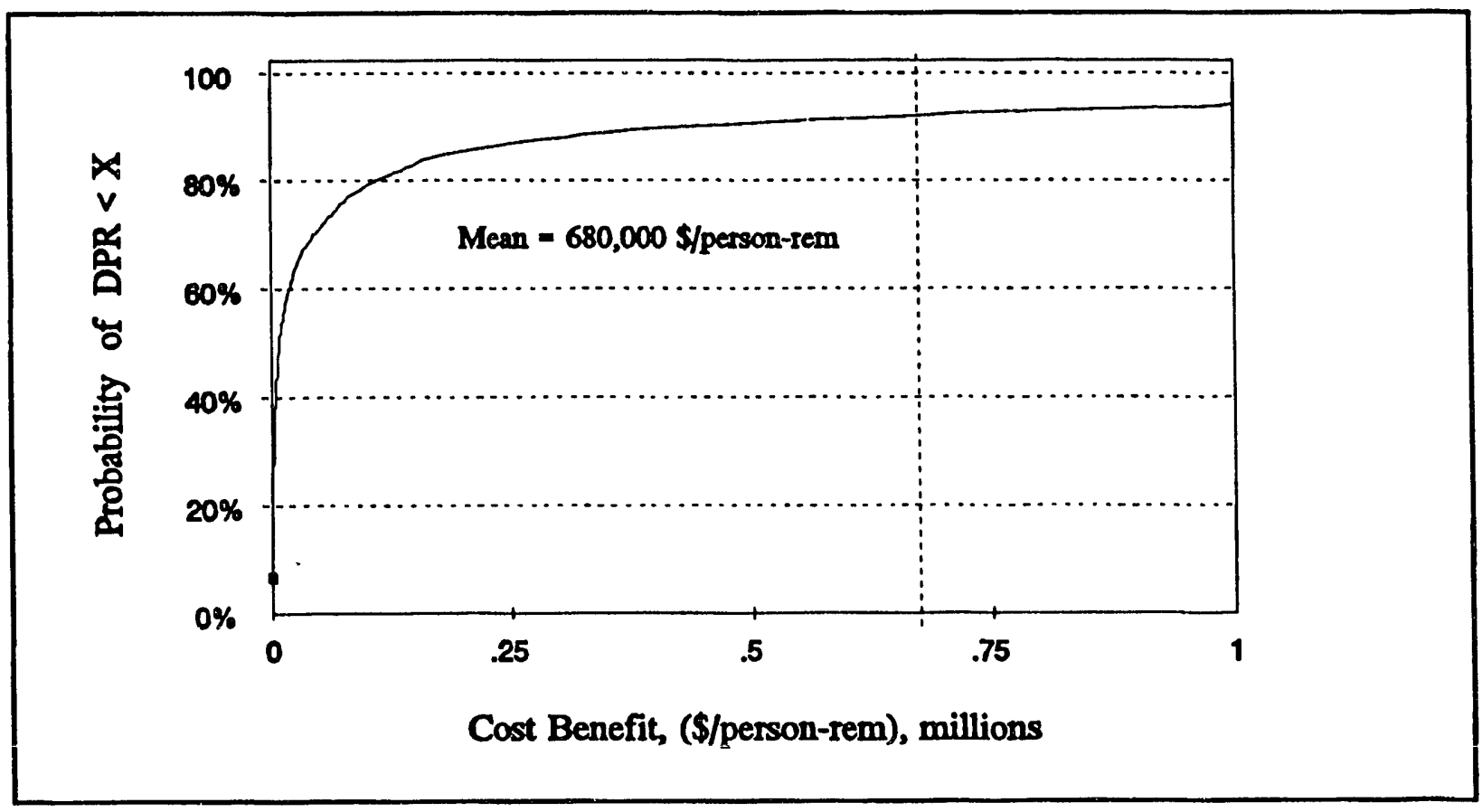

Figure A-10. CDF of DPR ratio for Westinghouse plant (Case 1, 20 years with OSAC). 


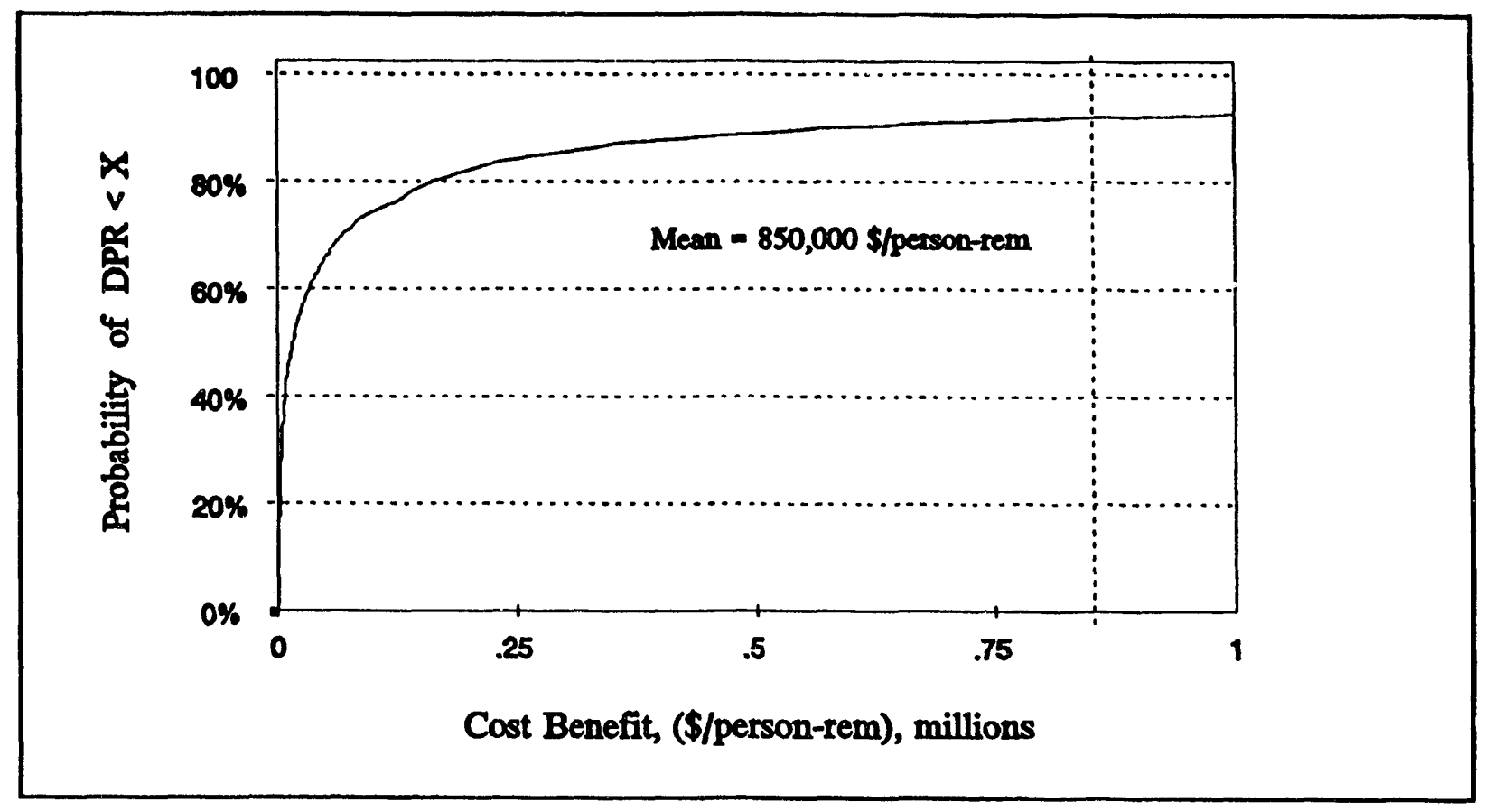

Figure A-11. CDF of DPR ratio for Westinghouse plant (Case 1, 40 years without OSAC).

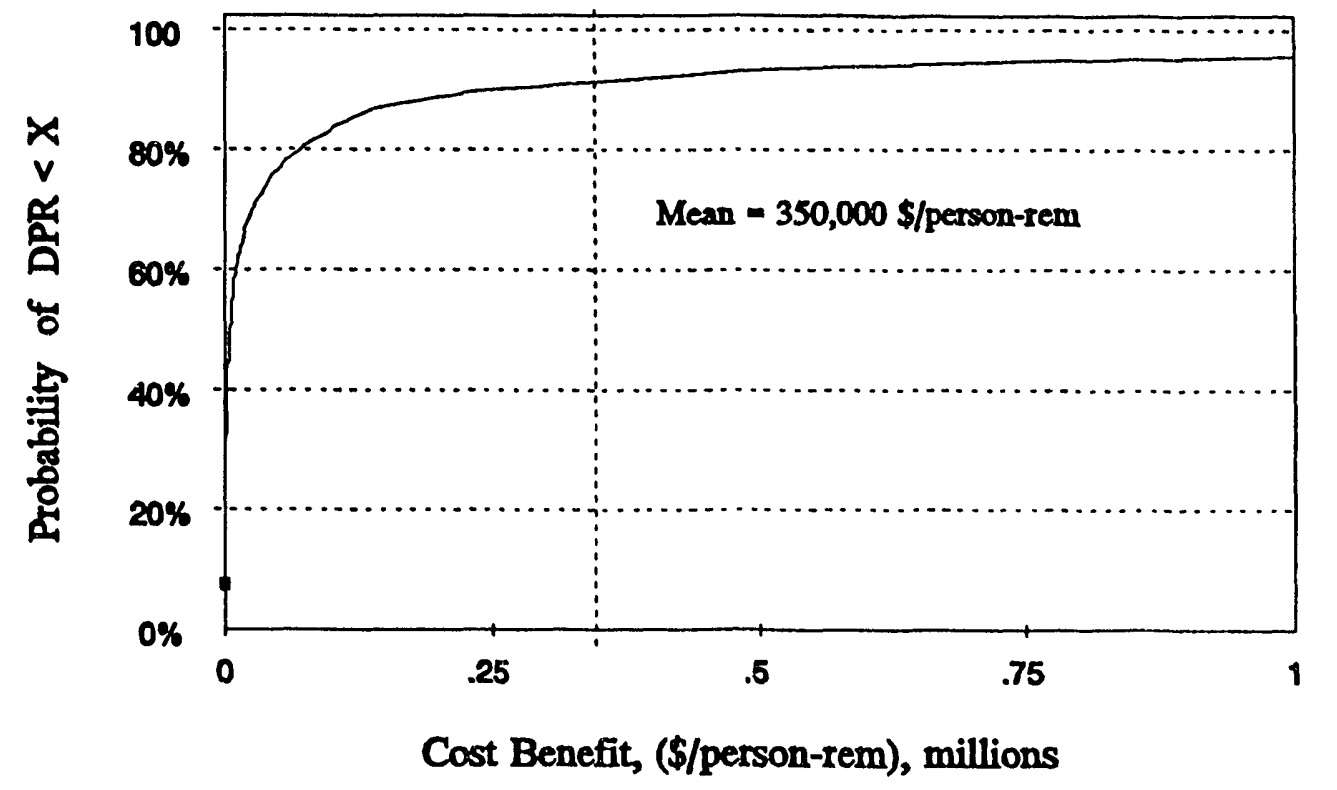

Figure A-12. CDF of DPR ratio for Westinghouse plant (Case 1, 40 years with OSAC). 


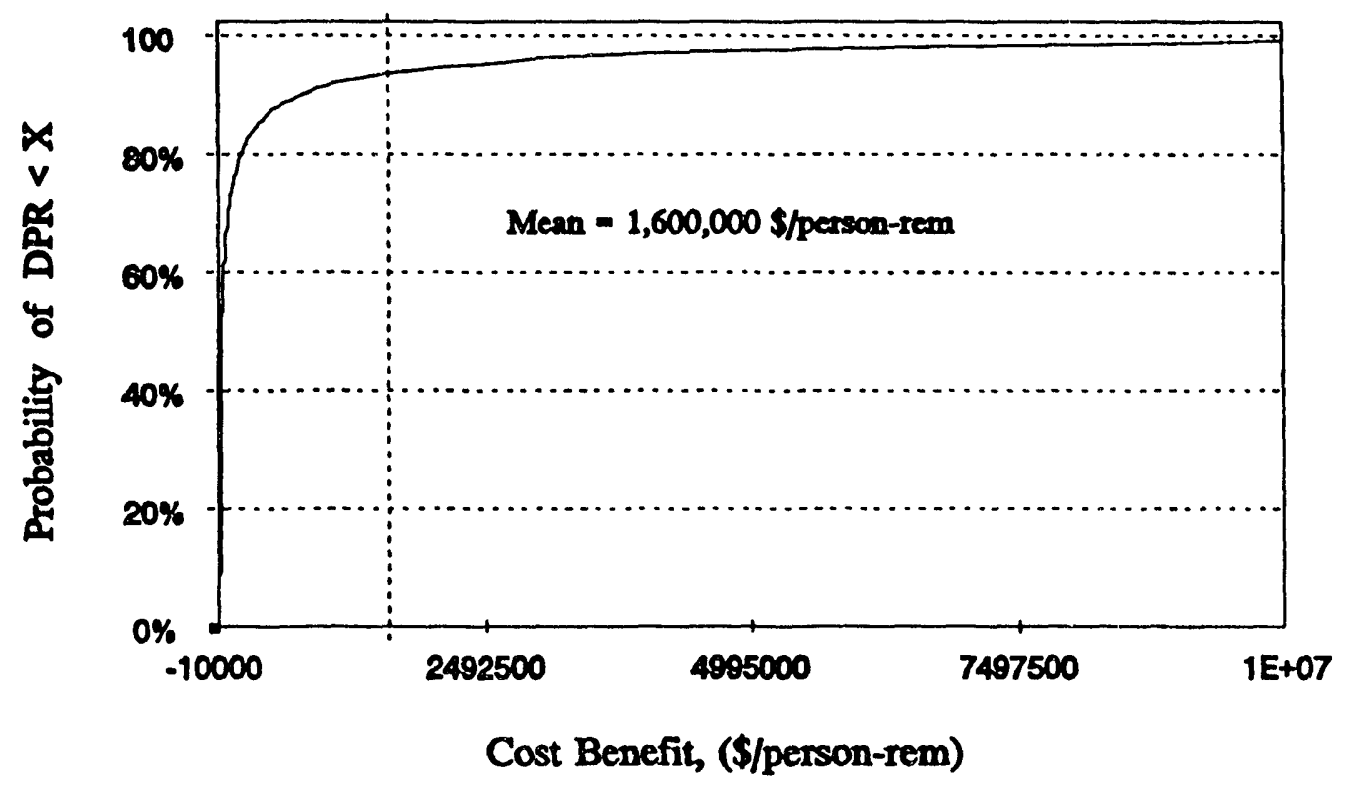

Figure A-13. CDF of DPR ratio for Westinghouse plant (Case 2, 20 years without OSAC).

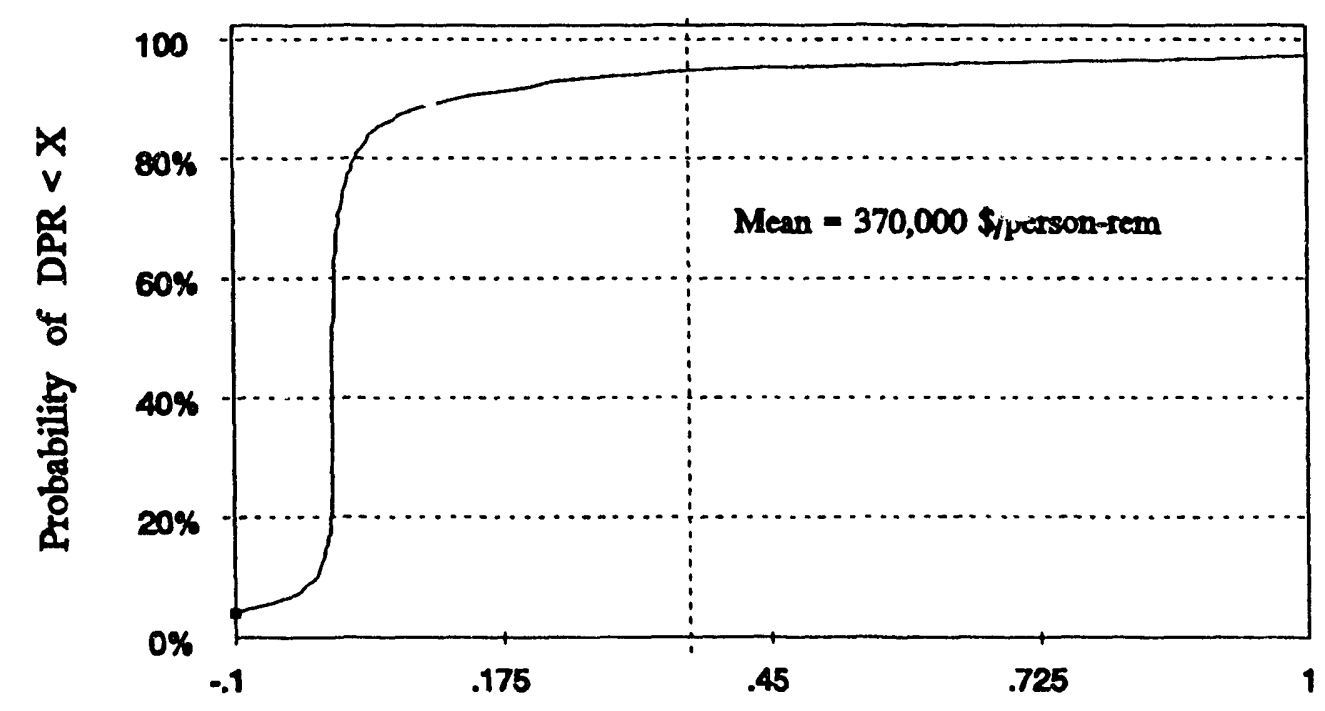

Cost Benefit, (\$/person-rem), millions

Figure A-14. CDF of DPR ratic for Westinghouse plant (Case 2, 20 years with OSAC). 


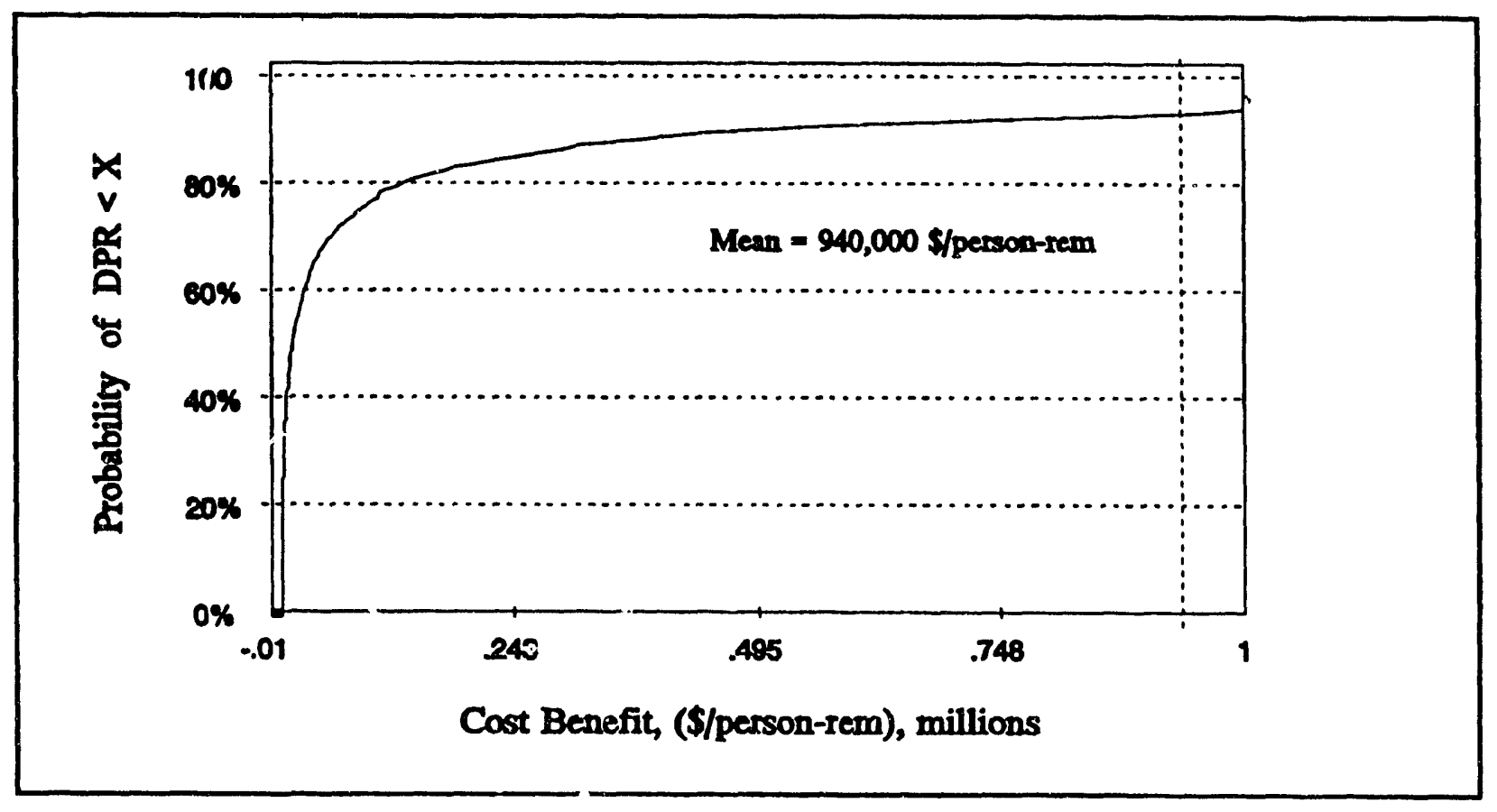

Figure A-15. CDF of DPR ratio for Westinghorse plant (Case 2, 40 years without OSAC).

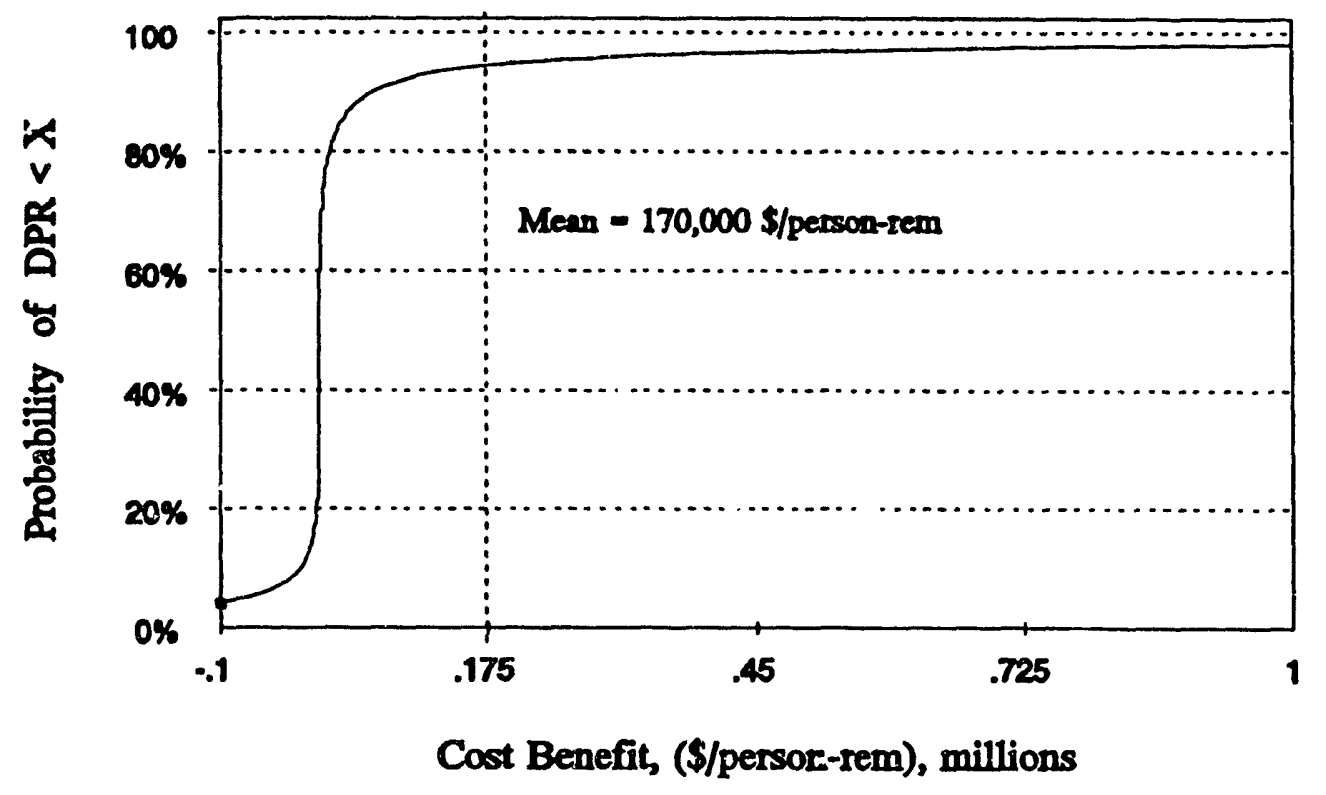

Figure A-16. CDF of DPR ratio for Westinghouse plant (Case 2, 40 years with OSAC). 


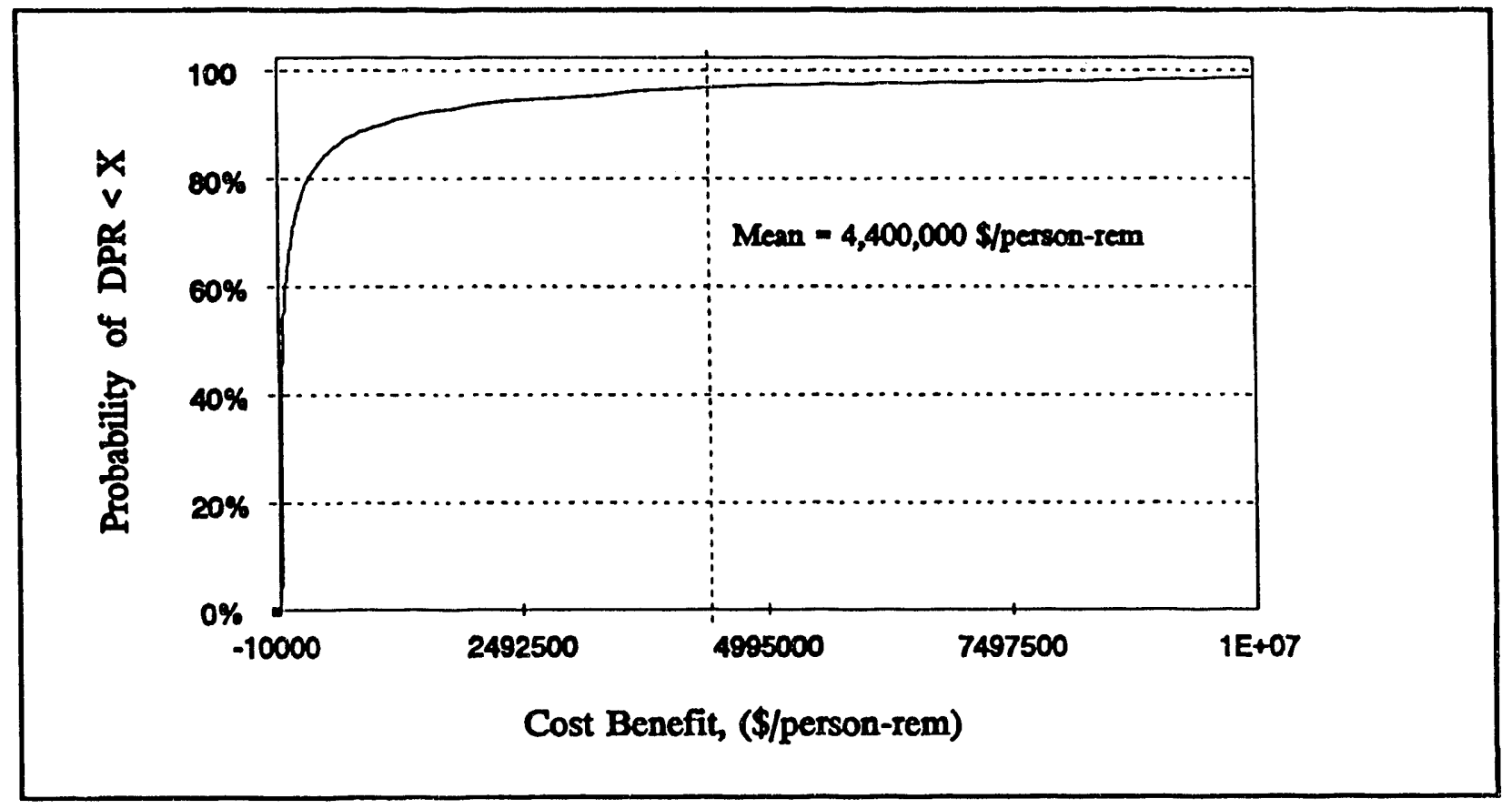

Figure A-17. CDF of DPR ratio for CE plant (Case 1, 20 years without OSAC).

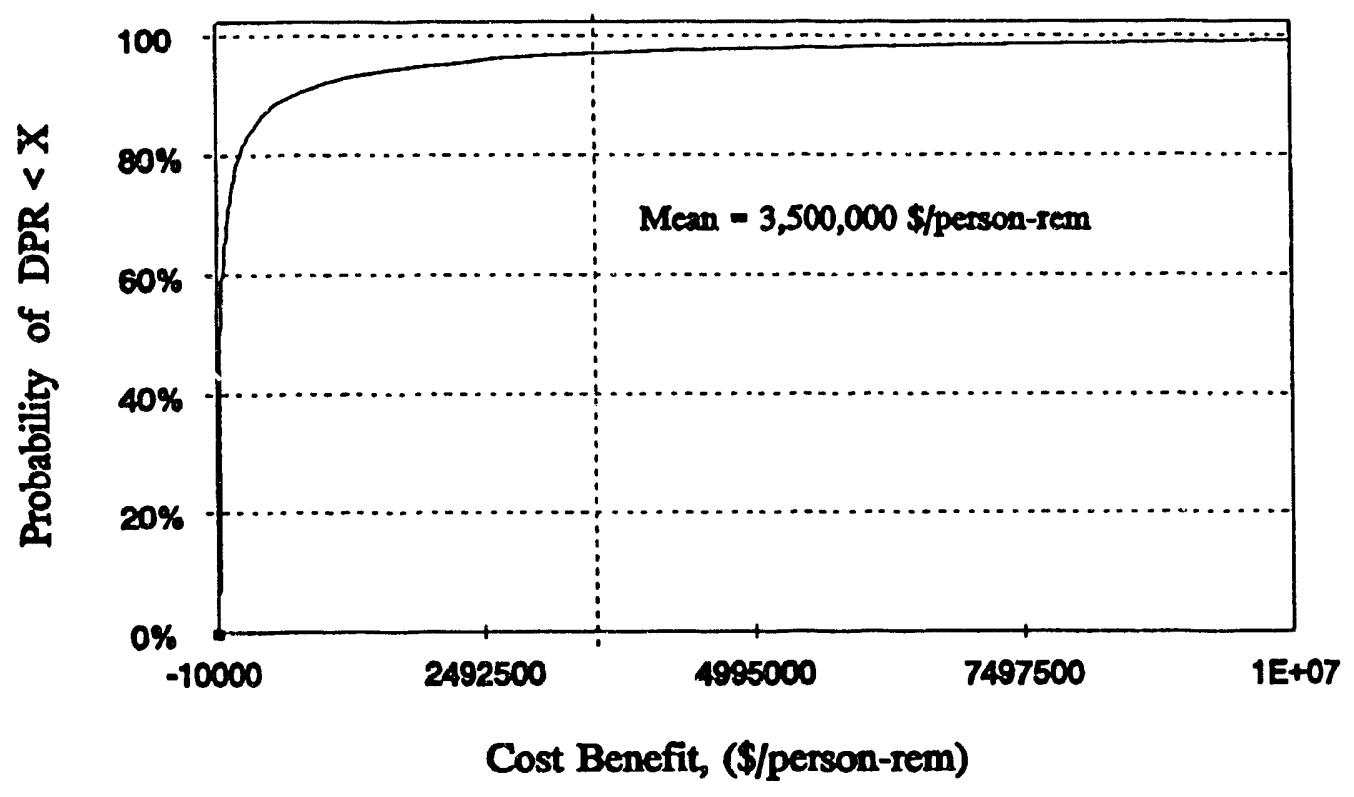

Figure A-18. CDF of DPR ratio for CE plant (Case 1, 20 years with OSAC). 


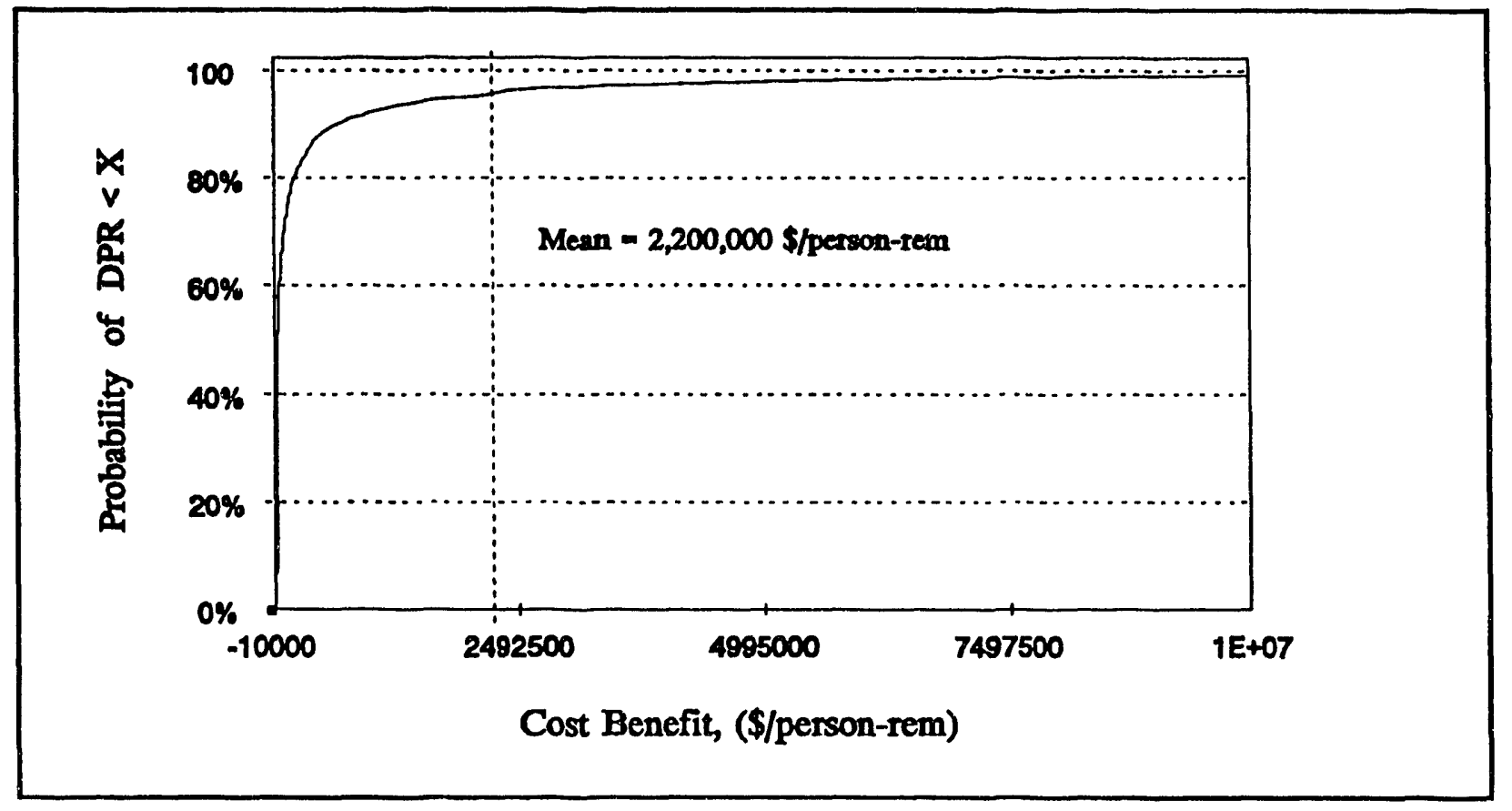

Figure A-19. CDF of DPR ratio for CE plant (Case 1, 40 years without OSAC).

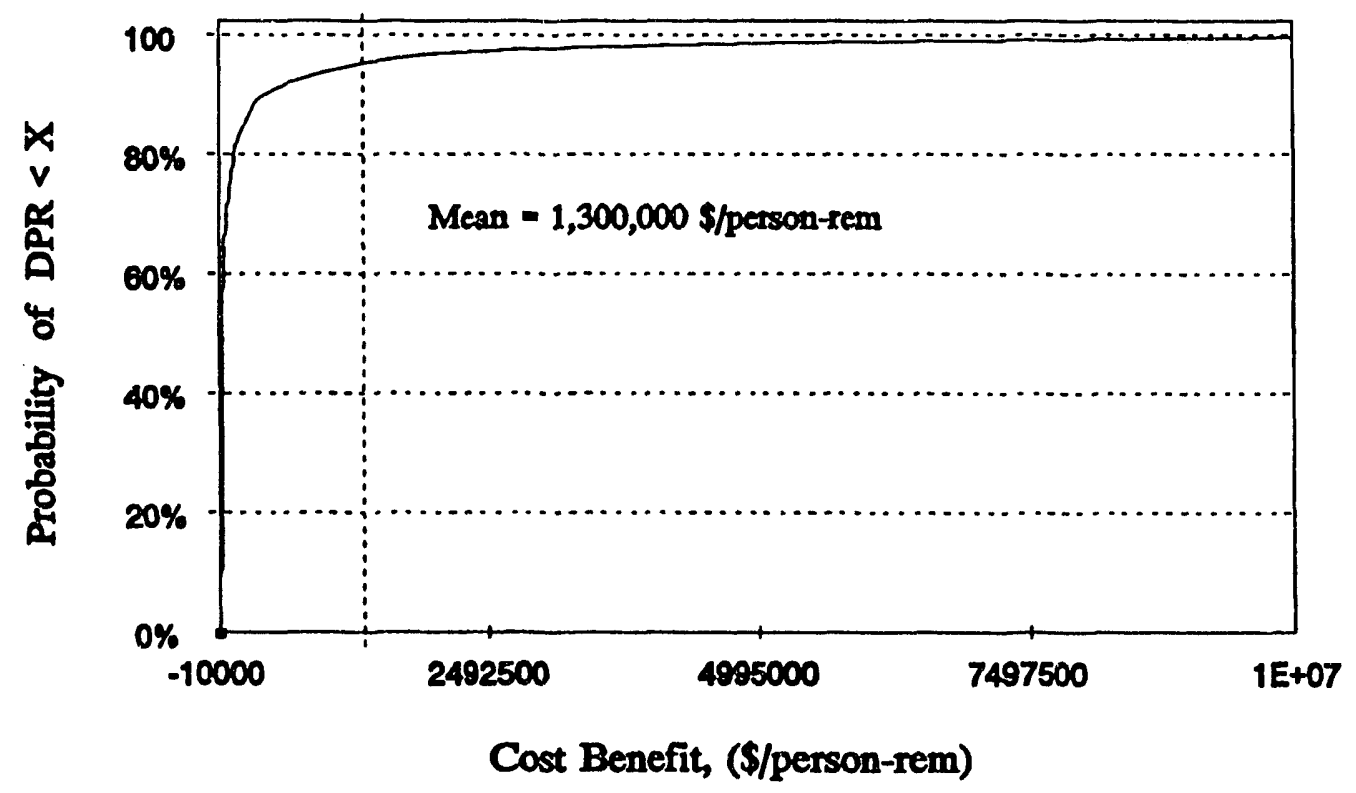

Figure A-20. CDF of DPR ratio for CE plant (Case 1, 40 years with OSAC). 


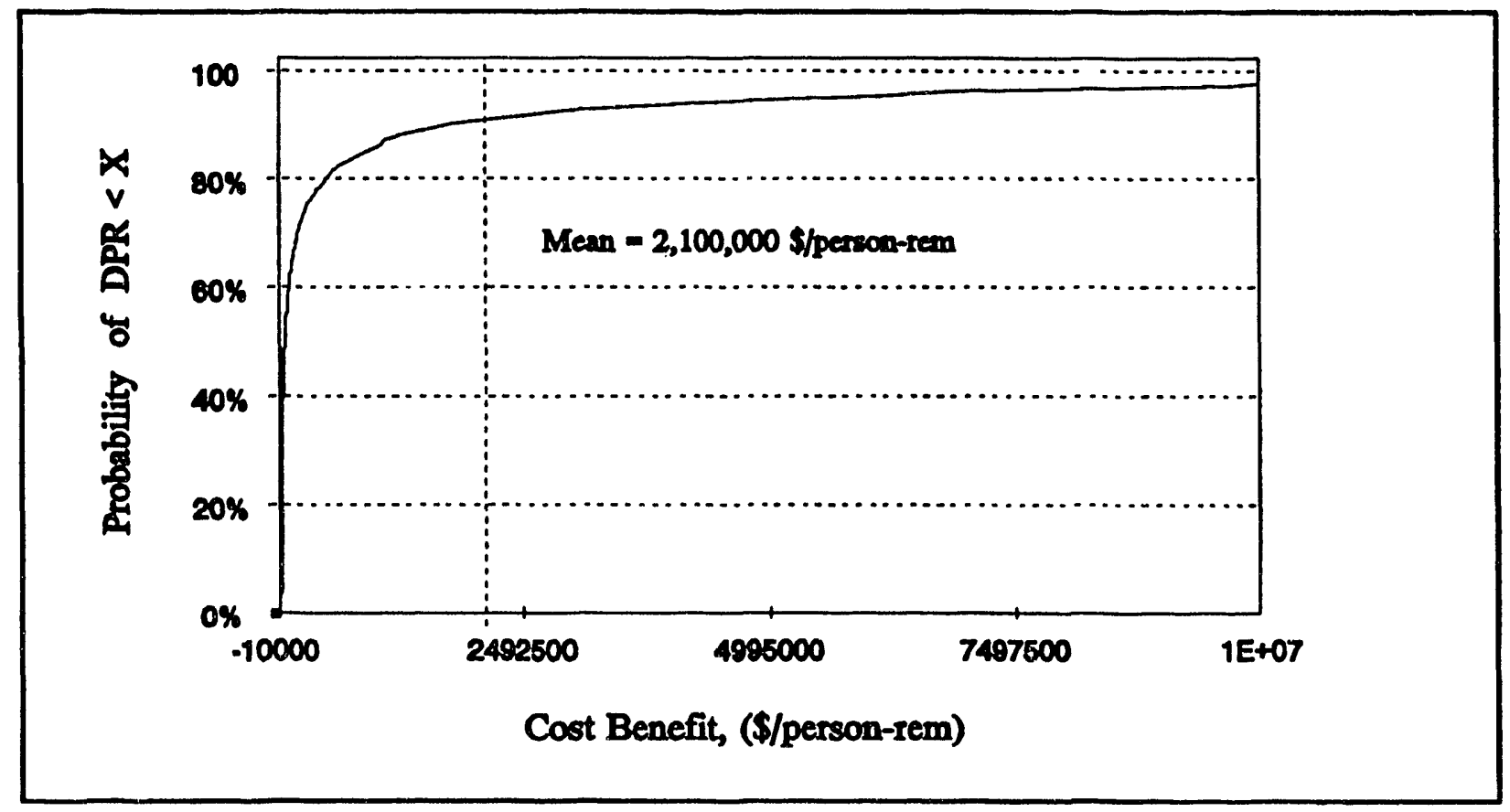

Figure A-21. CDF of DPR ratio for CE plant (Case 2, 20 years without OSAC).

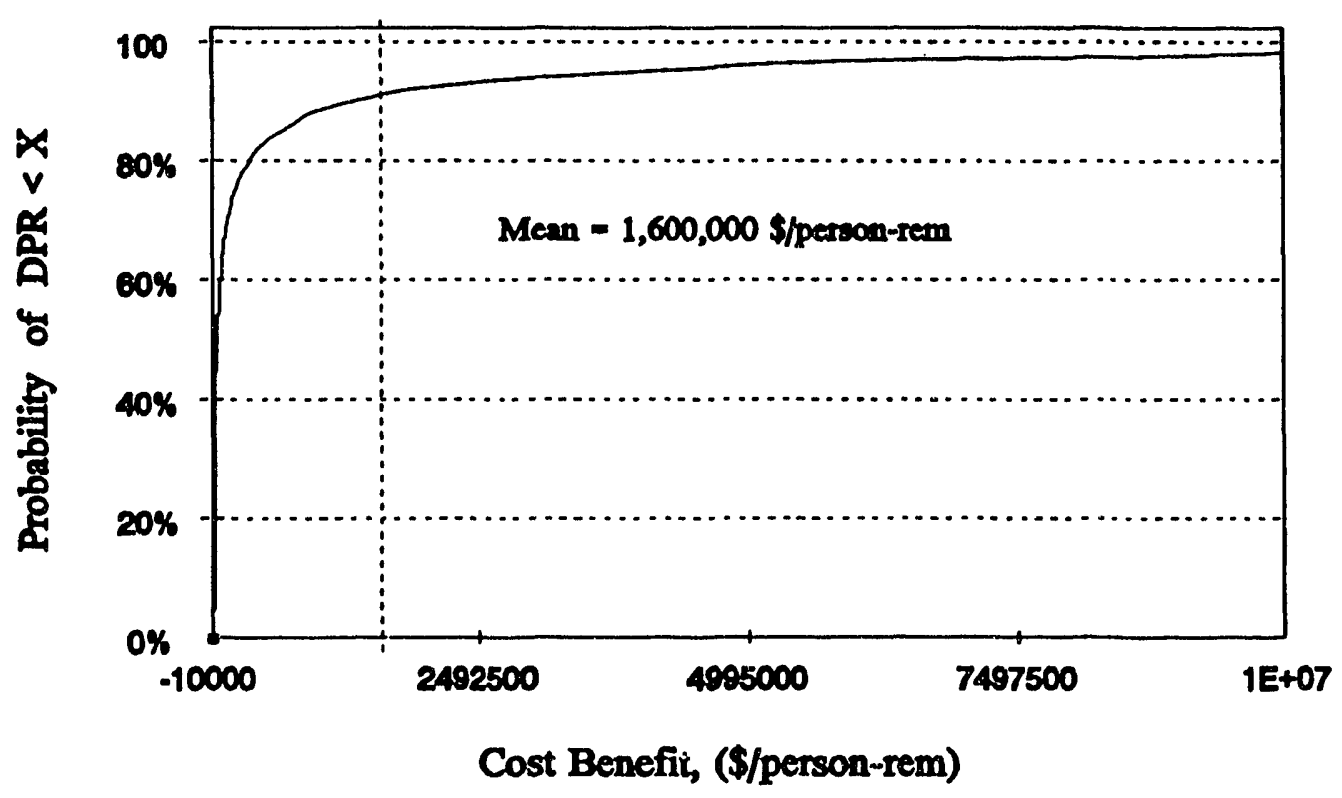

Figure A-22. CDF of DPR ratio for CE plant (Case 2, 20 years with OSAC). 


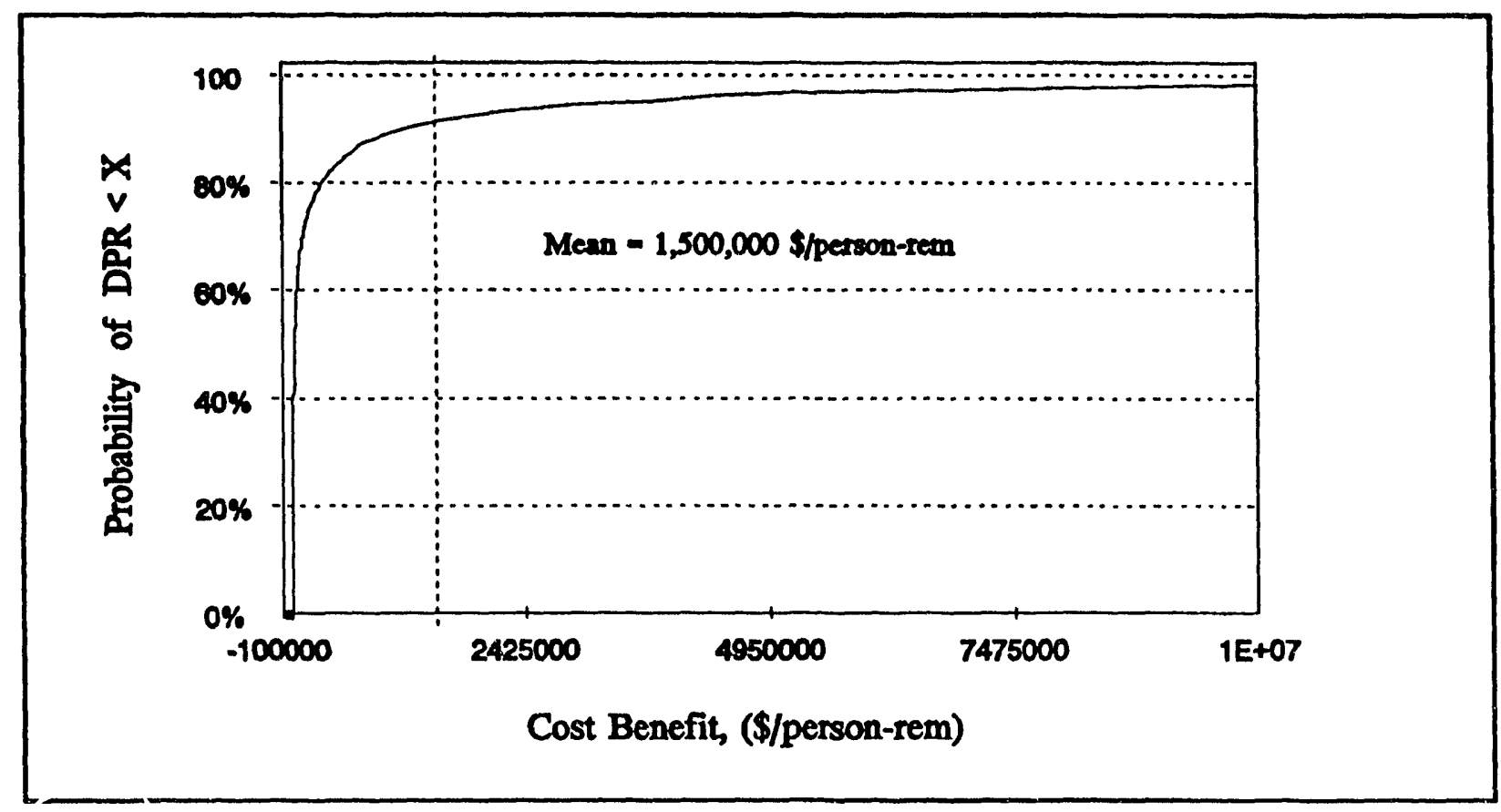

Figure A-23. CDF of DPR ratio for CE plant (Case 2, 40 years without OSAC).

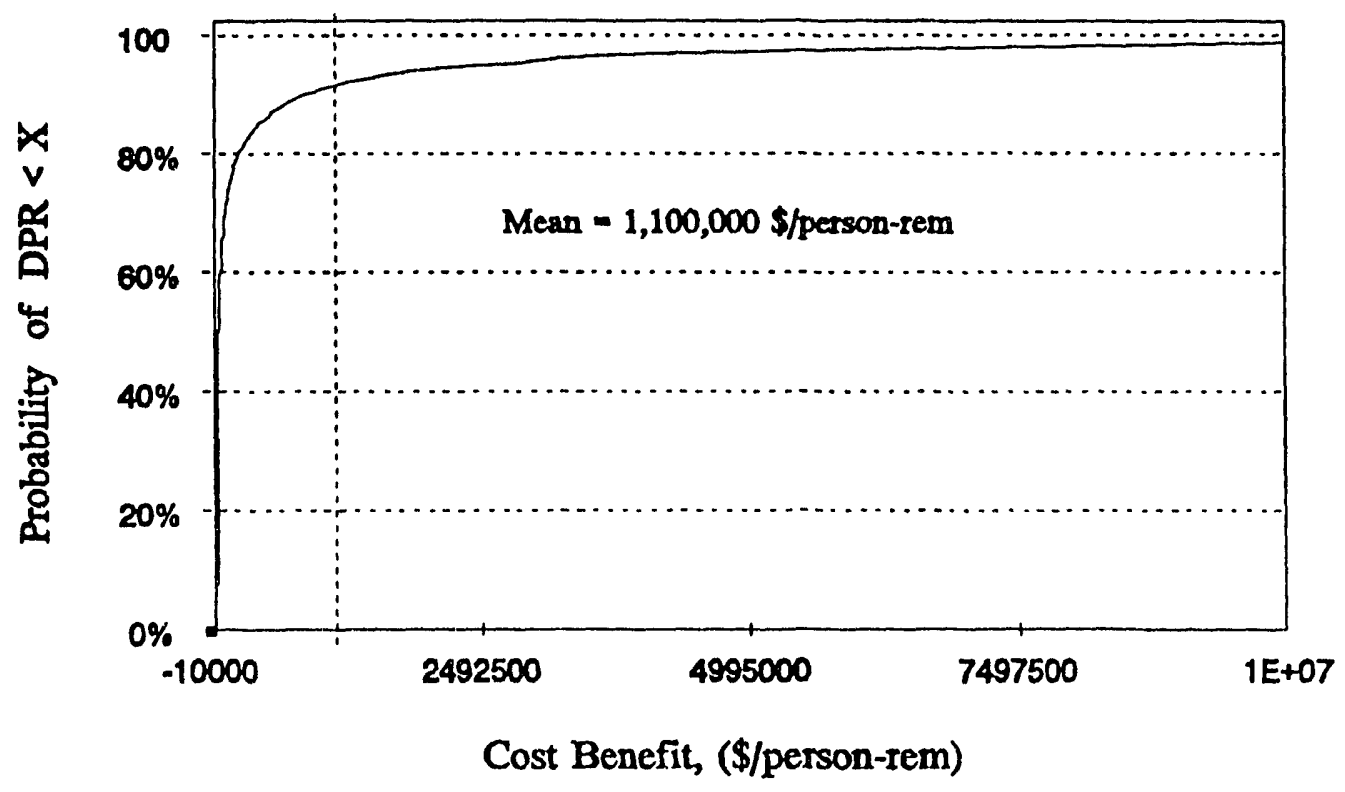

Figure A-24. CDF of DPR ratio for CE plant (Case 2, 40 years with OSAC). 


\section{Appendix B}

\section{Summary of PWR Sensitivity to Alterations in the Interfacing-Systems LOCA, EPRI NP-262}




\section{Summary of PWR Sensitivity to Alterations in the Interfacing-Systems LOCA, EPRI NP-262}

The report, $P W R$ Sensitivity to Alterations in the InterfacingSystems LOCA (Ref. 1) evaluates the "V" sequence from the reactor safety study (Ref. 2). Specifically, the report evaluates several potential improvements to interfacing systems, one of which is installation of a pair of check valves with subsequent periodic leak testing.

The report evaluated several potential failure modes for a Surry "V" sequence. The six different proposed failure modes were (with leaks being defined as gross leaks)

1. $V_{1}$ rupturing and then $V_{2}$ rupturing

2. $V_{2}$ rupturing and then $V_{1}$ rupturing

3. $V_{1}$ ruptures internally and $V_{2}$ leaks

4. $V_{2}$ ruptures internally and $V_{1}$ leaks

5. $V_{1}$ leaks and then $V_{2}$ leaks
6. $V_{2}$ leaks and then $V_{1}$ leaks.

From the above six failure modes, three of the modes were eliminated. Case 1 was eliminated because $V_{2}$ must rupture before $V_{1}$ (see Figure B-1). Cases 5 and 6 were eliminated because it was assumed that simultaneous leaks would be discovered at startup.

Reference 1 used a linear estimate (over 40 years) to obtain an event frequency of $5.5 \times 10-8 /$ year for the case of two check valves with periodic (assuming four shutdowns per year) leak testing. The EPRI report results were summarized in the conclusions by "... .the results also demonstrates the need to perform complete analyses in order to dictate design constraints on important systems." A complete analysis should incorporate some of the techniques contained in the EPRI report, such as probabilistic modeling of the key failure modes.

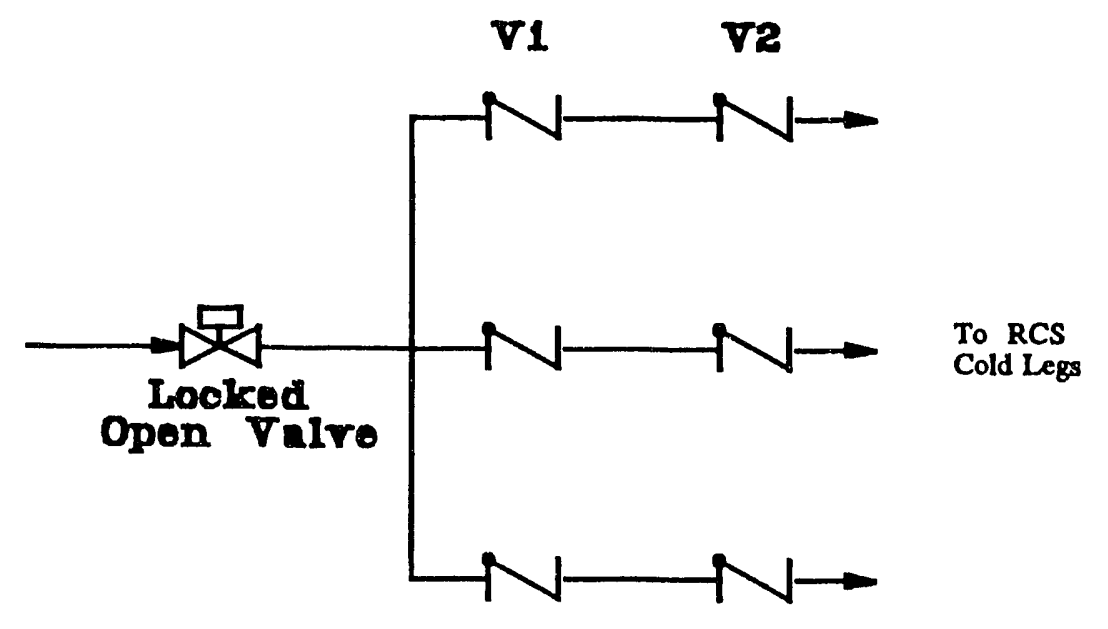

Figure B-1. Event $V$ pressure isolation valve configuration. 


\section{B.1 REFERENCES}

1. F. L. Leverenz, Jr. et al., PWR Sensitivity to Alterations in the Interfacing-Systems LOCA, Electric Power Research Institute, EPRI NP-262, September 1976.
2. Nuclear Regulatory Commission, "Reactor Safety Study-An Assessment of Accident Risks in U. S. Commercial Nuclear Power Plants," WASH-1400 (NUREG 75/014), October 1975. 


\section{Appendix C}

\section{Summary of Interfacing Systems LOCA: \\ Pressurized Water Reactors}




\section{Summary of Interfacing Systems LOCA: Pressurized Water Reactors}

This appendix provides a summary of how interfacing system loss-of-cooling accidents (ISLOCAs) have been treated in previous Probabilistic Risk Assessments (PRAs). It provides a brief description of the interfacing system boundaries, failure modes, failure data, and failure models. The PRAs summarized here were chosen because they were readily available.

\section{C.1 NUREG/CR-5102}

The report, Interfacing Systems LOCA: Pressurized Water Reactors, NUREG/CR-5102 (Ref. 1), investigated events for interfacing system lines at three different plants. At each plant, applicable interfacing lines were determined. For example, at the Indian Point 3 plant, the following lines were accounted for

- Low pressure injection lines (4 lines)

- Residual heat removal suction line (1 line)

- High-pressure injection lines (5 lines)

- Core flooding tank (accumulator) outlet lines (4 lines)

- Letdown lines (1 line)

- Excess letdown line (1 line).

Additionally, the report presented the results of an industry data search for interfacing system events. Two data sources, the RECON data base and the Nuclear Power Experience operating events listing, were used to collect data. These data were then used to estimate failure rates for several different failure modes, including

- Leak failure modes

- Disk rupture failure modes

- Failure to operate (reseat) on demand

- Failure to operate (hold) on demand.

The collected data and calculated failure rates were then used with simple system equations to attempt to estimate frequencies of interfacing system events. For example, to calculate the mean failure rate of two check valves in scries, the following equation was used:

$<\lambda_{s}^{t}(1,2)>\leq \lambda_{1}^{2} T+2 \lambda_{1} \lambda_{d}$ where

$\lambda_{1}^{2}=$ the mean frequency of the leak failure mode

$\mathrm{T}=$ the time interval between leak tests for the check valves

$\lambda_{d}=$ the mean probability of the "failure to operate (reseat) on demand."

Other similar types of equations were used for analyzing different scenarios. These equations were then quantified (using the collected data) for a combination of different cases and different potential flow rates.

The calculated interfacing system event frequencies were applicable to all lines in a particular system. These aggregate frequencies could be broken down into a "per-line" value. Table $C-1$ lists the plant interfacing system events (overpressurization) frequencies on a per-line basis for the low pressure injection pathways. These frequencies are lower than the INEL ISLOCA analysis frequency (i.e., $4.11 \times 10^{-6} /$ year) primarily due to the use of correlated variables in the Idaho National Engineering Laboratory (INEL) analysis.

Table C.1. Per-line interfacing system frequencies calculated from aggregate frequencies in NUREG/CR-5102 (Ref. 1).

\begin{tabular}{ll} 
Plant & $\begin{array}{l}\text { Event frequency } \\
\text { (per line per year) }\end{array}$ \\
\hline Indian Point 3 & $5.98 \times 10^{-7}$ \\
Oconee & $3.72 \times 10^{-7}$ \\
Calvert Cliffs & $5.78 \times 10^{-10}$ \\
\hline
\end{tabular}

\section{C.2 Surry}

The authors of the Surry PRA (Ref. 2) analyzed ISLOCA events at the boundary between the discharge of the low pressure injection (LPI) system and reactor coolant system (RCS). The Surry configuration consists of a single normally open motor operated valve (MOV) at the common discharge of the LPI pumps. Following the MOV, the injection line splits into three lines, each equipped with two check valves in series. The authors quantified the ISLOCA frequency through the three paths via expert opinion as described in Reference 3. In Reference 3, five experts were asked to quantify the frequency of event $V$ for the Surry valve configuration. The five experts came up with four different ways of doing it. They used the following definitions to describe their models: 
$\lambda_{T}: \quad$ total frequency (per year) of an ISLOCA

$\lambda_{1}$ : the frequency of a rupture of the RCS side check valve

$\lambda_{H P}: \quad$ the frequency of failure for a check valve with high pressure differential

$\lambda_{L P}: \quad$ the frequency of failure for a check valve with low pressure differential a rupture

$\beta$ : the beta factor for common cause failure of two check valves

$P(2 \mid 1): \quad$ the probability of the second check valve fail ing given that the first check valve has failed

$S: \quad$ the probability or frequency that a check valve is stuck open. $S$ is given as either a failure rate or demand failure probability

$O: \quad$ the probability that the operator will fail to recognize that a check valve has failed to close
$D: \quad$ the number o times the check valve is closed between tests

$T: \quad$ the time between inspections in years (9 months assumed for Surry).

The experts each provided their own data for the above quantities. They then considered the following failure modes:

- Rupture of both valves, including common cause failure

- Failure of the first valve [either on the RCS or residual heat removal (RHR) side] to close followed by rupture of the second valve

- Rupture of the first valve occurring after failure of the second valve to close.

The experts then came up with the following expressions to account for these failure modes using the variable definitions above.

Expert A:

$$
\lambda_{T}=\lambda_{1} P(2 \mid 1)+2 \lambda_{1} S D
$$

Expert B:

$$
\lambda_{T}=0.99\left(\lambda_{H P} \lambda_{L P}(T / 2)+\lambda_{H P} \lambda_{H P}(T / 2)\right)+0.01\left(\left(\lambda_{H P}+\lambda_{L P)} * \beta\right)+2\left(\lambda_{H P S D}\right)\right.
$$

Experts $C$ and $D$ :

$\lambda_{T}=\lambda_{1} P(2 \mid 1)+2 \lambda_{1} S(T / 2)$

Expert E:

$\lambda_{T}=\lambda_{1} P(2 \mid 1)+2 \lambda_{1}\left(\lambda_{1}(T \mid 2)\right)+2 \lambda_{1} S D$

Reference 3 provides a detailed description of how each expert justified the above models that will not be repeated here. The Surry authors combined the results obtained from each expert into a single RCS-RHR interface ISLOCA frequency. The result was a mean ISLOCA frequency per path of 3.8E-7/year.

\section{C.3 Seabrook Station}

The authors of the Seabrook Station PRA(Ref. 4) considered ISLOCA scenarios at the boundaries between the RCS and the LPI system/RHR system. The boundaries they considered include both the hot leg suction path boundary and the cold leg injection boundary. The cold leg injection boundary includes two normally open MOVs and one in the discharge line of each LPI pump. These valves are outside of containment and in the high pressure portion of the LPI/RCS interface. Each line passes through the containment downstream from the MOV and splits into two injection lines. These lines are eacn equipped with two check valves arranged in series that normally provide the isolation between the high pressure and low pressure systems. This arrangement provides four possible failure paths, each requiring the failure of two series valves. The hot leg suction boundary includes two lines, each with two MOVs arranged in series. In evaluating the ISLOCA frequency for these boundaries, the authors considered the following failure modes:

- Disc rupture of the check valves in the cold leg injection lines of the residual heat removal system

- Disc rupture $c$ the two series motor-operated valves in the normal RHR hot leg suction 
- Disc rupture of the MOV equipped with a stem mounted limit switch and disc failing open while indicated closed in the other motor-operated valve in the normal RHR hot leg suction.

The authors treated the check valves in the cold leg injection path as standby redundant barriers. They assumed the downstream check valve must fail before the upstream valve is challenged and that both valves have the same rupture rate. This results in a per-path failure rate of:

$$
<\lambda_{\text {path }}>=\frac{1}{2} \lambda^{2} T
$$

where

$$
\begin{array}{ll}
\left\langle\lambda_{\text {path }}\right\rangle & =\begin{array}{l}
\text { mean frequency of ISLOCA along } \\
\text { this path }
\end{array} \\
\lambda & =\quad \begin{array}{l}
\text { mean disc rupture frequency } \\
(1.55 \mathrm{E}-8 / \text { hour })
\end{array} \\
T & =\quad \begin{array}{l}
\text { the time period between testing } \\
(8760 \text { hour }) .
\end{array}
\end{array}
$$

The authors evaluated the above expression with the indicated values and obtained a mean per-path ISLOCA frequency of $2.57 \mathrm{E}-7 / \mathrm{year}$. There are four trains, so the total frequency for this path becomes 1.03E-6/year. A quick check calculation shows that the per-path value should be closer to 9.22E-9/year. The authors could have obtained the above values from the indicated data by the use of correlated failure rates; however, they did not mention the use of correlated failure rates.

The authors considered two ways for the hot-leg suction path to fail. The first was by rupture of the two series MOVs. The authors treated this the same way as the check valves above (as a standby redundant barrier). This time the test interval was 13,140 hours, the time between refueling shutdowns. The second way in which the hot-leg suction boundary can fail is by gear disengagement of one MOV followed by rupture of the other. The authors used a failure-to-close-while-indicating-closed demand probability of $1.07 \mathrm{E}-4$. The probability of failure is then the unavailability of a standard MOV over a 1-year period multiplied by the frequency of disc rupture. The authors used a frequency of disc rupture of $1.36 \mathrm{E}-4 /$ year. The frequency of event $V$ along this path is then $1.45 \mathrm{E}-8$ /year.

The total event $\mathrm{V}$ frequency claimed by the PRA for all paths and all failure modes was $1.84 \mathrm{E}-6 /$ year.

\section{C.4 Millstone 3}

The authors of this PRA (Ref. 5) identified three V-sequence scenarios. The first was disc rupture of the check valves in the cold leg injection lines of low-pressure safety injection and recirculation system. The Millstone 3 valve configuration is similar to that of Seabrook described above, except that it has three check valves in each cold leg injection line instead of two. The authors calculated the total ISLOCA frequency for the four paths in this scenario as

$F(I S L O C A)=4[F(V 1) \times P(V 2 \mid V I) \times P(V 3 \mid V 1, V 2)]$

where

$$
\begin{array}{ll}
F(I S L O C A)= & \begin{array}{l}
\text { frequency of cold leg } \mathrm{V} \\
\text { sequence }
\end{array} \\
F(V 1) & \text { frequency of initial valve rupture } \\
& \begin{array}{l}
\text { (8.76E-4/year) } \\
\text { conditional probability of second } \\
\text { valve rupture }
\end{array} \\
P(V 2 \mid V 1) & \text { conditional probability of third } \\
& \text { valve rupture. }
\end{array}
$$

The authors did not consider failure modes with the check valve disc failing open to be credible because these valves are tested for leakage before reactor startup after each RCS depressurization. They considered disc rupture the sole applicable failure mode. They calculated the conditional probability of the second valve failure as

$\mathbf{P}(\mathbf{V} 2 \mid \mathrm{V} 1)=1 / 2 \lambda \quad T=6.48 \mathrm{E}-4$

where

$$
\begin{aligned}
\lambda= & \text { the valve failure rate }(8.76 \mathrm{E}-4 / \text { year) } \\
T= & \text { the component testing interval (about } \\
& 1.5 \text { years). }
\end{aligned}
$$

Finally, they calculated the conditional probability for the third valve failing by applying a beta factor equivalent to the conditional probability of a common mode failure of the third valve given failure of the first two. The beta factor was 0.129 . The calculated total frequency was 2.93E-7/year.

The second scenario was disc rupture of the check valves and disc rupture or disc transfer open of the MOV in the hot leg injection line of the LPI and recirculation system. The valve configuration consists of a single normally closed MOV outside of containment. Inside of containment the line separates into two injection lines, each with two series check valves. The authors calculated the ISLOCA frequency at this boundary as

$F(I S L O C A)=2[F(V 1) \times P(V 2 \mid V 1) \times P(V 3 \mid V 1, V 2)]$

where

$$
\begin{array}{ll}
F(I S L O C A)= & \begin{array}{l}
\text { frequency of hot-leg } \mathrm{V} \text { se } \\
\text { quence }
\end{array} \\
F(V I) & =\begin{array}{l}
\text { frequency of initial valve rup- } \\
\text { ture }(8.76 \mathrm{E}-4 / \text { year })
\end{array}
\end{array}
$$




$$
\begin{aligned}
& P(V 2 \mid V 1)=\text { conditional probability of sec } \\
& P(V 3 \mid V 1, V 2)=\quad \text { ond valve rupture }(6.48 \mathrm{E}-4) \\
& \text { MOV failure. }
\end{aligned}
$$

The authors assumed failure of the MOV could occur because of internal rupture, spurious opening, or because it was left open. They calculated the failure probability as

$$
P(V 3 \backslash V 1, V 2)=\frac{\lambda_{1}}{2}\left(\frac{T_{1}}{2}\right)+\lambda_{2} T_{2}+1.0 \times 10^{-3}
$$

where

$$
\begin{aligned}
& \lambda_{1}=\text { frequency of rupture (8.67E-4/year) } \\
& \lambda_{2}=\text { frequency of spurious MOV transfers } \\
& \text { (4.75E-6/hour) } \\
& T_{1}=\text { fault exposure time for valve rupture } \\
& T_{2}=\text { fault exposure time for spurious } \\
& \text { opening (24 hours). }
\end{aligned}
$$

The 24 hour fault exposure time the authors used for spurious opening was based on detection of the open indication in the control room. The last term in the above equation accounts for the possibility the operators will leave the valve open following a refueling. The authors bounded this possibility with a HEP of 1.E-3. The authors used the above expression to calculate $P(V 3 \mid V 1, V 2)$ as $1.44 \mathrm{E}-3$. When the authors summed the contributors the resulting $F(I S L O C A)$ for this pathway was $1.63 \mathrm{E}-9 /$ year.

The third scenario was disc rupture or disc transfer open of three, series, MOVs in the suction piping of the residual heat removal system. The authors excluded failure combinations with all three valves failing to close after shutdown because this would be apparent at startup. They also excluded transfer open for the first valve because the motor operators are not sized to open the valves against RCS pressure. They excluded spurious transfer open because power is removed from the valves. They concluded that the only credible failure mode is rupture of all three valves and calculated the frequency of ISLOCA along these paths with the following expression:

$F(I S L O C A)=2[F(V 1) \times P(V 2 \mid V I) \times P(V 3 \mid V 1, V 2)]$

where

$$
\begin{aligned}
& F(I S L O C A)=\text { frequency of RHR V se } \\
& \text { quence } \\
& F(V I) \quad=\quad \text { frequency of initial valve rup } \\
& P(V 2 \mid V 1)=\quad \begin{array}{l}
\text { ture }(8.76 \mathrm{E}-4 / \text { year }) \\
\text { conditional probability of sec }
\end{array}
\end{aligned}
$$

$$
P(V 3 \mid V 1, V 2) \quad=\quad \begin{aligned}
& \text { ond valve rupture } \\
& \text { conditional probability of } \\
& \text { third valve failing. }
\end{aligned}
$$

The authors based the probability of the second valve failing on the sum of the internal rupture and spurious opening probabilities. They did this after making arguments that spurious opening was not credible. They then went ahead and used an internal rupture probability of $6.48 \mathrm{E}-4$ and a spurious opening probability of $1.14 \mathrm{E}-4$, hence $P(V 2 \mid V 1)$ is $7.62 \mathrm{E}-4$. They calculated the probability of the third valve failing based on common mode failure with a beta factor of 0.129 . The resulting total frequency for this path was $1.72 \mathrm{E}-7 /$ year. The total frequency from all contributors was 4.67E-7/year. The study assumed these sequences lead directly to core damage and are not recoverable.

\section{C.5 Three Mile Island 1}

The authors of the Three Mile Island 1 PRA (Ref. 6) considered two scenarios. The first involved failure of two series check valves in the cold leg injection lines of LPI/ decay heat removal (DHR). The analysis accounted for periodic testing of the check valves after each shutdown, on an interval of 1.5 years. It also accounted for the possibility of detection of leakage through the outboard valve before failure of the inboard valve via inleakage to the accumulators. This resulted in a standby-redundant system model for the two check valves as

$$
<\lambda_{\text {path }}>=\lambda\left(\lambda T / 2+\lambda_{d}\right)
$$

where $\lambda$ and $\lambda_{d}$ appear to have been assigned a mean value of $8.3 \mathrm{E}-9$ (this is not clear from the discussion). The resulting ISLOCA frequency for two paths was 7.8E-8/year.

The second scenario the authors identified was failure of three normally closed series MOVs in the hot leg suction path of DHR. They judged failure of all three valves from random causes to be unlikely. Instead, they assumed (1) sequential failure of V1 and V2 followed by failure of V3 due to failure of V1 and V2, and (2) rupture of V1 disc, followed by failure of $\mathrm{V} 2$ due to $\mathrm{V} 1$ failure, and (3) failure of $V 3$ due to $V 2$ failure. 'The resulting path frequency was

$$
<\lambda_{\text {path }}>=2 \lambda\left(\frac{\lambda T}{2}\right) \lambda_{d}+\lambda \lambda_{d}^{2}
$$

Evaluating this expression with a $T$ of 1.5 ycars resulted in a value of $9.3 \mathrm{E}-10 / y$ ear. The authors were not clear about the values chosen for $\lambda$ and $\lambda_{d}$.

\section{C.6 Zion}

The authors of this PRA (Ref. 7) considered three scunarios. The first was disc rupture of the check valves in the 
cold leg injection lines of LPI/low pressure recirculation (LPR). The LPI/LPR cold leg injection boundary valve configuration consists of a normally open MOV in each of two pump discharge lines. The MOVs in each line are followed by a check valve. After the check valve, the !ines each split into two injection lines. Each injection line has two series check valves that provide the first barrier between the RCS and the low-pressure portion of the LPI/ LPR. The authors calculated the ISLOCA frequency at this boundary as

$$
\begin{aligned}
& P(V)=4(P(V 1))^{3} H E P \\
& \text { where } \\
& P(V)=\begin{array}{l}
\text { probability of event } \mathrm{V} \text { through this } \\
\text { path } \\
\text { probability of disc rupture for one } \\
\text { check valve } \\
\text { probability the operators will fail to } \\
\text { isolate the leak. }
\end{array} \\
& H E P \quad \text { is } \quad
\end{aligned}
$$

The authors calculated $P(V 1)$ using the reactor safety study (Ref. 8) check valve disc rupture failure rate (2.66E-8/hour) and assuming the check valves were subject to testing on the average of three times per year, with a maximum test interval of 1.5 years. This resulted in a $\mathrm{P}(\mathrm{V})$ value of $6.04 \mathrm{E}-11$. This number cannot be obtained from the numbers provided without assuming correlated failure rates (not mentioned in the PRA). The PRA took credit for the existence of flow orifices, relief valves, and operator action to isolate the leak. The authors used a probability for failure of the operators to isolate the leak of $1.3 \mathrm{E}-4$. This resulted in a mean $\mathrm{V}$ sequence frequency with failure to isolate of $1.02 \mathrm{E}-13$.

The second scenario the authors considered was disc rupture of the check valves and disc rupture or disc failing open of the motor-operated isolation valve in the hot leg injection line of LPI/LPR. The failure modes considered consist of three disc ruptures, or two disc ruptures (the check valves) and one disc leak (the MOV'). In this scenario the authors have conservatively assumed that if the check valves fail, the MOV will also fail. They also assumed that the operators are likely to diagnose and isolate the leak. The resulting expression for the event $\mathrm{V}$ probability for this scenario is

$P(V)=2(P(V 1))^{2} H E P$

where

$$
\begin{aligned}
& P(V)=\begin{array}{l}
\text { probability of event } \mathrm{V} \text { through this } \\
\text { path }
\end{array} \\
& P(V 1)=\begin{array}{l}
\text { probability of disc rupture for one } \\
\text { check valve }
\end{array}
\end{aligned}
$$

\section{$H E P=$ probability the operators will fail to isolate the leak.}

The authors evaluated the above expression using the same data as in the previous scenario and got a mean frequency of $3.30 \mathrm{E}-11 /$ year.

The last scenario considered was disc rupture or disc failing open of two, series, MOVs in the normal RHR circuit suction. The failure modes considered were disc rupture of both MOVs, or disc failing open in both MOVs, or disc failing open in one, and rupture of the other. Here disc failing open means failure of the disc to return to the closed position after use. The combinations with two discs failing to close were excluded because this would be detected before startup. The authors did not provide the equations used for this scenario, providing instead just the final event $V$ frequency of $1.05 \mathrm{E}-7 /$ year.

\section{C.7 Oconee}

The Oconee 1 PRA(Ref. 9) addressed ISLOCA scenarios at the boundaries between the RCS and the LPI/LPR. The PRA authors addressed three possible leak paths:

- Through the LPI system injection lines A and B that are isolated from the RCS by two check valves and a normally closed MOV

- Through the low pressure auxiliary spray line that is isolated by a check valve two normally closed manual valves, and a normally closed MOV

- Through the decay heat removal suction line that is isolated by two normally closed and pressure interlocked MOVs.

The PRA evaluated the following failure modes for the LPI injection lines leak path:

- Rupture-rupture

- Leak-leak

- Rupture-leak

- Leak-rupture.

The calculation of the ISLOCA frequency via this path took into account the plant leak testing procedures as follows. A year was divided into four 3-month intervals. In the first interval, the check valves were assumed to fail only by rupture because a leak test at the beginning of the period was assumed to have eliminated the demand failure possibility (leakage caused by failure to reseat). Eiring the second period, a shutdown at the end of the first period is assumed to create the possibility of a demand failure (failure to reseat). A second shutdown at the end of the third period increases the likelihood of the failure 
to reseat (another demand). At the end of this period 9 months have elapsed, and leak testing ensures that the leak failure moc es are again zero. Using a rupture rate of $7.8 \mathrm{E}-7 /$ hour anc a leak demand failure rate of $9.8 \mathrm{E}-5 / \mathrm{de}$ mand, the failur a probability for one sct of check valves was calculated for the first 3 months as

$P(I S L O C A)=\left(\lambda_{r} T\right)\left(\lambda_{r} T\right)$

where

$$
\begin{aligned}
& P(I S L O C A)=\text { probability of two check } \\
& \text { valves rupturing } \\
& \lambda_{r} \quad=\quad \text { check valve failure rate } \\
& \text { (2.E-7/hour) } \\
& T=\text { time during which valve could } \\
& \text { fail (2190 hour). }
\end{aligned}
$$

For the second 3 months, the failure rate included demand failures so that all failure modes were represented as

$\left.P(I S L O C A)=\lambda_{r} T\right)\left(\lambda_{r} T\right)+\left(n \lambda_{d}\right)\left(\lambda_{r} T\right)+\left(\lambda_{r} T\right)\left(n \lambda_{d}\right)+\left(n \lambda_{d}\right)^{2}$

where

$\begin{array}{lll}P(I S L O C A) & = & \text { probability of two check valves failing } \\ \lambda_{r} & = & \text { ci.eck valve rupture failure rate }(2 . \mathrm{E}-7 / \mathrm{hour}) \\ T & = & \text { time during which valve could fail }(2190 \text { hour }) \\ n & = & \text { number of close remands made on check valve } \\ \lambda_{d} & = & \text { probability a check valve will fail to reseat after use }(9.8 \mathrm{E}-5 \text { per demand). }\end{array}$

In the above expression the first term represents the rupture-rupture failure mode, the recond term represerits leak-rupture, the third term represents ruptureleak, and the fourth term represents leak-leak.

In the third interval, there have been two demands so $n$ in the above ruation is 2 . In the last interval, the failure prc bability is again described by just the rupture-rupture fail ure mode. When the authors applied numbers to the above equations and summed over all four periods, they produced a yearly failure probability of $2.1 \mathrm{E}-6 /$ year for the check valves.

The MOV would still have to open to produce an ISLOCA event. The authors assumed the MOV could open against full RCS pressure and that two failure modes should be modeled. The failure modes were

- Inadvertent operation, including inadvertent safeguards actuation and uperator error. This combined probability was $1.1 \mathrm{E}-2 /$ year

- Rupture with a yearly probability of 1.0E-3.

Summing the probabilities of the two MOV failure modes and multiplying by the failure probability for the two check valves provides the yearly probability for the ISLOCA path, 4.4E-8/year. The authors treated the auxiliary spray line by accounting for the following three failure modes:

- Check valve rupture (1.7E-3/year)

- Commus: mode failure for two manual valves left opes: as a result of human error (2.E-3/year)
- Inadvertent opening of the MOV (as above, 1.3E-2).

Since the PRA required all three failures for an ISLOCA event, the authors obtained the mean annual frequency by multiplying the above quantities. The result v/as a mean annual frequency of 4.4E-8/year. Recovery actions were applied to this path, allowing a 1.E-1 probability that the operators will not isolate the break in time to prevent core damage.

The authors considered three event sequences that could lead to an ISLOCA path through the decay heat removal suction line. The first sequence requires three events

- The two MOVs must open

- Piping inside the reactor building must not fail

- Piping outside the reactor building must fail.

The first event was assumed to occur as a result of a common-mode human error signaling the valves to open (1.E-3/year) and failure of the two interlocks (1.E-2 each) for a total frequency of 1.E-7/year. The probability that the pipe break is inside the containment was 0.9 .

The second sequence requires

- Either MOV is left open (1.3E-4)

- The other valve ruptures (1.1E-3/year)

- The line breaks outside containment $(0.10)$.

In this scenario, one valve could be left open a previous use if it was signaled to close but failed $1.0 \mathrm{~L}, \mathrm{use}$. This first event was quantified by using a fail to close 
probability of $6.4 \mathrm{E}-3$, and multiplying by failure to recognize that it is still open (0.01). The rupture probability for the other valve was :.1E-3/year. Finally, the break must be outside of containment $(0.10)$. The total is then

$2(6.4 E-3)(.01)(1.1 E-3)(0.10)=1.4 E-8 /$ year.

The final DHR sequence the authors considered was

- One MOV ruptures

- The other MOV ruptures

- The line breaks outside of containment.

Thus,

$(1 . E-7)(8760)(1 . E-7)(8760 / 2)(0.1)=3.8 E-8 /$ year.

An additional factor of 0.8 was used to account for the time the plant is at high pressure. The total for all paths is then 1.4E-7/year.

\section{C.8 Sequoyah}

The authors of the Sequoyah PRA (Ref. 10) considered ISLOCA paths through the check valves at the boundary between the RCS and the LPI system. The ISLOCA paths comprise two lines that pass through containment in separate penetrations. Each line has a normally open MOV outside of containment. After the MOV and inside containment, the lines each branch into two injection lines, each equipped with two isolation check valves. Therefore, the Sequoyah plant has four pairs of series check valves that provide the isolation between the RCS and the LPI system. The authors evaluated the following potential failure modes for these valves:

- Random or dependent rupture of the valve internals on both check valves. The authors assumed rupture of the upstream valve would go undetected until rupture of the second valve occurred. They also assumed the valve closest to the RCS would have to fail first, or the accumulator tank would drain and be detected before the second valve could fail.

- Rupture of the downstream valve combined with the failure of the upstream valve to be closed on demand.

The authors relied on the expert elicitation results from Reference 3 to quantify these failure modes. The analysis for Sequoyah was very similar to that performed for Surry (see Section C.2). The resulting ISLOCA frequency for each pathway was $2.7 \mathrm{E}-7 /$ year. 


\section{C.9 REFERENCES}

1. G. Bozori et al., "Interfacing Systems LOCA: Pressurized Water Reactors," NUREG/CR-5102, February 1989.

2. R. C. Bertucio, J. A. Julius, "Analysis of Core Damage Frequency: Surry, Unit 1 Internal Events," NUREG/CR-4550, Vol. 3, Rev. 1, Parts 1 and 2, April 1990.

3. T. A. Wheeier et. al., "Analysis of Core Damage Frequency From Internal Events: Expert Judgment Elicitation," NUREG/CR-4550, Vol 2, April 1989.

4. Pickard, Lowe, and Garrick, Inc., Seabrook Station Probabilistic Safety Assessment, PLG-0300, December 1983.

5. "Millstone Unit 3 Probabilistic Safety Study," Northeast Utilities, Berlin, CT, August 1983.
6. Pickard, Lowe, and Garrick, Inc., Three Mile Island Unit 1 Probabilistic Risk Assessment, PLG-0525, November 1987.

7. "Zion Probabilistic Safety Study," Commonwealth Edison Co., Chicago, IL, September 1981.

8. Nuclear Regulatory Commission, "Reactor Safety Study-An Assessment of Accident Risks in U.S. Commercial Nuclear Power Plants," WASH-1400, (NUREG 75/014), October 1975.

9. "A Probabilistic Risk Assessment of OCONEE Unit 3," NSAC-60, Electric Power Research Institute, Palo Alto, CA, June 1984.

10. R. C. Bertucio and S. R. Brown, "Analysis of Core Damage Frequency: Sequoyah, Unit 1 Internal Events," NUREG/CR-4550, Vol. 5, Rev. 1, Part 1, April 1990. 


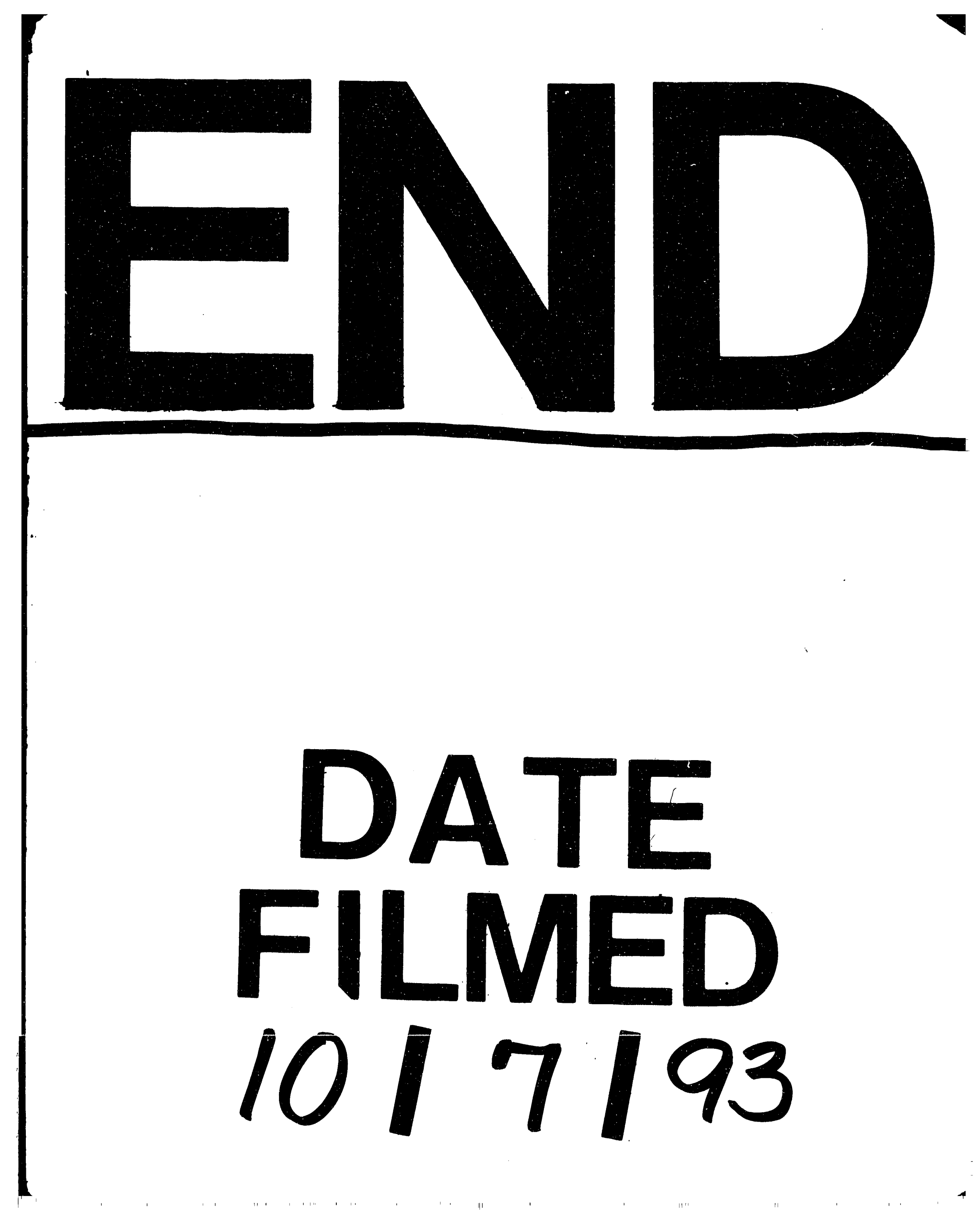


